NBER WORKING PAPER SERIES

\title{
NO-BUBBLE CONDITION: MODEL-FREE TESTS IN HOUSING MARKETS
}

\author{
Stefano Giglio \\ Matteo Maggiori \\ Johannes Stroebel
}

Working Paper 20154

http://www.nber.org/papers/w20154

\author{
NATIONAL BUREAU OF ECONOMIC RESEARCH \\ 1050 Massachusetts Avenue \\ Cambridge, MA 02138 \\ May 2014
}

We thank Daron Acemoglu, Sugato Bhattacharyya, Antje Berndt, Nick Barberis, Luigi Bocola, Markus Brunnermeier, John Campbell, VV Chari, John Cochrane, Marco Di Maggio, Eugene Fama, Emmanuel Farhi, Robert Flood, Xavier Gabaix, Edward Glaeser, Bob Hall, Harrison Hong, Mervyn King, Narayana Kocherlakota, Stefan Nagel, Thomas Philippon, Monika Piazzesi, Tomasz Piskorski, Neil Shephard, Andrei Shleifer, Alp Simsek, Jules van Binsbergen, Stijn van Nieuwerburgh,Wei Xiong, MarkWatson, Bill Wheaton, as well as seminar participants at NBER Monetary Economics, HBS Finance Retreat, Chicago Booth, NYU Stern, Texas Finance Festival, Boston University/Boston Fed Conference on Macro-Finance Linkages, and the New York Junior Macroeconomics and Finance Group meeting for helpful discussions. We are grateful to Miguel de Faria e Castro for excellent research assistance. We gratefully acknowledge the generous research support from the HarvardWeatherhead Center for International Affairs, the NYU Stern Center for the Global Economy and Business, and the Fama-Miller Center and the Initiative on Global Markets at the University of Chicago Booth School of Business. We thank Rightmove and iProperty for sharing part of their data. This Version: May 2015. The views expressed herein are those of the authors and do not necessarily reflect the views of the National Bureau of Economic Research.

NBER working papers are circulated for discussion and comment purposes. They have not been peerreviewed or been subject to the review by the NBER Board of Directors that accompanies official NBER publications.

(C) 2014 by Stefano Giglio, Matteo Maggiori, and Johannes Stroebel. All rights reserved. Short sections of text, not to exceed two paragraphs, may be quoted without explicit permission provided that full credit, including $(\mathcal{C}$ notice, is given to the source. 
No-Bubble Condition: Model-free Tests in Housing Markets

Stefano Giglio, Matteo Maggiori, and Johannes Stroebel

NBER Working Paper No. 20154

May 2014, Revised May 2015

JEL No. E44,G02,G11,G12,R30,R31

\begin{abstract}
$\underline{\text { ABSTRACT }}$
We test for the existence of housing bubbles associated with a failure of the transversality condition that requires the present value of payments occurring infinitely far in the future to be zero. The most prominent such bubble is the classic rational bubble. We study housing markets in the U.K. and Singapore, where residential property ownership takes the form of either leaseholds or freeholds. Leaseholds are finitematurity, pre-paid, and tradable ownership contracts with maturities often exceeding 700 years. Freeholds are infinite-maturity ownership contracts. The price difference between leaseholds with extremely-long maturities and freeholds reflects the present value of a claim to the freehold after leasehold expiry, and is thus a direct empirical measure of the transversality condition. We estimate this price difference, and find no evidence for failures of the transversality condition in housing markets in the U.K. and Singapore, even during periods when a sizeable bubble was regularly thought to be present.
\end{abstract}

Stefano Giglio

University of Chicago

Booth School of Business

5807 S. Woodlawn Avenue

Chicago, IL 60637

and NBER

stefano.giglio@chicagobooth.edu
Johannes Stroebel

Stern School of Business

New York University

44 West 4th Street

New York, NY 10012

and NBER

johannes.stroebel@nyu.edu

Matteo Maggiori

Department of Economics

Harvard University

Littauer building

1805 Cambridge Street

Cambridge, MA, 02138

and NBER

maggiori@fas.harvard.edu 
The existence of bubbles in asset markets is one of the fundamental debates in economics and finance, yet challenges to designing appropriate tests for bubbles have prevented an empirically-driven resolution to this debate. In this paper, we propose a model-free and direct empirical test for the existence of bubbles associated with failures of the transversality condition, the most prominent of which is the classic rational bubble. Our test overcomes many of the challenges that pervade the existing empirical literature.

The classic rational bubble is the workhorse model of bubbles in macroeconomics. It is based on a failure of the transversality condition that requires the present value of a payment occurring infinitely far in the future to be zero. In this paper, we call the claim to this infinitely-delayed payment the "bubble claim," and denote its price by $B_{t}$. The transversality condition, sometimes also called the "no-bubble condition," requires that:

$$
B_{t}=\lim _{T \rightarrow \infty} E_{t}\left[\xi_{t, t+T} P_{t+T}\right]=0,
$$

where $\xi_{t, t+T}$ is a model-implied discount factor between dates $t$ and $t+T$, and $P_{t+T}$ is the payment at time $t+T$. The price of the bubble claim, $B_{t}$, is the present discounted value of the payment at time $t+T$, for $T$ infinitely large. Theories about classic rational bubbles provide a sharp null and alternative hypothesis: $B_{t}=0$ if there is no bubble, and $B_{t}>0$ if there is a bubble, because it implies a positive price today for a claim that postpones payments indefinitely and, therefore, has zero fundamental value.

The classic rational bubble has received widespread attention in the theoretical literature, with seminal papers by Samuelson (1958), Diamond (1965), Blanchard and Watson (1982), Tirole (1982, 1985), and Froot and Obstfeld (1991). It has since become the dominant model of bubbles in macroeconomics (e.g., Caballero and Krishnamurthy, 2006; Arce and López-Salido, 2011; Martin and Ventura, 2012, 2014; Doblas-Madrid, 2012; Giglio and Severo, 2012; Galí, 2014; Galí and Gambetti, 2014; Caballero and Farhi, 2014). We review this literature in Section 1.

Despite the central role of classic rational bubbles in theoretical models, empirical evidence on their existence has remained elusive. The natural test for classic rational bubbles is to verify whether claims to payments at infinite maturity do, in fact, have zero present value. This direct test, however, has been impossible to conduct so far, because we normally do not observe traded claims to payments that only occur at (even approximately) infinite maturity. Due to the challenges with directly measuring the price of very long-run financial claims, researchers have resorted to indirect, model-dependent tests of bubbles, thus incurring the joint hypothesis problem: every test of a bubble is a joint test of the presence of the bubble in the data and the validity of the model applied by the econometrician. ${ }^{1}$

\footnotetext{
${ }^{1}$ Both sides of the debate on the efficient market hypothesis agree on this fundamental difficulty. Shleifer
} 
We provide a direct test of classic rational bubbles by exploiting a unique feature of housing markets in the U.K. and Singapore, where property ownership takes the form of either very long-term leaseholds or freeholds. Leaseholds are finite-maturity, pre-paid and tradable ownership contracts, often with initial maturities of 999 years, while freeholds are infinite-maturity ownership contracts. The price difference between leaseholds with extremely-long maturities (e.g., more than 700 years) and freeholds for otherwise identical properties captures the present value of a claim to the freehold at lease expiry, and thus closely approximates the price of the bubble claim, $B_{t}$. We estimate this price difference to obtain a direct estimate of the price of the bubble claim, and test whether it is indeed positive. Our empirical strategy has the advantage of being both model free and direct. It is model free in the sense that all structural models agree that the fundamental value of the claim $B_{t}$ is zero. It is direct because we test the very condition that defines the bubble, the no-bubble condition, rather than deriving and testing indirect, model-implied necessary or sufficient conditions for the existence of a bubble.

Our empirical analysis is based on proprietary information on the universe of property sales in the U.K. and Singapore between 1995 and 2013. These data contain information on transaction prices, leasehold terms, and property characteristics such as location and structural attributes. We estimate the price of the bubble claim by comparing the prices of leaseholds with maturities between 700 years and 999 years to the prices of freeholds across otherwise identical properties. We use hedonic regression techniques to control for possible heterogeneity between leasehold and freehold properties. We find that extremelylong leaseholds are valued identically to otherwise similar freeholds. Our results, therefore, show no violation of the no-bubble condition in these markets. This is true on average, as well as when focusing on time periods and geographic regions with an ex-ante higher probability of finding a bubble, such as regions with high house price-income ratios.

We focus on housing markets in the U.K. and Singapore, because the institutional setup provides a clean test of classic rational bubbles; we are silent on the possibility of bubbles in other asset classes and time periods. In addition, residential real estate has been the subject of enormous bubble-related attention in recent years. Figure I shows the behavior of house prices in the U.K. and Singapore, both in levels and relative to measures of fundamentals. Both countries experienced episodes of strong increases in real house prices, as well as in price-income and price-rent ratios during our sample. These periods have often been described as exhibiting a housing bubble. Section 2 reviews this evidence.

Motivated by such evidence, a sizable academic literature has speculated about the presence of bubbles in housing markets during our sample period. See Section 2.1 and Glaeser and Nathanson (2014) for a review. Indeed, we show that the leading existing time-

(2000) remarks: "The dependence of most tests of market efficiency on a model of risk and expected return is Fama (1970)'s deepest insight, which has pervaded the debates in empirical finance ever since." 
series tests for classic rational bubbles, such as Phillips et al. (2014), suggest the presence of such bubbles in both countries during our sample. In the theoretical literature, Martin and Ventura (2012), Galí (2014), and Galí and Gambetti (2014) motivate their rational bubble model with the recent boom-bust pattern in house prices, and Kocherlakota (2009), Arce and López-Salido (2011), Basco (2014), and Miao et al. (2014) provide a classic rational bubble model tailored to explain recent house price movements. We therefore conclude that our focus on the housing markets in Singapore and the U.K. during a period of extreme boom-bust cycles provides a setting with an ex-ante very good chance of detecting a bubble; however, our results show that no classic rational bubble was actually present.

We address a number of potential challenges to our methodology of directly testing for classic rational bubbles in these housing markets. ${ }^{2}$ One concern is that freeholds might be inferior on unobservable property characteristics, and that their price parity with leaseholds is therefore masking a bubble. We show that this is not the case, by documenting that annual rents are identical across leasehold and freehold properties. Since relevant differences in property characteristics should be reflected in these rents, this shows that the flow utility from inhabiting either type of property is the same. This finding is not surprising, since properties with extremely-long leaseholds and freeholds located in the same geography are essentially identical on all observable characteristics, making it unlikely that they would differ substantially on unobservable characteristics. We also show that freehold and leasehold contracts are similarly liquid, and have a similar "time-on-market" when listed for sale, addressing concerns that differences in liquidity might mask a bubble.

In addition, we discuss a number of institutional features of these housing markets that might affect our interpretation. We first consider how the assignment of redevelopment rights and maintenance costs affects the relative pricing of leasehold and freehold properties. We show that, institutionally, neither of these forces should have a quantitatively important effect on the relative value of extremely-long leases. Consistent with this, we find that the absence of a significant price difference is stable across regions and properties with differentially valuable redevelopment options. The price difference is also unaffected by different practices of assigning maintenance responsibilities. We also show that taxes, lease extensions, concerns about property rights, and the differential timing of sales and originations of different types of contracts do not affect our estimated price differences. In addition, the fact that we obtain the same results in two markets with different institutional and economic environments, the U.K. and Singapore, minimizes the concern that our nobubble result is due to market-specific institutional frictions. Therefore, while our empirical

\footnotetext{
${ }^{2}$ Potential challenges to our test have to conjecture (i) the possibility that a bubble is present, thus making the freehold more valuable than the extremely-long leasehold, but that (ii) some confounding factor increases the price of the extremely-long leasehold precisely by the amount of the bubble. The two contracts would then trade at the same price, as we estimate in the data, which would mimic an equilibrium without a bubble.
} 
set-up is, if anything, biased toward finding a bubble, we conclude that no institutional features of extremely-long leaseholds significantly affect their value relative to freeholds.

The theory of bubbles is vast and richly varied, with different authors associating different phenomena with the term "bubble." Section 1 provides more details on the nomenclature adopted in this paper, and the exact scope of our test. The takeaway is that we can rule out any bubble associated with a failure of the transversality condition. The most prominent such bubble is the classic rational bubble described above, but failures of the transversality condition can also arise, for example, in the myopic-rational-expectations equilibrium of Tirole (1982), and in economies with differences in beliefs à la Harrison and Kreps (1978). We focus on bubbles that require a failure of the transversality condition because they are an important workhorse model of bubbles and the dominant model in macroeconomics, and because we can offer a clean test for such bubbles. These are not the only models of bubbles, and our paper and test methodology are silent on the possible presence of bubbles that can occur in finite-horizon economies or on finite-maturity assets.

Determining the empirical relevance of bubbles associated with failures of the transversality condition can provide guidance as to which types of bubbles theoretical models should focus on. It is often argued that the dominance of the classic rational bubble in macroeconomics is due to its theoretical tractability, rather than to its realism. However, this modeling choice is not innocuous: for example, we show in Section 6 that while classic rational bubbles grow faster with higher interest rates, the resale-option bubble at the core of Harrison and Kreps (1978), Scheinkman and Xiong (2003), and Simsek (2010), which our tests are silent on, shrinks when interest rates increase. Our tests, therefore, contribute to advance the debate around the effects of central banks "leaning against the wind" by raising interest rates to combat asset-price bubbles (Bernanke, 2002, 2010; Allen and Gale, 2004; Galí, 2014). More generally, since we find no evidence for the classic rational bubble that dominates the macroeconomics literature, it will be important going forward to understand how the positive and normative conclusions of this literature would change in the presence of a (possibly irrational) finite-horizon bubble.

\section{Theoretical Review}

In this section we review the aspects of the theoretical literature on bubbles that are most relevant to this paper. Brunnermeier and Oehmke (2013) and Shleifer (2000) provide more comprehensive reviews. Since the literature contains much disagreement about what individual authors consider a bubble, we organize our work around the fact that we are testing any bubble associated with a failure of the transversality condition.

Consider an asset that pays dividend $D_{t}$ in each period, and denote its price at time $t$ by $P_{t}$. If $\xi_{t, t+T}$ is a valid stochastic discount factor for this asset, we have: 


$$
P_{t}=E_{t}\left[\xi_{t, t+1}\left(P_{t+1}+D_{t+1}\right)\right] .
$$

The price today equals the present discounted value of the price and the dividend tomorrow. ${ }^{3}$ Applying a recursive argument and the law of iterated expectations, we obtain:

$$
P_{t}=\sum_{s=1}^{\infty} E_{t}\left[\xi_{t, t+s} D_{t+s}\right]+B_{t}, \quad B_{t} \equiv \lim _{T \rightarrow \infty} E_{t}\left[\xi_{t, t+T} P_{t+T}\right],
$$

where we have defined $\xi_{t, t+s} \equiv \prod_{j=0}^{s-1} \xi_{t+j, t+j+1}$, so that $\xi_{t, t+s}$ is the stochastic discount factor between periods $t$ and $t+s$. The price of the asset is decomposed into its fundamental value (i.e., the present discounted value of dividends), and a bubble component, $B_{t}$. If present, the bubble evolves according to $B_{t}=E_{t}\left[\xi_{t, t+1} B_{t+1}\right]$, with $B_{0}>0$. If $B_{t}>0$, then there is a bubble. ${ }^{4}$ We next discuss which type of bubbles are associated with this condition. We also show that while $B_{t}>0$ is a sufficient condition for a bubble, it is not a necessary condition, and we briefly review bubbles that are not ruled out by our test.

The most prominent class of bubbles associated with $B_{t}>0$ is the classic rational bubble. ${ }^{5}$ In the seminal papers of Blanchard and Watson (1982) and Froot and Obstfeld (1991), the failure of the transversality condition occurs because the bubble grows at the discount rate applied to the asset, which in these models is assumed to be a constant rate of return. ${ }^{6}$ A subsequent theoretical literature formalizes the conditions under which a classic rational bubble can arise. For example, standard neoclassical theories rule out this bubble, because it is inconsistent with the optimization problem of an infinitely-lived representative agent, or inconsistent with backward induction in a finite horizon setting (Brock, 1982; Tirole, 1982; Santos and Woodford, 1997). In settings with asymmetric information and a finite number of infinitely-lived agents, the "no-trade theorems" also preclude the existence of classic rational bubbles (Tirole, 1982; Milgrom and Stokey, 1982). These theoretical challenges have inspired a literature demonstrating that the classic rational bubble can occur in economies with combinations of overlapping generations, incomplete markets,

\footnotetext{
${ }^{3}$ Note that while the existence of a stochastic discount factor (SDF) requires the law of one price to hold, this mild restriction is not strictly necessary for our empirical tests. As will become clear, we will test whether an asset that pays dividends arbitrarily far into the future (or, alternatively, pays no dividends) has a positive or zero price in the equilibrium observed in the data. This test does not require the existence of an SDF, nor does it require any restrictions on the rational or behavioral origin of prices. We adopt the SDF exposition for convenience, and review its implication for our empirical tests in Section 3.2.

${ }^{4}$ We focus on the case $B_{t}>0$, rather than $B_{t}<0$, because a negative bubble can be easily ruled out in theory if there is free disposal of rents. Nonetheless, our test would detect negative bubbles if they were present.

${ }^{5}$ We use the term "classic" to denote the vast literature on rational bubbles in the style of Tirole (1985). Other authors have derived bubbles that they also call rational bubbles, but that can occur in finite-horizon economies (see Conlon, 2004; Doblas-Madrid, 2014). These latter bubbles are not the subject of our test.

${ }^{6}$ These models are a particular case of equation 2 in which $\xi_{t, t+s}=R^{-s}$, and $R$ is the gross expected rate of return on the asset. Subsequent literature has allowed for time-varying discount rates.
} 
and financial frictions (Tirole, 1985; O'Connell and Zeldes, 1988; Kocherlakota, 1992, 2008; Farhi and Tirole, 2012; Doblas-Madrid, 2012). ${ }^{7}$ This literature reaffirmed the theoretical plausibility of the classic rational bubble as an equilibrium phenomenon. It seems unlikely, therefore, that the active debate over the existence of classic rational bubbles can be settled on purely theoretical grounds; on the contrary, it is an inherently empirical question.

The theoretical literature has emphasized that while the classic rational bubble can occur on an asset that pays no dividends, such as money, it is essential that the asset has infinite maturity. The classic rational bubble cannot occur on an asset of arbitrarily long but finite maturity. These bubbles derive their value from agents' expectations of being able to resell the bubble claim at a sufficiently high price, with each agent expecting to sell the bubble to the next agent. The finite maturity of the asset breaks this loop, because no agent would want to hold the bubble in the last period before maturity; backward induction then makes it impossible for the bubble to be present in any earlier period.

A second necessary condition for bubbles to occur on assets in positive net supply, such as real estate, is that the bubble cannot asymptotically grow faster than the growth rate of the economy. Intuitively, if the bubble were to grow faster than the economy, it would eventually overtake the entire wealth of the economy as long as wealth and output are cointegrated. However, this does not mean that a classic rational bubble cannot occur in real estate markets. In fact, bubbles can exist (and grow at a low rate asymptotically) even on assets that, on average, have high returns, for two main reasons. First, the bubble can have different risk properties than the asset it pertains to; hence, it is quite possible that even a risky, high-return asset such as housing has a bubble component that is relatively safe and grows at a lower pace in the very long run. ${ }^{8}$ Second, in an economy with frictions, the rate of return on the asset can be higher than the rate at which the bubble grows, even if the bubble and the underlying asset are equally risky (Farhi and Tirole, 2012). These results do not overturn the necessary condition for the existence of a bubble derived by Tirole (1985), namely that the long-run growth rate of the bubble should be less than that of the economy, but they restore the theoretical case for bubbles by showing that such a condition could easily be satisfied in realistic set-ups. In addition, Tirole's restrictions are about the long-run (asymptotic) expected behavior of the bubble, and impose no structure on its short-run behavior, which can include periods of very rapid price growth.

In addition to the classic rational bubble, there is a set of bubbles with non-rational elements that also generate a failure of the transversality condition and are, therefore, also testable with our methodology. This set includes the myopic-rational-expectations bubble

\footnotetext{
${ }^{7}$ This work builds on research by Samuelson (1958) and Diamond (1965) on the value of fiat money and government debt. See also Scheinkman and Weiss (1986), Woodford (1986, 1990), and Miao and Wang (2011).

${ }^{8}$ This is the case, for example, in Galí (2014)'s economy, where the bubble is attached to risky capital, but the bubble itself is purely idiosyncratic and therefore earns the risk-free rate of return.
} 
of Tirole (1982). Tirole shows that in a set-up with finitely-many infinitely-lived agents, a classic rational bubble cannot occur with common priors, even in the presence of heterogeneous information. However, he also shows that a bubble could survive in this set-up if strict rationality is relaxed, and formalizes the concept of a myopic-rational-expectations equilibrium (used informally by Sargent and Wallace, 1973; Blanchard, 1979; Flood and Garber, 1980), as one where, in sequential trading, "in each period [the agents] compare their current trading opportunities with the expected trading opportunities in the following period." Thus "traders choose their trades on the basis of short-run considerations," hence the myopia. This deviation from rationality preserves a bubble with a failure of the transversality condition in this set-up.

An interesting literature has created models of bubbles that can occur even in finitehorizon economies or on finite-maturity assets (DeLong et al., 1990a,b; Allen et al., 1993; Barberis et al., 1998; Abreu and Brunnermeier, 2003; Barberis and Shleifer, 2003; Scheinkman and Xiong, 2003; Hong et al., 2006, 2008; DeMarzo et al., 2008; Simsek, 2010; Glaeser and Nathanson, 2015; Barberis et al., 2015). Our test is silent on the empirical relevance of these bubbles, but has an interesting connection to speculative bubbles based on disagreement of the type studied by Harrison and Kreps (1978), Scheinkman and Xiong (2003), and Simsek (2010). In these papers, agents agree to disagree: they have heterogeneous priors and are overconfident about their own information. This deviation from rationality is key, particularly in the most stringent set-up of finitely-many infinitely-lived traders in Harrison and Kreps (1978), to generate a failure of the transversality condition. However, this set-up also generates a bubble that is not associated with a failure of the transversality condition, and this latter "minimal" bubble is the main focus of Harrison and Kreps (1978), Scheinkman and Xiong (2003), and Simsek (2010). ${ }^{9}$ In Section 6, we provide a stylized framework that builds on Simsek (2010) to analyze both types of bubbles, and differentiate their economic content and testability in our data.

We re-emphasize that in our tests, while a finding of $B_{t}>0$ would show that a bubble exists in the data, a finding of $B_{t}=0$ would only rule out bubbles associated with failures of the transversality condition. It would not exclude the presence of other types of bubbles, in particular those that can exist in finite time like the "minimal" bubble in Harrison and Kreps (1978), Scheinkman and Xiong (2003), and Simsek (2010). By ruling out one important and prominent class of bubbles, but not others, we hope to guide future research toward more empirically-plausible models of bubbles. This is particularly relevant given our results in Section 6, where we show that the positive and normative implications of models with bubbles crucially depend on the type of bubble that is considered.

\footnotetext{
${ }^{9}$ Harrison and Kreps (1978) and Scheinkman and Xiong (2003) explicitly acknowledge the possibility of multiple types of bubbles in their framework, but then select and analyze only the equilibrium with the "minimal" bubble in the sense made clear in Section 6.
} 


\section{Existing Evidence of Bubbles in Real Estate Markets}

Housing markets are at the center of much of the recent discussion of asset bubbles in macroeconomics and finance. In this section, we first show that during our sample period, the housing markets in the U.K. and in Singapore featured many characteristics associated with bubbles in the literature. While each characteristic alone is not proof of the presence of a bubble, their combination is often used to provide support to the commonly-held view that there likely was a bubble in these housing markets. We then turn to existing formal econometric time-series tests of classic rational bubbles, and show that they find evidence for such bubbles in the U.K. and Singapore housing markets during our sample period.

\subsection{Market Characteristics Suggestive of Bubbles}

In Figure I we explore the time-series of prices and fundamentals in the U.K. and Singapore housing markets, and show that they display many of the features of asset bubbles. In the top row we plot the log of real house prices in the two countries. The most recent boom in U.K. house prices started in the mid-1990s, but was preceded by several other boom-bust episodes, for example in the mid-1980s. Similarly, Singapore experienced several run-ups and collapses in house prices since the 1970s, and most recently a house price crash and recovery around the 1997 Asian financial crisis. In both countries, real house prices grew quickly and reached elevated levels in the global housing boom years of 2000-2007; for example, real house prices increased by $86 \%$ in the U.K. during this period.

The middle row of Figure I shows that house prices relative to fundamentals also exhibited patterns consistent with the presence of a bubble. We plot the log of scaled prices, $\log \left(\right.$ price $\left._{t} / f_{t}\right)$, for different measures of fundamentals $f_{t}$ : rents, median income per capita, GDP per capita, and household consumption per capita. Appendix A.1 provides a detailed description of the construction of all series and their data sources. During our sample, there were several episodes in which prices increased relative to fundamentals. For example, between 1995 and 2005, the price-rent ratio in the U.K. more than doubled; prices also rose relative to our other measures of fundamentals. The price-rent ratio in Singapore showed similar run-ups in prices relative to fundamentals in the mid-1990s.

Such price increases, in particular relative to fundamentals, are often interpreted as signs of housing bubbles (see, for example, Case and Shiller, 2003; Himmelberg et al., 2005; Caballero and Krishnamurthy, 2006; Wheaton and Nechayev, 2008; Piazzesi and Schneider, 2009; Glaeser et al., 2010; Mayer, 2011; Galí, 2014; Nathanson and Zwick, 2014). The bottom row of Figure I shows that non-academic market participants and observers also regarded these price movements as bubbles. We plot a "bubble index," constructed by counting the number of references to "real estate bubbles" in major national newspapers (see Appendix A.1 for details). In both countries, fast increases in house prices were 
accompanied (and partly followed) by a large increase in references to housing bubbles in national newspapers. Panel E also zooms in on the dramatic movements in U.K. house prices during our sample period 1995-2013, not only at the country level, but also in the areas of London and Prime Central London, where price run-ups were even larger.

\subsection{Existing Formal Tests of Classic Rational Bubbles}

The empirical literature that formally tests for asset bubbles is vast but, despite the notable research effort, also largely inconclusive. In their recent survey of the literature on bubbles, Brunnermeier and Oehmke (2013) conclude that "identifying bubbles in the data is a challenging task. The reason is that in order to identify a bubble, one needs to know an asset's fundamental value, which is usually difficult to measure."

The previous literature testing for bubbles with failures of the transversality condition faces a number of econometric and interpretational issues. Rather than reviewing each paper in detail, we highlight the main difference between our approach and that of the previous literature; Appendix A.2 provides more details. ${ }^{10}$ Previous tests have focused on indirect measures of failures of the no-bubble condition, by testing the cointegration between prices and some transformation of current dividends (Diba and Grossman, 1988a), imposing a structural model of the present discounted value of dividends (Shiller, 1981), or testing model-implied necessary conditions for the existence of a bubble (Abel et al., 1989). Given the dependence of the results on the different assumptions required in each case, these tests - while influential - were overall inconclusive. For example, Evans (1991) shows that the cointegration test of Diba and Grossman (1988a) may fail to detect bubbles that periodically collapse. ${ }^{11}$ Merton et al. (1985) highlight that Shiller (1981)'s test is sensitive to the specification of the appropriate fundamental model. Farhi and Tirole (2012) show that the dynamic-inefficiency conditions tested in Abel et al. (1989) are no longer necessary for the existence of bubbles in the presence of financial frictions. ${ }^{12}$ Our approach, as detailed

\footnotetext{
${ }^{10}$ See Flood and Hodrick (1990) for a survey of the econometric difficulties in the previous literature; see also Flood and Garber (1980), Diba and Grossman (1988b), and West (1987). The earliest tests focused on bubbles in the price level during hyperinflations. For example, Flood and Garber (1980) test the rational expectations model of Sargent and Wallace (1973), and find no evidence of bubbles.

${ }^{11}$ Within theory models, the origin of bubbles remains unclear, and bubbles are often assumed to be present at the start of the model. Similarly, within many models, a bubble cannot arise again after it has collapsed. Diba and Grossman $(1987,1988 b)$ point out these difficulties, both as theoretical challenges to the existence of rational bubbles, and as empirical problems for their detection. From a theory perspective, proponents of rational bubbles have shown that the inception argument is not stringent. They argue that it is reasonable to think of all assets as having an arbitrarily small, but strictly positive, bubble attached to them at all points in time. These bubbles then only become interesting to economists when stochastically they become "big." In this world, a bubble collapse is simply a reversion from a state in which the bubble is "big" to one in which it is arbitrarily small. The bubble can then arise again in the future, in the sense that it can stochastically become "big" again. This is the sense in which we refer to collapses or increases in the size of the bubble.

${ }^{12}$ On the possible misspecification of Shiller (1981)'s volatility bounds as a test for classic rational bubbles, see Mankiw et al. (1985) and Flood and Hodrick (1986). Geerolf (2014) finds favorable evidence for the dynamic inefficiency of advanced economies, and links it to the empirical plausibility of asset bubbles.
} 
in the next section, overcomes many of these challenges, because we directly measure deviations from the no-bubble condition. ${ }^{13}$

More recent advances by Phillips et al. (2011) and Phillips et al. (2014) build on the insight of Diba and Grossman (1988a) that, if a bubble is present, prices are more explosive (i.e., integrated of a higher order) than dividends. These tests address the concern of Evans (1991) that, in small samples, periodically collapsing bubbles might look more stationary than their true data generating process. They do so by allowing for integration tests on subsamples of the data, while appropriately adjusting the test statistics. In fact, recent work has applied such explosive root tests to housing markets, and has found evidence in favor of classic rational bubbles: Garino and Sarno (2004) focus specifically on the U.K., while Pavlidis et al. (2013) and Engested et al. (2015) provide evidence of classic rational bubbles in house prices for many countries, including the United Kingdom.

We build on these papers by employing the testing methodologies of Phillips et al. (2011) and Phillips et al. (2014) to verify that the most advanced existing econometric timeseries tests for classic rational bubbles suggest the presence of such bubbles in the U.K. and Singapore housing markets during our sample. Appendix A.2 provides details on the implementation of these tests. In the U.K. between 1952 and 2014, the Phillips et al. (2014) test identifies 1972-1973 and 2002-2004 as bubble episodes with a $10 \%$ confidence level. ${ }^{14}$ In Singapore, the test identifies three bubble episodes between 1975 and 2014: 1980-1981, 1993-1996, and 2007. The top and middle rows of Figure I shade these periods.

\section{Institutional Setting and Empirical Test}

In this section, we describe our empirical approach to directly estimating the value of the bubble claim, $B_{t}$. We first introduce the institutional setting of the housing markets in the U.K. and Singapore. In the interest of space, this review is relatively concise. In Section 5 and Appendix A.3, we extensively discuss these and other institutional features, and consider how they might affect our empirical approach. For example, we show that the treatment of redevelopment rights, the assignment of maintenance costs, the presence of potentially restrictive covenants, and the tax system do not significantly affect the relative pricing of extremely-long leaseholds and freeholds.

\subsection{Institutional Setting}

Residential real estate ownership in both the U.K. and in Singapore comes in two forms: infinite-maturity ownership, called a freehold, and long-duration, finite-maturity owner-

\footnotetext{
${ }^{13}$ Our test also differs from the predictability test for bubbles suggested by Cochrane (2011), because we test the existence of a bubble directly in the level of an asset price. Cochrane's test focuses on whether the bubble accounts for any variation in price-dividend ratios over time and therefore cannot rule out the existence of a bubble that accounts for a constant, and possibly sizable, fraction of the asset price.

${ }^{14}$ The test statistic for bubble detection is not significant in 2003, but is significant in both 2002 and 2004.
} 
ship, called a leasehold. A leasehold is a grant of exclusive possession of the property for a clearly defined, finite period of time during which the tenant can exclude all other people from the property, including the freeholder (Burn et al., 2011) ${ }^{15}$ In the U.K., common initial lease lengths are 99, 125, 150, 250, and 999 years. In Singapore, initial lease lengths are either 99 or 999 years. During the life of the lease, the lessee is entitled to similar rights as a freeholder would be, including the right to mortgage and rent out the property. Leaseholds and freeholds are also treated equally for tax purposes. Unlike for commercial leases, the vast majority of the costs associated with a residential leasehold comes through the up-front purchase price; annual payments, the so-called "ground rents," are small to nonexistent, and do not significantly affect the prices paid for leaseholds. Leasehold properties are traded in liquid secondary markets, where the buyer purchases the remaining term of the lease. The markets for freehold and leasehold properties are fully integrated, and the two types of contracts are advertised side-by-side by real estate agents and on online platforms. Once the lease expires, the ownership reverts back to the residual freeholder.

In the U.K., there is a broad set of residual freeholders, including large private corporations, aristocratic estates, the Church of England, Oxford and Cambridge colleges, and the Royal Family. In Singapore, by far the largest residual freeholder is the government of Singapore, represented by the Singapore Land Authority (SLA). In Singapore, leaseholders have no statutory right to lease extensions or to acquire the underlying freehold interest, a process called enfranchisement. In the U.K., the Leasehold Reform Act 1967 has provided owners of houses with the right to extend the lease or enfranchise at market prices. Such transactions entail significant costs, including those for engaging a valuer and a solicitor, as well as the uncertainty and costs of a possible court trial. In Section 5, we discuss a number of factors that might differentially affect the flow utility of leasehold and freehold properties, such as potentially restrictive covenants, taxes, and the assignment of maintenance costs and redevelopment rights, and show that their quantitative effect on prices is small.

\subsection{Empirical Test}

The institutional setting of the U.K. and Singapore is uniquely suited to directly testing the transversality condition, equation 1 , since it allows us to estimate the present value of a claim to the freehold occurring at extremely-long horizons (e.g., $T>700$ years). Let us define by $P_{t}$ the price of the freehold contract at time $t$, and by $P_{t}^{T}$ the price of the

\footnotetext{
${ }^{15}$ This contract structure is not unique to the U.K. and Singapore. The real estate literature has studied the pricing of leasehold and freehold contracts in a variety of settings and countries (e.g., Capozza and Sick, 1991; Wong et al., 2008; Iwata and Yamaga, 2009; Tyvimaa et al., 2014; Bracke et al., 2014; Gautier and van Vuuren, 2014). None of these papers focuses on the implications for studying bubbles. Giglio et al. (2015) also exploit this institutional set-up, but use it to address a different economic question: the estimation of very long-run discount rates. Due to the different economic question, their use of the data also differs from the present paper. While they focus on shorter (0-300 year) leases on flats, we focus on extremely-long (700+ years) leases and freeholds on houses.
} 
leasehold contract with maturity $T$ at time $t$. The freehold is the claim to the infinite stream of rents generated by the property, while the leasehold is the claim to the rents for the first $T$ years. A simple algebraic substitution, detailed in Appendix A.4, shows that $P_{t}-P_{t}^{T}=$ $E_{t}\left[\xi_{t, t+T} P_{t+T}\right]$. Intuitively, the difference in value between a freehold and a $T$-maturity leasehold is the present value of the claim to the infinite stream of rents starting $T$ years from today. This is also the present value of the claim to the freehold $T$ years from now.

We focus on leaseholds with maturities in excess of 700 years, a horizon sufficiently long to approximate well the infinity limit of the transversality condition: ${ }^{16}$

$$
P_{t}-P_{t}^{T} \approx B_{t}=\lim _{T \rightarrow \infty} E_{t}\left[\xi_{t, t+T} P_{t+T}\right], \quad \text { for } T>700 \text { years. }
$$

We test whether the transversality condition, equation 1, holds, by testing whether the price difference between extremely-long leaseholds and freeholds is zero. To make the interpretation of this difference easier, we normalize the price discount by the price of the freehold: $\operatorname{Disc}_{t}^{T} \equiv \frac{P_{t}^{T}}{P_{t}}-1$. Then, $-\operatorname{Disc}_{t}^{\infty}$ is the fraction of the current price of the asset (the freehold) that is due to the classic rational bubble. We correspondingly formulate our null hypothesis of no classic rational bubbles as: $\operatorname{Disc}_{t}^{T}=0$ for $T>700$ years.

Our test exploits the theoretical restriction that classic rational bubbles cannot exist on any asset of arbitrarily long but finite maturity (see Section 1). The bubble could affect the price of a freehold, an infinite maturity asset, but cannot affect the price of a leasehold, a finite maturity asset. Based on this restriction, the test makes two identifying assumptions: that leasehold and freehold cash flows only differ in their maturity, and that maturities greater than 700 years are a close approximation to the infinity limit, i.e., that the present value of rents more than 700 years in the future is essentially zero. Validating the first assumption is the key focus of our empirical estimation (Section 4) and robustness checks (Section 5). We next discuss the second assumption.

We find a horizon between 700 and 999 years to be sufficiently long to approximate the infinity limit of the no-bubble condition. We (informally) quantify the approximation error, by considering the Gordon (1982) growth environment where rents grow at rate $g$, and are discounted at a constant rate $r$. A simple derivation, provided in Appendix A.4, shows that $\operatorname{Disc}_{t}^{T}=-e^{-(r-g) T}$. In the absence of a bubble, even a very low net discount rate $r-g$ of $1 \%$ would imply leasehold discounts as low as $-0.09 \%$ and $-0.001 \%$ at 700 and 900 years, respectively. A net discount rate of $1 \%$ is much lower than the values normally estimated in the literature, which has found average housing returns $r$ to be above $6 \%$ and real rent

\footnotetext{
${ }^{16}$ Being able to directly verify the value of the bubble claim is uncommon, since we generally either observe prices of claims to cash flows at all horizons (e.g., equities), or prices of claims to cash flows for finite but relatively short horizons (e.g., bonds). For example, the U.K. government has issued some (callable) perpetuities; however, the longest finite-maturity bond that could be used to back out the equivalent zerocoupon price has a maturity of only 40 years, a horizon unsuitable to approximate the infinity limit.
} 
growth $g$ to be below $1 \%$, leading to a more plausible calibration of $r-g$ above $5 \% .{ }^{17}$ This confirms that our horizon is sufficiently long for the approximation to hold well, even in the presence of very low net discount rates. ${ }^{18}$

Finally, while it is expositionally convenient to employ the concept of a stochastic discount factor, $\xi_{t, t+T}$, the existence of which requires no deviations from the law of one price, our empirical tests do not strictly require even this mild restriction. Even if the law of one price was violated, both in the data and in a model of bubbles with frictions, a classic rational bubble would still be defined as a positive price for an asset that postpones cash-flows indefinitely, and our test would correctly identify it in the real estate market.

\section{Testing the No-Bubble Condition}

In this section, we present results from our empirical tests of the no-bubble condition. We first describe the data used in the analysis. We then provide aggregate results that pool transactions from all years. We also present more geographically and temporally disaggregated results, for which we focus on sub-samples of the data that, based on observable characteristics, were ex-ante more likely to contain a bubble.

Estimating the relative price of leaseholds and freeholds is challenging, because the underlying properties are heterogeneous assets, and we do not observe the same properties transacting both as leaseholds and as freeholds. Therefore, to estimate Disc $c_{t}^{\infty}$, we need to compare prices across properties that are either freeholds or leaseholds. Since these properties could differ on important dimensions such as size and location, we need to control for these differences. To do so, we use hedonic regression techniques, which allow us to consider the variation in prices across contract types for different properties, while controlling for key characteristics of each property (see Rosen, 1974). Section 5 addresses possible concerns about confounding explanations for our results.

\subsection{U.K. Residential Housing Data}

We obtain transaction-level administrative data on all residential property sales in England and Wales between 1995 and 2013 from the U.K. Land Registry. The data include the price paid, information on the property type, the full address, and a "new construction" indicator. In addition, the Land Registry provided us with an indicator of whether the transaction was for a freehold or a leasehold property, as well as information on lease characteristics such as origination date and lease length. For a large subset of properties,

\footnotetext{
${ }^{17}$ See, for example, Flavin and Yamashita (2002) and Favilukis et al. (2010). Giglio et al. (2015) estimate long-run net discount rates for housing of $1.9 \%$. Such a discount rate is consistent, in the absence of bubbles, with zero leasehold discounts at horizons greater than 700 years.

${ }^{18}$ Pástor and Veronesi (2003) point out that market valuations might appear bubbly, despite the absence of bubbles, if there is sufficient uncertainty about growth prospects of dividends, with the possibility of $r-g$ being close to 0 in the long run. This possible confounding effect is not a concern for our estimates, because we find valuations to be inconsistent with the presence of a classic rational bubble.
} 
we also obtain proprietary information on property characteristics such as the number of bedrooms, bathrooms, and the size, age, and condition of the property. These are collected by Rightmove.co.uk from "for sale" listings and other data sources. ${ }^{19}$ We observe a full set of hedonic characteristics for approximately $52 \%$ of the properties transacting since 1995.

We focus on houses in the U.K., because this market is dominated by freeholds and extremely-long leaseholds, whereas flats are mainly sold as shorter leaseholds. Our final sample contains about 7.6 million transactions between 1995 and 2013 for houses with a full set of hedonic characteristics. Extremely-long leaseholds account for $4.7 \%$ of our transaction sample, freeholds account for $94.3 \%$, and shorter leaseholds constitute the remaining transactions. Appendix Figure A.1 plots a heatmap of the share of all transactions that are of extremely-long leaseholds across 3-digit postcodes. ${ }^{20} \mathrm{~A}$ white postcode indicates an area with no extremely-long leasehold transaction; a black postcode indicates an area where at least $2 \%$ of transactions are of extremely-long leaseholds. While $1 \%$ or $2 \%$ may seem like a small percentage, given the large size of our data set it is large enough in absolute terms to provide us with good identification. While we find transactions of extremely-long leaseholds everywhere in the U.K., there is a clear concentration in the north of England (around Manchester and Liverpool), as well as the South-West. Importantly, there are also several areas in London with a sizable fraction of extremely-long leaseholds; some of our analysis will focus exclusively on this area, depicted in Appendix Figure A.2.

Since we focus on estimating the price difference between freeholds and extremelylong leaseholds (with 700+ years of remaining maturity), we provide key summary statistics for these two contract types in the U.K. data. Panel A of Table I reports the mean, median, and standard deviation of the log price, the number of bedrooms and bathrooms, and the age and size of the property. Column 7 reports the average unconditional difference between the two contract types. Extremely-long leasehold properties are, on average, slightly cheaper, smaller, and older than freehold properties. Column 9 shows the average difference in each characteristic between extremely-long leaseholds and freeholds, conditional on 3-digit postcode $\times$ transaction year $\times$ property type fixed effects. Once we control for spatial and temporal heterogeneity, extremely-long leaseholds and freeholds are even more similar, with all the differences being economically trivial. We conclude that variation in the geographic distribution of leasehold and freehold properties is the key driver of the small unconditional differences in characteristics.

More evidence supporting this conclusion can be seen in Figure II, which plots residuals from a regression of property characteristics on 3-digit postcode $\times$ transaction year $\times$ property type fixed effects separately for extremely-long leaseholds and freeholds. Panel

\footnotetext{
${ }^{19}$ Rightmove.co.uk is the U.K.'s largest property portal, with more than 13 million unique monthly visitors.

${ }^{20}$ These postcodes, which are also called "postcode districts," constitute the level of geographic fixed effects in our analysis. On average, there are 24,700 inhabitants per postcode district.
} 
A shows that, conditional on these fixed effects, leaseholds and freeholds have the same price distribution; in other words, the price similarity in Table I is not just true on average, but across the entire distribution. Panels B - E show that the conditional distribution of hedonic characteristics is also very similar for extremely-long leaseholds and freeholds.

\subsection{Singapore Residential Housing Data}

We obtain transaction-level administrative data for all private residential housing sales in Singapore from the country's Urban Redevelopment Authority. We observe approximately 379,000 arms-length transactions between 1995 and 2013. For each transaction, there is information on the sale price and date, the lease terms, and characteristics of the property. Panel B of Table I provides summary statistics on the characteristics of extremely-long leaseholds and freeholds in our Singapore transaction sample. Extremelylong leaseholds tend to be marginally cheaper than freeholds; they are also slightly larger and younger. The absolute differences in observable characteristics and prices across freeholds and extremely-long leaseholds are economically small, whether or not we control for property type or location. About $6.6 \%$ of our transaction sample consists of extremely-long leaseholds, $47.7 \%$ of freeholds; the remaining transactions are for shorter leaseholds.

Figure III shows the distribution of residuals from a regression of the transaction price and each characteristic on 5-digit postcode $\times$ transaction year $\times$ property type fixed effects, separately for extremely-long leaseholds and freeholds. As was the case in the U.K., conditional on the fixed effects, the distributions of the transaction price and the observable characteristics are nearly identical for freeholds and extremely-long leaseholds.

\subsection{No-Bubble Condition: Aggregate Results}

The summary statistics presented in Sections 4.1 and 4.2 show that, conditional on the fixed effects (being of the same property type, located in the same postcode, and sold at the same time), extremely-long leaseholds and freeholds transact at essentially identical prices in both the U.K. and Singapore. However, this could be either because there is no classic rational bubble, or because leasehold properties are more attractive, thus masking the presence of a bubble. To control for possible differences in observable property characteristics, we study the price difference between extremely-long leaseholds and freeholds by estimating the following hedonic regression separately for the U.K. and Singapore:

$$
\log \left(\text { Price }_{i, p, h, t}\right)=\alpha+\beta \text { ExtremelyLongLease }_{i}+\gamma \text { Controls }_{i, t}+\phi_{p} \times \rho_{h} \times \psi_{t}+\epsilon_{i, p, h, t} .
$$

The unit of observation is a transaction of property $i$, of property type $p$, in postcode $h$, at time $t$. The variable ExtremelyLongLease $e_{i}$ is an indicator of whether property $i$ is sold as a leasehold with more than 700 years of remaining maturity. The excluded category in the regression is freeholds. The coefficient $\beta$ captures the log price discount of extremely- 
long leaseholds relative to otherwise similar freeholds. We control for average prices in a property's geography by including property type by postcode by time of sale fixed effects, $\phi_{p} \times \rho_{h} \times \psi_{t}{ }^{21}$ For the U.K., we use 3-digit postcodes; for Singapore, we use 5digit postcodes. These geographies correspond to areas that are both sufficiently large to have variation across contract type, but also sufficiently small for the housing stock to be relatively homogeneous. We also control for various characteristics of the property using standard hedonic variables. ${ }^{22}$ Standard errors are clustered at the postcode level.

Table II shows results from regression 3 for the U.K. (columns 1 - 4) and Singapore (columns 5 - 8). Our preferred specifications, reported in columns 1 and 5, use the transaction year to account for time fixed effects, $\psi_{t}$. For both the U.K. and Singapore, there is no significant difference between the prices of extremely-long leaseholds and freeholds. While estimates are less precise for Singapore, where we observe fewer transactions, for the U.K. the price difference is a precisely-estimated zero. This shows that, on average, there was no classic rational bubble in house prices in the U.K. and Singapore during our sample period.

To understand the quantitative implications of our results, consider that our (statistically insignificant) point estimates imply that the bubble, if present, would have a magnitude of $1 \%$ of the value of freeholds in Singapore. In the U.K., the price difference is even smaller, at $0.1 \%$ of the value of the freehold, and we can rule out a classic rational bubble that contributes more than $1.1 \%$ to the price of a freehold with $95 \%$ confidence. The level of such a bubble would be economically small, and it cannot explain the observed house price fluctuations. As discussed in Section 2.1, between 2000 and 2007, U.K. house prices increased by $86 \%$. For a bubble worth $0.1 \%$ to explain this price increase, it would have had to grow by $86,000 \%$ during those 7 years. ${ }^{23}$

\footnotetext{
${ }^{21}$ For U.K. houses, the property types are "detached," "semi-detached," and "terraced." For Singapore, the property types are "apartment," "condominium," "detached house," "executive condominium," "semidetached house," and "terraced house." In Singapore, we also interact the fixed effects with whether the property is a "land" or a "strata" title. Land title properties occupy land that is exclusive to the owner (e.g., a detached house), whereas a strata title comprises units in cluster housing (e.g., an apartment). Owners of strata properties enjoy exclusive title only to the airspace of their individual unit. The land that the development is built on is shared by all the owners of the project.

${ }^{22}$ For both the U.K. and Singapore, we control for the size and age of the property in a flexible way. For property size in the U.K., we split the property size distribution into 50 equally-sized groups, and include the corresponding dummy variables in the regression; for Singapore we allow for 40 equally-sized groups. Age is controlled for by adding a dummy variable for each possible integer value. In addition, for the U.K., we include as controls the number of bathrooms, the number of bedrooms, the property condition, whether there is parking, whether the property is new, and the type of heating. In Singapore, we include the number of units in the development. We also include transactions of shorter leaseholds (with less than 300 years remaining) in our sample, controlling for the lease length remaining at the time of transaction by including dummies for buckets of maturities as in Giglio et al. (2015). We include these shorter leaseholds in our sample - even though they are not the focus of this paper - to maximize power, since they help identify the hedonic coefficients and the fixed effects. All results are robust to excluding them.

${ }^{23}$ We thank an anonymous referee for suggesting this calibration. Call $P_{t}=\left(P_{t}^{f}+B_{t}\right)$, where $P_{t}$ is the
} 
To confirm the quality of our data, Panels A to D of Appendix Figure A.3 show the estimated coefficients on the key hedonic characteristics from the U.K. regression in column 1 of Table II. Panels A and B of Appendix Figure A.4 show the same from the Singapore regression in column 5 of Table II. We find that larger properties, younger properties, and properties with more bedrooms and bathrooms all trade at higher prices.

To test the robustness of our results, we also use the transaction quarter and month to account for time fixed effects; the results, which are shown in columns 2 and 3 of Table II for the U.K. sample, and columns 6 and 7 for the Singapore sample, are robust to these variations. In addition, in the regressions shown in columns 4 and 8 , we winsorize the dependent variables at the $5 \%$ level, to ensure that our results are not obscured by outlier observations. As before, we detect no differences between the prices paid for extremelylong leaseholds and freeholds.

We labeled our tests as model-free in the sense that they do not require imposing a structural model to compute the fundamental value of the asset. Regression 3 does, however, impose an empirical model in computing how the hedonic characteristics are related to prices. Table II shows that our regression specification is robust to variations in the fixed effects. In addition, by including separate dummy variables for the various quantiles of the distribution of each hedonic variable, we allow for a flexible functional form of the dependence of prices on the hedonic variables (see Appendix Figures A.3 and A.4). To confirm that our results are robust to different empirical specifications, we next report results of a propensity score matching estimation (Rosenbaum and Rubin, 1983).

We first compute, for each observation, a propensity score that indicates the likelihood that the property is treated (i.e., is an extremely-long leasehold as opposed to a freehold), as a function of the characteristics of the property. This propensity score is obtained from a logit regression of the extremely-long leasehold indicator on the property's hedonic characteristics. We then match each leasehold transaction to the freehold transaction with the closest propensity score that occurred in the same year and postcode as the leasehold transaction. This is the freehold which, given its hedonic characteristics, had the closest ex-ante probability of being an extremely-long leasehold. We then compare the average prices across pairs of matched freehold-leasehold transactions. The results of our matching estimator are consistent with those of the hedonic regression analysis: the average log price difference between extremely-long leaseholds and freeholds in the U.K. is - 0.0006 (standard error 0.0028) and 0.0040 in Singapore (standard error 0.0337). In both cases, the difference is economically and statistically indistinguishable from zero. We conclude that there is no

observed price, $P_{t}^{f}$ is the fundamental value, and $B_{t}$ is the bubble term. Suppose that all observed price movements are attributed to the bubble term (i.e., the fundamental value does not change). The relative price growth between times 0 and $t$ is then: $\left(P_{t}-P_{0}\right) / P_{0}=\left(B_{t}-B_{0}\right) / P_{0}=\frac{B_{t}-B_{0}}{B_{0}} \frac{B_{0}}{P_{0}}$. Since $\frac{B_{0}}{P_{0}}=0.001$, a growth rate of prices of $86 \%$ in 7 years requires a growth rate of the bubble of $86,000 \%$ over the same period. 
evidence in our data supporting the presence of a classic rational bubble.

\subsection{No-Bubble Condition: Time-Series and Cross-Section}

The tests reported in the previous section show that, on average, the prices of freeholds and extremely-long leaseholds are very similar, thus rejecting the presence of a classic rational bubble on average. It is, however, possible that a classic rational housing bubble was large only in some parts of our sample, and then collapsed. ${ }^{24}$

In this section, we therefore consider subsamples of transactions that maximize the possibility of detecting a classic rational bubble. We first focus on transactions in years where the test of Phillips et al. (2014) suggests the presence of a classic rational bubble (see Section 2.2). Columns 1 and 2 of Table III show results from the U.K. (2002-2004) and Singapore (1995-1996, 2007), respectively. In those samples, extremely-long leaseholds are, if anything, priced slightly higher than otherwise similar freeholds, though the economic magnitude of those differences is small, and they are not generally statistically significant. This shows that there was no classic rational bubble in housing markets, even during years when the most advanced existing time-series tests suggest that one was present.

More generally, Panels A and B of Figure IV report the price difference between extremelylong leaseholds and freeholds for the U.K. and Singapore, estimated separately for each year. While our statistical power decreases and standard errors increase, there is no evidence of a classic rational bubble in any year between 1995 and 2013. For the U.K., the point estimate of a bubble never accounts for more than $1.2 \%$ of house prices, and it is never statistically significant at the $5 \%$ level. These time-series tests are of particular interest, because they show the absence of a classic rational bubble even during periods when the housing market looked "bubbly" on many of the indicators discussed in Section 2.1.

We next investigate the possibility that bubbles could have emerged only in some geographic areas. ${ }^{25}$ Columns 3 and 4 of Table III focus on transactions in London as well as in Prime Central London (PCL), defined as the neighborhoods of Mayfair, Knightsbridge, Belgravia, Chelsea, and Kensington. Panel E of Figure I shows that these areas had aboveaverage house price growth during our sample. The area of PCL is of particular interest for our analysis, because it experienced some of the biggest house price increases, features

\footnotetext{
${ }^{24}$ In fact, as discussed in Section 2.2, this possibility is one of the main shortcomings of the first generation of time-series tests of bubbles. The second-generation time-series test of Phillips et al. (2014) addresses this concern by looking for explosive price behavior in subsamples of the available data. While this test finds statistical evidence for classic rational bubbles in some periods in our sample, these results could also be classifying very fast, temporary changes in prices due to time-varying discount rates as bubbles (see Cochrane, 1992). Our test, on the other hand, is purely cross-sectional, and is independent of the discount rates applied by households. Therefore, our test will always correctly reject the presence of a rational bubble if a bubble is not present, while the time-series of prices is contaminated by time variation in discount rates.

${ }^{25}$ Note that, in general, rational bubbles in real estate cannot be too localized, because the increases in prices in one area would eventually trigger a substitution with the housing stock in neighboring areas, thus leading to price increases in progressively more extended areas.
} 
high price-rent ratios, and has attracted significant inflows of foreign money, suggesting that its housing stock is treated as a store of value in a manner consistent with rational bubble theory (see Farhi and Tirole, 2012). ${ }^{26}$ Specifically, Knight Frank (2013) reports that 49\% of buyers in PCL between 2011 and 2013 were foreign residents; for the whole of London, this number was lower, but still significant at $20 \%$ of all buyers. ${ }^{27}$ Our test finds no evidence of a classic rational bubble in either of these areas, because the price difference between extremely-long leaseholds and freeholds is small and indistinguishable from zero.

We also obtain data on price-income ratios for each Middle Layer Super Output Area (MSOA) in the U.K. for the years 2004 and 2007 (see Appendix A.1.2 for details). MSOAs are a geographic hierarchy designed to improve the reporting of small area statistics in England and Wales. There are 7,201 unique MSOAs, each with between 2,000 and 6,000 households, and an average population size of 7,500. In areas with high price-income ratios, property prices are high relative to observed fundamentals, and are thus more likely to contain a bubble. Yet, column 5 of Table III shows that there was no classic rational bubble even in areas with the highest $20 \%$ price-income ratio in 2004. Column 6 similarly shows that there was no classic rational bubble in those MSOAs that experienced the largest increases in price-income ratios between 2004 and 2007.

Finally, we consider the time it takes to sell a house as a proxy for how "hot" a particular housing market is; this measure is interesting, since markets where houses sell very quickly are more conducive for prices to deviate from fundamentals (Novy-Marx, 2009). We obtain "for sale" listing information for about 1.8 million transactions of houses in the U.K. since September 2001 from Rightmove.co.uk. For these listings, we measure the time between the first listing and the eventual sale, i.e., the "time-on-market," and then calculate the average time-on-market for each MSOA-year. In column 7 of Table III we focus on transactions in MSOA-years in the lowest $20 \%$ of the time-on-market distribution. Even in these subsamples, we find no evidence for a classic rational bubble.

The cross-sectional analysis in Table III shows that there was no classic rational bubble in areas with very high price-income ratios, high growth rates of the price-income ratio, and low time-on-market, all of which represent measures of the likelihood of finding a bubble. In panels C, D, and E of Figure IV we report the discounts of extremely-long leaseholds relative to freeholds across all quintiles of the distribution of these variables. The

\footnotetext{
${ }^{26}$ In its Q4 2010 Buy-To-Let Review, the Association of Residential Letting Agents reports gross annual rental yields for PCL of $4.79 \%$, compared with a national yield of 5.04\%. By Q4 2012, the rental yield in PCL had fallen to $4.46 \%$, while the national rental yield rose to $5.23 \%$. Lower rental yields, which correspond to higher price-rent ratios, suggest higher prices relative to fundamentals. For an analysis of foreign capital flows to London, see also Cheshire (2014), Badarinza and Ramadorai (2014), and Sá (2014).

${ }^{27}$ This analysis is based on the inspection of 3,500 leases (in addition to internal sales at Knight Frank) for new construction properties across different areas of London. Residency of buyers is based on the proprietor record in each title available from the Land Registry. See Appendix A.1.4 for more documentation of foreign capital flows into the U.K. property market.
} 
coefficients reported in columns 5 through 7 of Table III correspond to the top quintile (for measures of price-income ratio level and growth) or bottom quintile (for time-on-market) of each panel. We find no evidence of a classic rational bubble in any of the cross-sections we study; there is also no pattern in the relative pricing of extremely-long leaseholds and freeholds across our measures of the ex ante likelihood of finding a bubble.

\section{Frictions and the Pricing of Extremely-Long Leaseholds}

We next address concerns that institutional features of housing markets in the U.K. and Singapore might influence the relative pricing of extremely-long leaseholds and freeholds, and would thus interfere with our test's ability to detect classic rational bubbles.

We first focus on the role of potentially-unobserved differences in property characteristics and potentially-different liquidity across contract types. We then consider whether any of the institutional features discussed in Section 3.1 and Appendix A.3 significantly affect the relative pricing of extremely-long leaseholds and freeholds. We show that none of these institutional features provide a challenge to our conclusion that no classic rational bubble was present. In particular, we show that the assignment of redevelopment rights and maintenance costs, the potential presence of ground rents, and the tax framework do not significantly bias our tests. Finally, we consider whether concerns about the stability of property rights, the finite maturity of leasehold contracts, or the market-timing by freeholders affect our test for classic rational bubbles, and conclude that they do not.

\subsection{Unobserved Property Characteristics}

Despite our ability to control for many observable property characteristics in regression 3 , one might worry that extremely-long leaseholds and freeholds could differ on unobservable property characteristics. If extremely-long leasehold contracts did indeed correspond to better properties, this could mask the presence of a bubble. We consider this to be unlikely, as we show in Section 4.1 that leasehold houses are marginally worse on observable characteristics; it is then unlikely that they are sufficiently better on unobservable characteristics to mask a possible bubble. However, to formally rule out this concern, we argue that if leasehold properties were truly better on unobservable characteristics, this should affect their rental value. In fact, a property's rental value should capture all property characteristics that affect its price, including those unobservable to the econometrician but observed by the renters, such as the degree of maintenance.

To test whether extremely-long leaseholds and freeholds differ on unobservable property characteristics, we obtained more than 100,000 rental listings for Singapore from iProperty, the country's leading real estate online portal. These listings cover the period 20102013. About 60,000 listings are for freehold properties, and 7,000 are for properties with extremely-long leaseholds. We repeat regression 3, but substitute the log of the annual rent 
as the dependent variable. As shown in columns 1 and 2 of Table IV, there is no difference in the annual rents between the two types of contracts. ${ }^{28}$

For the U.K., we scanned the leading online property portals, rightmove.co.uk and zoopla.co.uk, to obtain all 65,000 rental listings for houses that were live on March 30, 2015. As shown in column 3 of Table IV, after we control for observable property characteristics, we find no significant difference in annual rents for extremely-long leasehold and freehold houses. ${ }^{29}$ These results confirm that unobservable property characteristics cannot explain our result of zero price difference between extremely-long leaseholds and freeholds.

\subsection{Market Liquidity}

A second possible force that could bias our test against finding a bubble is if freehold properties were less liquid than extremely-long leaseholds in the resale market, and if they would therefore trade at a discount relative to these leaseholds in the absence of a bubble. To test whether this hypothesis confounds our test, we use the time-on-market measure constructed using the Rightmove "for sale" listings data described in Section 4.4 as the dependent variable in regression 3. As discussed, time-on-market provides a useful proxy for the liquidity of the asset (see Genesove and Han, 2012; Piazzesi et al., 2013). Columns 4 and 5 of Table IV show that extremely-long leaseholds sit on the market for an average of 2 days longer than freeholds. This difference is small relative to an overall average time on market of about 140 days. Differences in liquidity between the two contract types are therefore unlikely to confound our results. In addition, Section 4.4 showed that the price differences between extremely-long leaseholds and freeholds is consistently small across areas with very different average liquidity.

\subsection{Institutional Differences Across Contract Types}

We next discuss institutional features of leasehold contracts that might affect the relative valuation of extremely-long leaseholds and freeholds. While most of these features would, if anything, reduce the value of a leasehold, and would therefore bias us in favor of finding a classic rational bubble, we actually show that they have no significant effect on the value of extremely-long leases. We focus on the institutional setting in the U.K., since the size of the country allows for cross-sectional tests to directly quantify the potential impact

\footnotetext{
${ }^{28}$ To provide confidence in the quality of these rental price data, Panels C and D of Appendix Figure A.4 show the coefficients on the key hedonic characteristics in the regression; as with transaction prices, larger and younger properties rent for higher annual amounts.

${ }^{29}$ Since Rightmove and Zoopla do not provide the exact address for rental listings (they choose not to do so, we believe, to prevent potential renters from contacting listing agents directly rather than through the site), the scraping of these data involved obtaining the address of each property by reverse-geocoding the location where a property marker was placed on Google Maps. See Appendix A.1.3 for details. Since fewer property characteristics are available for rental listings, we can only control for the number of bedrooms and bathrooms, as well as a "furnished" indicator. As for the benchmark analysis, the coefficients on the control variables, shown in Panels E and F of Appendix Figure A.3, confirm the quality of the rental data.
} 
of particular institutional features. Since Singapore's legal system is based on English common law, many of the principles are the same across the two countries.

\subsubsection{Maintenance and Service Charges}

We first consider how the responsibility for property maintenance affects the valuation of extremely-long leaseholds. Under English common law, the basic principle regarding the responsibility for property maintenance is that of caveat lessee, or "let the lessee beware." This principle implies that, in the absence of an express agreement between the parties, neither the leaseholder nor the freeholder is responsible for repairs. ${ }^{30}$ This principle is generally interpreted as excluding responsibility by the freeholder regarding the state of the property (Garner and Frith, 2013). ${ }^{31}$ The law, therefore, leaves it to the parties involved to determine whether the leaseholder or the residual freeholder is responsible for carrying out maintenance and repairs. However, independently of who is responsible for conducting the maintenance, for long leases the cost of the maintenance is always borne by the leaseholder.

In particular, when the contract places the responsibility for maintenance on the freeholder, the cost of "these tasks, however, must be paid for, and that burden will be placed on the leaseholder" (Garner and Frith, 2013). This is usually done through a "service charge," which is a payment by the leaseholder for services provided by the freeholder. These services include not only maintenance and repairs, but can also cover insurance of the building and, in some cases, provision of central heating, lifts, porterage, estate staff, lighting, and the cleaning of common areas.

Generally speaking, leasehold contracts specify that leaseholders living in houses are responsible for their own maintenance, while leaseholders living in blocks of flats with many common areas pay a service charge in return for maintenance and repairs by the freeholder. While data on individual properties' service charges are not available, data from the 2011-12 English Housing Survey (EHS) show that, on average, only 7.4\% of leaseholders living in houses pay a service charge, with the others conducting maintenance and repairs themselves. For leaseholders living in flats, $68 \%$ pay a service charge. ${ }^{32}$

In the presence of a service charge, one possible concern is whether that service charge corresponds to the private market cost of the services provided. In particular, one might worry that a freeholder could use the service charge to extract economic rents from "captive" leaseholders. This concern would bias our test toward (mistakenly) finding a bubble,

\footnotetext{
${ }^{30}$ Repairs and maintenance are a separate issue to improvements and redevelopment of a property, which we deal with explicitly in Section 5.3.2. In the case of the internal areas of the property, there is an obligation for the leaseholder to maintain the premises, through an implied covenant to inhabit the property in a "tenantlike manner." See Appendix A.3 for details.

${ }^{31}$ For example, Garner and Frith (2013) note that this principle rules out the protection normally afforded to consumers who have recourse toward the seller/manufacturer in case of defective products.

${ }^{32}$ The average service charge paid by leaseholders living in a house is $£ 681$ p.a.; for leaseholders living in flats, the average service charge is $£ 1,282$ p.a., presumably because it covers a wider range of services.
} 
because it lowers the value of a leasehold compared to a freehold. However, in practice a freeholder's ability to extract rents is severely limited. First, the Commonhold and Leasehold Reform Act 2002 grants leaseholders the right to challenge the reasonableness of service charges with a Leasehold Valuation Tribunal (now First-tier Tribunal, Property Chamber). Second, the Act provides a right for leaseholders to force the transfer of the landlord's management functions to a special "right to manage" company. This does not require the landlord's consent, and significantly limits her ability to extract unreasonable service charges (see also Appendix A.3.2).

Most professional freeholders appoint a management company to manage the properties and carry out repairs. A second concern, therefore, is that economies of scale make freeholders more efficient at conducting maintenance than individual leaseholders. These possible efficiency gains would bias our tests toward finding no bubble, because they would reduce the total cost of maintaining a leasehold, increasing its value relative to a freehold. However, if these efficiency gains were large, even individual freeholders could contract out maintenance work to large companies, thus sharing in the efficiency gains.

To test whether these possible biases affect the relative pricing of extremely-long leaseholds and freeholds, we next conduct several cross-sectional tests that show that our results are robust to considering only segments with large or small service charges. A first set of regressions compares the relative pricing of extremely-long leaseholds across houses and flats. ${ }^{33}$ As discussed above, since apartment buildings have more common areas than houses, these properties are more likely to have repair work carried out by the freeholder, in return for the leaseholders paying a service charge. If the presence of these service charges had important pricing implications for extremely-long leaseholds, then we would expect our results to be sensitive to the split between houses and flats. Columns 1 to 3 of Table $\mathrm{V}$ show results from regression 3 for flats, with variations in the choice of time fixed effects. As we observed for houses, extremely-long leaseholds on flats trade at the same price as otherwise similar freeholds. As a second test, column 4 focuses on transactions of houses following the Commonhold and Leasehold Reform Act 2002, which, as described above, further strengthened the legal protection of leaseholders against the imposition of unreasonable service charges by freeholders. The price difference between extremely-long leaseholds and freeholds continues to be zero in this sample.

While the English Housing Survey shows that, on average, only $7.4 \%$ of leaseholders in houses pay a service charge, there is significant regional heterogeneity within this subgroup. Among the three regions identified by the EHS, the share of leasehold houses with

\footnotetext{
${ }^{33}$ Flats are not the main focus of our analysis, since most of them trade on leaseholds between 99 and 250 years of initial maturity; only 3\% of flats trade as freeholds. In addition, as discussed in Giglio et al. (2015), since lease registration was more spotty prior to the Land Registration Act 2002, for flats we need to focus on transactions since 2003.
} 
service charges varies between $2.6 \%$ for the Northern Region in which most extremelylong leaseholds are located, to 30.9\% for the "Rest of England" region. ${ }^{34}$ Columns 5 and 6 of Table $\mathrm{V}$ show results from regression 3 separately for these two regions. Again, there is no price difference between extremely-long leaseholds and freeholds, independently of how common service charges are.

A final concern is whether any agency conflicts related to the assignment of maintenance responsibilities might lead to leasehold properties being more or less well maintained than freehold properties. This is directly ruled out by the analysis in Section 5.1, which showed that properties rent for identical amounts, irrespective of whether they trade as extremely-long leaseholds or freeholds.

\subsubsection{Assignment of Redevelopment Rights}

Since the extremely-long leasehold contracts considered in our tests span several hundred years, it is important to understand the provisions that regulate the ability of leaseholders to make adjustments and improvements to the property, or to redevelop it.

The treatment of redevelopment rights could affect leasehold values through two channels. First, if one were to lose the value of improvements after the expiry of the lease, this might reduce the leaseholders' incentives to engage in profitable redevelopment, and thus reduce the value of the leasehold (Capozza and Sick, 1991). However, the quantitative importance of having to forfeit improvements to the property at lease expiry depends on the remaining lease length, because the effect on the leasehold price today is the present value of giving up these improvements. Since this present value is essentially zero for extremelylong (700+ year) leaseholds, even when evaluated at low discount rates, redevelopment rights do not affect the value of extremely-long leaseholds through this channel.

A second concern, and one which is potentially more important in our setting, is that leaseholders might be prevented from making adjustments to the property during the lifetime of the lease, which could immediately reduce the value of extremely-long leaseholds. While this would bias our tests in favor of finding a classic rational bubble, we show below that such restrictions are rarely binding for extremely-long leases, and therefore have no quantitatively important effect on our results.

First, as we discuss in detail in Appendix A.3, formal restrictions on leaseholders' ability to make changes to the property are limited. Leaseholders are generally allowed to make non-structural improvements without the consent of the freeholder. For example, the leaseholder can renovate the house. For structural changes to the property, the leaseholder usually has to obtain the consent of the freeholder. However, a covenant against the making of improvements without consent is subject to the provision that consent shall

\footnotetext{
${ }^{34}$ The "Northern Region" includes the NUTS1 regions North West, North East, and Yorkshire and the Humber. The "Rest of England" region includes the NUTS1 regions Eastern, East Midlands, West Midlands and South West. The third region covers the NUTS1 regions London and South East.
} 
not be unreasonably withheld (see Section 19(2) of the Landlord and Tenant Act 1927). A freeholder would have to show that the redevelopment significantly and adversely affects her rights to ownership. In the case of extremely-long leases, most redevelopments would not infringe on the rights of the residual freeholder. This restriction is therefore unlikely to significantly affect the value of those leaseholds.

Consistent with this, Table I shows that leasehold and freehold properties are similarly old and similarly large, suggesting that restrictions on constructing newer or larger properties on leasehold land are not quantitatively important. In addition, as shown in Section 5.1, rents for leasehold and freehold properties are very similar, demonstrating that any restrictions on a leaseholder's ability to perform improvements are limited.

To provide further evidence that redevelopment options do not significantly affect the prices of extremely-long leaseholds, we next test for cross-sectional variation in the price difference between such leaseholds and freeholds across areas with differential redevelopment potential. If there were meaningful restrictions on a leaseholder's ability to redevelop a property, then this would depress the relative price of leaseholds particularly in areas with high redevelopment potential. We construct different measures of the redevelopment potential of regions in the U.K.; we then classify areas into quintiles according to the distribution of each measure, and compute the $700+$ year leasehold discount across quintiles.

Columns 1 and 2 of Table VI show the results of regression 3, when we measure an area's redevelopment potential by the change in the housing stock between the 2001 and 2011 censuses. Areas with significant growth in the housing stock are areas that attract major residential real estate investment, and houses in those areas are likely to have larger redevelopment potential. The most disaggregated U.K. geography at which the housing stock is reported is the Lower Layer Super Output Area (LSOA); there are 34,378 unique LSOAs, populated by between 400 and 1,200 households. Column 1 uses the full sample, while column 2 focuses on transactions between our two census observations, 2001 and 2011. We find no statistically significant price difference between extremelylong leaseholds and freeholds either in high-redevelopment-potential areas (top quintile) or in low-redevelopment-potential areas (bottom quintile). Figure V graphs these leasehold discounts for each quintile, with each panel corresponding to one column in Table VI.

In columns 3 and 4 of Table VI we exploit a different measure of redevelopment potential: the transactions share of new properties in each LSOA (column 3), or in each LSOAyear (column 4). Again, regions with many sales of newly-built properties promise more redevelopment potential for existing units. While a few of the estimates - in some of the quintiles - are statistically significant, they are all economically small, and only one has a sign consistent with the presence of a bubble (with a magnitude of $1.2 \%$ ). There are no patterns for the price differences between extremely-long leaseholds and freeholds across the various quintiles of redevelopment potential. 
In columns 5 and 6 of Table VI we present a third measure of redevelopment potential: the transaction share of flats in each LSOA (column 5), or in each LSOA-year (column 6). Areas with many flats offer opportunities for land-use intensification for the houses in our regression sample, whereby one house could be profitably redeveloped into a larger number of flats. Again, we find no evidence for a classic rational bubble across any of the quintiles of the distribution of this measure of redevelopment potential.

Finally, while the houses that we consider in our main analysis might have significant redevelopment option value, units within structures should have much less. If leasehold contracts meaningfully constrained the redevelopment option, then we would expect the price difference between leaseholds and freeholds to vary across houses and flats. However, we showed in Section 5.3.1 that the absence of a price difference between extremelylong leaseholds and freeholds is consistent across both houses and flats.

Overall, there is no difference between the prices of extremely-long leaseholds and freeholds, even for properties with very high redevelopment potential. This confirms the prior, based on our analysis of the institutional framework, that restrictions to a leaseholder's ability to redevelop a property do not significantly affect the relative value of extremelylong leaseholds and freeholds.

\subsubsection{Ground Rents}

In the U.K., leaseholders sometimes have to pay annual ground rents to the freeholder, since the purchase price of the lease only covers the temporary ownership of the structure. The land technically still belongs to the residual freeholder who, in principle, has the right to request that the lessee make regular payments for the use of the land. Ground rents are set separately for each property, and no comprehensive database exists. If such payments significantly affected the value of leaseholds, we would expect those leaseholds to trade at a price discount to freeholds, which would be observationally equivalent to a classic rational bubble. The absence of a price difference between leaseholds and freeholds suggests the quantitative importance of ground rents to be small. Consistent with this, the 2011-12 English Housing Survey shows that the amounts involved are usually very small (£10$£ 100$ per year), and in many cases are either zero or a symbolic amount ("a peppercorn"). Among those households that report paying ground rents, the median household reported annual rents of about $£ 25$. Even in cases where the ground rent is in principle positive, it is often zero in practice, because for the rent to be collected the freeholder has to make a specific written request to the leaseholder. Such requests are often not made, because the amounts collected would be too small to cover the administrative costs.

\subsubsection{Leasehold Extensions and Expiries}

Leaseholders and freeholders can in principle agree on a price to extend the contract and increase the maturity of the lease ("lease extension"), or, alternatively, transfer the whole 
freehold interest to the leaseholder ("enfranchisement"). Such transactions are more common in the U.K. than they are in Singapore, where the largest freeholder, the Singapore Land Authority, has made it clear that their "policy is to allow leases to expire without extension." ${ }^{35}$ These transactions, and in particular the extensions, are generally undertaken on short duration leases to avoid expiration and reversion of the property to the freeholder, and are not common for the extremely-long leases that are the focus of this paper. ${ }^{36}$ Since these are private market transactions among willing participants, we would expect them to happen at market values: the freeholder receives a mutually-agreed compensation for the sale of part or all of the residual value of the freehold..$^{37}$

The possibility that a contract of finite maturity, like the leasehold, could be extended at market prices by purchasing a new contract, in this case an extended lease or the freehold, does not affect our test for classic rational bubbles. In an equilibrium with classic rational bubbles, the freehold would be more expensive than the extremely-long leasehold precisely by the amount of the bubble. Lease extensions that add a finite number of years to a leasehold contract with more than 700 years of remaining maturity would be priced at essentially zero, because the new lease would still not include the bubble and would have the same fundamental value as the old lease. Instead, enfranchisements would occur at a price that equals the value of the bubble, because by acquiring the infinite-maturity freehold interest, the leaseholder would obtain the bubble that is attached to it. ${ }^{38}$

In the U.K., but not in Singapore, leaseholders of houses in some cases have the statutory right to enfranchise or extend the lease by 50 years (Leasehold Reform Act 1967). The law stipulates that, while such rights are granted, the freeholder needs to be compensated for any loss of value at market prices. ${ }^{39}$ These statutory rights do not materially affect our empirical results. In fact, our results are consistent across the U.K. and Singapore,

\footnotetext{
${ }^{35}$ Extensions in Singapore are possible in exceptional circumstances, and are considered on a case by case basis, where the main criteria is whether "they are in line with planning intention and help to further specific economic and social objectives." Direct quotes in this footnote and the text above are from an SLA press release available at http://www.sla.gov.sg/htm/new/new2008/new0109.htm.

${ }^{36}$ More than $80 \%$ of extensions in Giglio et al. (2015)'s sample occur on leases with fewer than 80 years left.

${ }^{37}$ Lease extensions are not always registered with the Land Registry, and are not included in our data.

${ }^{38}$ In this case, the existence of a liquid and competitive secondary market for leasehold and freehold contracts minimizes the concern that prices might not be competitive and reflect bilateral bargaining between the two parties. See our evidence in Section 5.2.

${ }^{39}$ In fact, the price "shall be the amount which at the relevant time the house and premises, if sold in the open market by a willing seller, might be expected to realise." In practice, this means that if the two parties, the leaseholder and the freeholder, cannot reach an agreement in the private market, they can resort to a court (a Leasehold Valuation Tribunal for most of our sample) tasked with determining the "market price" of the extension or enfranchisement. Court decisions, even if clearly related to a selected sample of market participants, have always been consistent with our empirical result that there is no difference in value between extremely-long leaseholds and freeholds. If compensation was awarded to the freeholder, it was unrelated to the future value of the contract, i.e., the possible bubble, and instead connected to the loss of immediately payable ground rents. In none of the many court decisions we investigated did any participant raise the possibility of a classic rational bubble and the related resale option value of the freehold contract.
} 
but no statutory rights are present in Singapore. For the U.K., the statutory rights can only adversely bias our test if enfranchisements are underpriced; but even in this case, the statutory rights could not explain our finding of a zero price difference between contracts estimated with very tight standard errors. For this to happen in the presence of a bubble, leaseholders must expect to be able to get the freehold for free and with certainty, in effect expropriating the freeholder. This runs contrary to the evidence by Giglio et al. (2015), who show that the private market and the courts impose compensation that is negatively related to remaining maturity for shorter-maturity leaseholds (between 80 and 300 years). Finally, lease extensions and enfranchisement involve significant transaction costs for the leaseholder, thus reducing the possible price impact of the statutory rights. ${ }^{40}$

\subsubsection{Taxation and Stamp Duty}

Purchases of property in the U.K. are subject to a transaction tax (stamp duty land tax, or SDLT). The tax applies equally to freehold and leasehold transactions. The tax schedule is progressive: for example, the purchase of a property up to $£ 125,000$ is tax exempt, while a purchase of a property between $£ 125,001$ and $£ 250,000$ is taxed at $1 \%$ of the total purchase price. ${ }^{41}$ There are no taxes on the ongoing ownership of a property. Local council taxes are always paid by the inhabitant, independent of whether she lives in a freehold or leasehold property.

Similarly, the purchase of property in Singapore is subject to stamp duty irrespective of the form and duration of ownership. The first SG $\$ 180,000$ are assessed at $1 \%$, the next $\$ 180,000$ at $2 \%$, and each additional increase in the sale price at $3 \%$. In addition, Singapore also taxes the ongoing ownership of a property, again irrespective of the form of ownership. Property taxes are levied on the Annual Value (AV), the tax-authority assessed one-year rental income of the property. For rental properties, the tax rate is set at $10 \%$ of $\mathrm{AV}$; for owner-occupied properties, it rises from $0 \%$ on the first SG $\$ 6,000$ to a marginal rate of $6 \%$ for AVs exceeding SG $\$ 65,000 .{ }^{42}$ As we show in Section 5.1, the rental income, and therefore the Annual Value, of a property is unaffected by the form of ownership.

If a bubble were present, these progressive tax schedules would make leases more attractive, since the leasehold might avoid incurring the higher tax bracket because it does not include the price of the bubble. While this would bias against finding a bubble, the effect is most likely negligible. Only buyers of properties that are very close to the boundaries of the tax bracket would be affected, and since the brackets are relatively large,

\footnotetext{
${ }^{40}$ The leaseholder has to pay the cost of valuation services, legal counseling, and legal expenses, and has to bear the uncertainty associated with possible court proceedings.

${ }^{41}$ In December 2014, SDLT marginal rates were raised, but the higher marginal tax rates were only assessed on the incremental value in the higher tax brackets, not on the entire value. This does not affect the transactions in our sample.

${ }^{42}$ Starting from January 1, 2014, property taxes were made more progressive. This does not affect any of the transactions during our sample period.
} 
especially in the U.K., the effect on the average price difference is unlikely to be quantitatively important. Furthermore, under the null hypothesis of our statistical test that there is no classic rational bubble in the data, taxation introduces no bias to our test.

\subsection{Heterogeneous Buyers and Frictions}

A further possible concern is that the market for leaseholds and freeholds might be segmented in the presence of heterogeneous buyers. ${ }^{43}$ In the U.K., there are no legal restrictions that prevent agents from transacting either of the two contracts.

However, even in the absence of legal restrictions, one could be concerned about implicit restrictions. To address this concern, we study whether buyers of freeholds and leaseholds differ in ways indicative of market segmentation. Since our data set does not report buyer characteristics, we instead analyze data on owners of houses from the Survey of English Housing, an annual household-level survey conducted between 1993 and 2007. The survey contains information about 187,335 households, and it reports several household characteristics, as well as whether the household owns a freehold or a leasehold. Table A.2 shows that observable differences between house owners who are freeholders or leaseholders are minimal. In particular, the first two columns of the table report the sample means and standard deviations of the main variables. Column 3 shows the average difference between leaseholders and freeholders. Column 4 shows the difference conditional on geographic fixed effects, while column 5 shows the difference conditional on geographic fixed effects as well as our hedonic controls (to the extent they are available in this data set). As is clearly visible from columns 4 and 5, once we control for geographic fixed effects, there is no economically or statistically significant difference between freeholders and leaseholders in our sample. For example, the difference in weekly income between owners of leasehold and freehold houses is less than $£ 5$, and there is no difference in the number of family members. These results minimize the concern that the two markets are segmented in a meaningful way.

Financing frictions are also not a concern for our tests. While it is possible that leaseholds with particularly short maturities of less than 60 years are less valuable as collateral for mortgages, extremely-long leaseholds are treated identically to freeholds for financing purposes. $^{44}$ Intuitively, while a 999-year lease will eventually run down to 60 years of

\footnotetext{
${ }^{43}$ From a theoretical perspective, the main concern is segmentation. Our tests are robust to the presence of heterogeneous agents as long as they can all trade the freehold and leasehold contracts. In equilibrium, these agents would have to agree on the price of all traded assets, including the bubble asset. Our tests would then correctly detect the equilibrium pricing of the bubble asset. Segmentation is a possible concern precisely because it could prevent this equalization of valuations in market prices.

${ }^{44}$ Banks in the U.K. typically require 30 years of remaining lease length after the expiry of the mortgage. Since the most common length of U.K. mortgages is 25 years, this restriction starts to bind for leases shorter than 60 years. Similarly, in Singapore households are not allowed to use their pension contributions for a property downpayment if the lease has fewer than 60 years of maturity.
} 
maturity left and then might incur a loss in its collateral value, this loss is 939 years into the future and has no impact, even at low discount rates, on the current value of the lease. Consistent with this, Appendix Table A.2 shows that freeholders and leaseholders have the same probability of having financed their house with a mortgage. Overall, we can exclude the possibility that any of our results are driven by differential financing frictions between extremely-long leaseholds and freeholds.

\subsection{Bubbles and Finite-Maturity Assets}

Our test for the presence of classic rational bubbles relies on the maturity difference between extremely-long leaseholds and freeholds. We next document that in both the U.K. and Singapore, extremely-long leaseholds indeed have finite maturity, and distinctly differ in this respect from freeholds.

Both in the U.K. and in Singapore, leaseholds are, by definition, finite maturity contracts. At expiration, the land and structure revert back to the underlying freeholder. This difference in maturity between (and among) leaseholds and freeholds is at the heart of the contract, and the reason why the different types of contracts exist. The law is both strict and explicit on the requirement that a valid lease has to be of both finite and determinate maturity. As we describe in detail in Appendix A.3.3, in the U.K. a remarkably stable judicial principle for the last 500 years holds that a lease with uncertain (potentially infinite) maturity is invalid. Furthermore, if a lease with finite and determinate maturity purports to also grant some rights that are of infinite maturity, then the lease is deemed to be valid only for those terms that have finite and determinate maturity.

The reversion of ownership at lease expiration is enforced by the government. In fact, in both countries a leasehold public record is expunged on expiration from the central title registry, and expired leaseholds have no validity (Burn et al., 2011). The government actively tries to inform the public about the finite maturity of leasehold contracts. For example, the Minister for National Development in Singapore, Gerald Giam (2014), stated, when asked about the government's policy toward expired leases: "The value of the flats will be zero at the end of their 99-year lease."

Investors correctly perceive that the leasehold claim to rents has finite maturity. Indeed, the data for shorter maturity leaseholds, which are the focus of Giglio et al. (2015), show that market participants are aware of leasehold expiration, because the pricing of shorter leases varies significantly with their maturity. For example, even relatively long leaseholds with 300 years of unexpired maturity are priced somewhat below the extremely-long leaseholds and freeholds considered in this paper. Leaseholds with 100 years remaining maturity trade at more than a $10 \%$ discount to extremely-long leaseholds. Consistent with this, between 2000 and 2014 an average of 44,674 leaseholds were terminated every year, 
a process that is formally called "lease determination." 45 The maturity of the contract is also a salient characteristic in the marketing process of the properties. Appendix Figures A.5 to A.9 show examples of online property listings in both the U.K. and Singapore; the contract structure and lease length are highly-salient aspects of the property description. Similarly, the maturity of the contract features prominently in other marketing materials, such as brochures or store displays.

As highlighted in Section 3.2, our test relies on the theoretical restriction that classic rational bubbles cannot occur on finite-maturity assets, because backward induction rules them out. Having established that the leasehold as a claim to rents has a well-understood and consistently-priced finite maturity, a more subtle theoretical concern is that the leasehold contract could trade at positive value after lease expiry. In particular, one might be concerned that while the contract states that it has finite maturity and only confers a claim to rents for that duration, the contract today could trade at a significant premium (the bubble) compared to the present value of rents, because agents expect to be able to sell the expired lease for substantial amounts after it has stopped conferring any property rights. ${ }^{46}$

However, the researchers that developed the theory of rational bubbles tried to provide discipline to their theory, to prevent such arguments from making it an empty philosophical statement. For example, Tirole (1985) remarks on the supply of bubbles that "I am always willing to pretend that a drawing I made when I was young is worth $\$ 1,000$, say. However I doubt I will be successful in convincing others that they should invest in it. [...] There are three conditions that are necessary to create a bubble: Durability, scarcity, and common beliefs." The conjecture that the leaseholds could trade as a pure bubble after the end of any property rights they confer does not satisfy the "common beliefs" or the "scarcity" requirements. The common belief requirement fails, because the market for such trading has never existed, nor does it currently exist, nor have we found evidence that market participants expect such a market to exist in the future. For example, Rightmove and Zillow, the two largest online realestate portals in the U.K., do not feature a single listing for an expired lease. Nor could we find any evidence that such a market exists in any other outlet. ${ }^{47}$ Similarly, this theoretical

\footnotetext{
${ }^{45}$ These numbers were obtained through a Freedom of Information Act (FOIA) request to the Land Registry. Numbers are reproduced with the kind permission of the Land Registry, (C) Crown copyright 2015. No detailed split by method of determination is available. In addition to the expiration of a lease ("effluxion of time"), other reasons for lease determination can include, for example, "determination on merger" and "determination by forfeiture."

${ }^{46}$ A related philosophical question is whether any contract ever has finite maturity. For example, one could argue that when one buys a 3-month Treasury bill, one buys both the finite maturity 3-month contract, and a separate claim, let's call it a "purple piece of paper," that has infinite maturity. After the expiry of the 3-month Treasury bill, the "purple piece of paper" could be traded as a pure bubble. Since this argument could be applied to any possible contract, not just leaseholds or real estate, it could invalidate the idea, and much of the common practice following from it, of the existence of any finite maturity contract.

${ }^{47}$ Conversations with market participants, including searches on online real-estate blogs, and inspection of court cases involving disputes among leaseholders and freeholders revealed no indication that participants are expecting such market to exist in the future.
} 
possibility fails the requirement for scarcity. In the reasoning of Tirole, a freeholder could simply generate many leases of very short duration (a day, a month?), because by doing so she would create many bubble claims that could be sold for large amounts of money. Each freeholder's incentive to over-create the bubble will, in equilibrium, destroy the bubble. These arguments clarify why, in practice, no classic rational bubble can occur on the finitematurity leasehold contracts.

Finally, we want to reemphasize that all these concerns do not apply to the freehold contract, which can reasonably have a classic rational bubble attached to it. Freehold contracts are of infinite maturity, have a large and well understood market that has existed in a stable form for centuries, are durable due to very stable property rights (see Section 5.6), and are clearly scarce, since only one freehold contract can be issued for each property. The bubble on a freehold does not have to trade separately because it can forever trade as part of the valid freehold and be transferred with it among agents.

\subsection{Stability of Property Rights}

One obvious concern when analyzing contracts with horizons that span several hundred years is whether agents today expect such property rights to be enforced in the future. Ex ante, such a concern might be more relevant for Singapore, a relatively young country. Yet, despite Singapore's relatively recent independence in 1965, it consistently tops the ranks of countries with the strongest property rights around the world. ${ }^{48}$ The enforcement of property rights is of paramount importance for a small open economy and world financial center. Similarly, the U.K. arguably has the strongest and longest track record of any country in upholding and promoting property rights. Concerns over the stability of its laws and institutions are as close to non-existent as can be found in real world applications of economic theory.

From a theoretical perspective we can distinguish two effects of property rights on our tests: a general concern with the enforceability of all contracts, in our case of both leaseholds and freeholds, and a concern with selective enforcement of one type of contract above the other. Classic rational bubbles rely on the existence of property rights that are strong enough that agents can expect today to sell the bubble asset at increasing prices to future generations of agents. If agents were expecting that governments would expropriate the bubble asset for sure at some future finite time, then no classic rational bubble could exist. While we cannot rule out this unobservable expectation of expropriation, by testing the theory in countries with very strong property rights and on an asset, real estate, that is comparatively harder to expropriate than fiat or intangible assets, we provide a testing

\footnotetext{
${ }^{48}$ For example, it is ranked number 7 worldwide in the 2013 International Property Rights Index compiled by The Property Rights Alliance, and ranked number 2 worldwide in the 2014 Index of Economic Freedom compiled by the Heritage Foundation.
} 
ground favorable to finding a classic rational bubble. ${ }^{49}$

A more nuanced possibility is that agents might expect leasehold and freehold contracts to be selectively enforced. If agents were to expect leasehold contracts to be reneged upon but freehold contracts to be upheld, then this could generate a price discrepancy between the two that resembled, mistakenly, a classic rational bubble. This effect makes our result of no classic rational bubble in the data a conservative one. On the contrary, if agents were to expect that leasehold contracts be converted into freehold ones for free, thus expropriating the rights of the underlying freeholder, our test would be biased against finding a classic rational bubble.

However, a long-standing tradition of strong institutional enforcement of both leasehold and freehold contracts minimizes the concern that our test could be biased by selective enforcement. Both types of contracts have been originated, traded, and enforced repeatedly in the past (see Section 5.5 for statistics on the number of lease determinations). We also stress that since both types of contracts are commonly used in private residential real estate transactions, selective enforcement would result in large-scale transfers that would be politically daunting for most governments. The stability of the contracting environment is highlighted by the fact that in our sample of U.K. transactions, we observe 271,661 secondary market transactions of leases that were originated before 1914, more than 100 years ago. We observe 25,497 transactions of leaseholds created more than 150 years ago. The oldest lease to transact in our U.K. sample was originally created in 1555. Similarly, in our sample of Singapore transactions, we observe 25,297 transactions of leases that were originated even before independence in 1965, and enforced despite the separation from the United Kingdom. The oldest lease to transact in our sample had originally been created in 1827, only three years after the Anglo-Dutch Treaty of 1824 confirmed the status of Singapore as a British possession, and only one year after the British East India Company included Singapore in the newly-formed Straits Settlements. Since past experience is likely to strongly influence expectations, concerns over current expectations of future ability to freely transact each type of contract are minimal.

\subsection{Timing the Market: Maturity Choice}

While the predictions of classic rational bubble models for trading volume are very sensitive to the specific modeling assumptions, and are often indeterminate, it is still interesting to investigate whether the origination of new leases, or the trading of existing ones, responds meaningfully to the possible presence of a bubble. For example, one could conjecture that if there were a bubble in some years, developers would opt to sell the new

\footnotetext{
${ }^{49}$ Importantly, if agents expected expropriation of the kind described above, our test would be perhaps less informative, since such complete expropriation is ruled out in the theory of the classic rational bubble, but still be unbiased since it would find no bubble in a set-up where the bubble indeed cannot exist.
} 
properties as freeholds to capture the bubble, rather than as long-dated leaseholds.

Figure VI shows that there is little yearly variation in the fraction of properties sold under each type of contract, extremely-long leasehold or freehold. In particular, the share of freeholds over the total of freeholds and extremely-long leaseholds does not respond to variations in the housing market, such as movements in the overall house price level or the price-rent ratio. Similarly, the trading activity does not respond to variation in the point estimates of our test for the bubble; recall that in any case the point estimates are both very close to zero and statistically insignificant. These facts hold both for newly-minted contracts, as well as for trading in the secondary market. We conclude that, consistent with the idea that there is no classic rational bubble in the data, there is no systematic variation in the type of contracts being traded or originated.

\section{Implications of Different Types of Bubbles}

In this paper, we rule out the presence of the large and influential class of bubbles that feature a failure of the transversality condition in the U.K. and Singapore housing markets. We remain silent on the presence of other types of bubbles that might occur in finite time. In this final section we show that distinguishing among different types of bubbles is important, highlighting that they have markedly different positive and normative implications.

While it is beyond the scope of this paper to provide a general treatment of these differences, we use a tractable, stylized framework to analyze one feature of bubbles that has attracted significant attention: the response of bubbles to interest rate changes. Both policy and academia have discussed whether monetary policy should "lean against the wind" by increasing interest rates to burst an asset price bubble. Similarly, there has been a lively debate on whether the Federal Reserve kept interest rates too low during the 20012005 period, thus contributing to asset bubbles, including in U.S. real estate (Bernanke, 2002, 2010; Allen and Gale, 2004; Obstfeld and Rogoff, 2009; Galí, 2014).

We show that the response of bubbles to interest rate changes depends crucially on the type of bubble considered. To do this, we consider a stylized economy that builds on the work of Harrison and Kreps (1978), Scheinkman and Xiong (2003), and Simsek (2013), and follows Simsek (2010). ${ }^{50}$ The economy has infinite horizon and is populated by overlapping generations. Each generation is alive for 1 period: agents born at time $t$ only consume when they are old, and die at time $t+1$. There are two assets: the riskfree rate in perfectly elastic supply at $1+r$, and an asset in positive supply of 1 unit that represents a claim to future dividends. Agents can borrow unlimited amounts, but cannot short the asset. ${ }^{51}$ Dividends are denoted $D_{t}$, and follow a stochastic process, such

\footnotetext{
${ }^{50}$ For a related empirical assessment, see Xiong and Yu (2011).

${ }^{51}$ Unlimited borrowing, as will become clear, allows us to not specify the mass of agents or their endowments. Upon birth, agents borrow what they need to invest in the risky asset.
} 
that $D_{t+1}=D_{t} s_{t+1}$, where $s_{t+1}$ is an i.i.d. random variable with compact and strictly positive support, and whose expected value is 1 . All traders are risk neutral, but they form expectations in different ways. Each period, two groups of traders are born: one group is optimistic about next period's dividend and thinks that $E_{t}^{o}\left[D_{t+1}\right]=D_{t}(1+\epsilon)$ with $r>\epsilon>0$, where $E_{t}^{o}$ denotes the expectation taken under the optimistic belief about the distribution of $s_{t+1}$. The other group of traders computes expectations using the true distribution of $s_{t+1}$. Both groups of traders agree on the distribution of further changes in dividends after the next period (i.e., $E_{t}^{o}\left[s_{t+j}\right]=E_{t}\left[s_{t+j}\right], \forall j \geq 2$ ). The optimist buy-andhold present discounted value of the asset is:

$$
P_{o, t} \equiv \sum_{j=1}^{\infty} \frac{E_{t}^{o}\left[D_{t+j}\right]}{(1+r)^{j}}=\frac{D_{t}(1+\epsilon)}{r} .
$$

This valuation is reminiscent of the Gordon (1982) valuation model for an asset with dividends constant at $D_{t}(1+\epsilon)$. We follow Harrison and Kreps (1978) and the subsequent literature, and take $P_{0, t}$ to be the measure of the fundamental value of the asset. ${ }^{52}$

The market value of the asset exceeds the fundamental value above, because it potentially contains two bubbles: a resale-option bubble and a purely-speculative bubble. Since agents can borrow and lend freely, the asset will be held in each period by the most optimistic agents in that period, thus satisfying the recursion:

$$
P_{t}=\frac{D_{t}(1+\epsilon)+E_{t}^{o}\left[P_{t+1}\right]}{1+r} .
$$

By forward iteration, this recursion yields:

$$
P_{t}=\frac{D_{t}(1+\epsilon)}{r-\epsilon}+(1+r)^{t} M_{t}
$$

where $M_{t}$ is a martingale for both optimists and neutral agents, with initial value at $t=0$ assumed to be $M_{0}>0$. It is convenient to rewrite this as:

$$
P_{t}-P_{o, t}=P_{o, t} \frac{\epsilon}{r-\epsilon}+(1+r)^{t} M_{t}=B_{H K, t}+B_{t} .
$$

In the language of Harrison and Kreps (1978), Scheinkman and Xiong (2003), and Simsek (2010), $P_{o, t}$ is a measure of the fundamental value, $B_{H K, t} \equiv P_{o, t} \frac{\epsilon}{r-\epsilon}$ is the Harrison and Kreps resale-option bubble with $\frac{\epsilon}{r-\epsilon}>0$, and $B_{t} \equiv(1+r)^{t} M_{t}$ is the purely-speculative bubble.

The term $\frac{\epsilon}{r-\epsilon}$ in equation 4 reflects a (proportional) increase in market price compared to the fundamental value that is due to the fact that optimists in each period anticipate

\footnotetext{
${ }^{52}$ Intuitively, the literature thinks of bubbles as being related to speculation in sequential trading, and thus chooses a buy-and-hold valuation, that, by definition, does not reflect the value of future re-trading of the asset, to be the fundamental value. Other definitions of the fundamental value are certainly possible, but we choose the one that dominates the literature for consistency.
} 
being able to sell to future optimists. This is the resale-option bubble that is the focus of Harrison and Kreps (1978), Scheinkman and Xiong (2003), and Simsek (2010). While these papers and this section consider an infinite-horizon economy and asset for convenience, this type of bubble would also be present in a finite-maturity asset or a finite-horizon economy, with the property that the bubble converges to zero as the horizon declines to the last period. As highlighted in Section 1, our tests are silent on this kind of bubble.

Harrison and Kreps (1978) and Scheinkman and Xiong (2003) note, however, that their economies feature equilibria with an additional type of bubble, the purely-speculative bubble $B_{t}=(1+r)^{t} M_{t}$. This bubble grows in expectation at rate $r$, and originates from the infinite maturity of the asset. It is purely speculative, because it only requires the infinite circular argument of an expectation to potentially sell the asset to other agents in the future. ${ }^{53}$ Our tests rule out this purely-speculative bubble by showing that $M_{t}=0$.

One immediate consequence of our tests is to bound the maximum possible bubble that occurs in Harrison and Kreps (1978)-type of economies, and to provide support for the theoretical decision in Harrison and Kreps (1978), Scheinkman and Xiong (2003), and Simsek (2010) to select and focus on the minimal bubble equilibrium where $M_{t}=0$.

However, selecting among the two types of bubbles is not a purely quantitative decision. On the contrary, it is an important theoretical decision, since the two bubbles have markedly different positive and normative implications. For example, the two types of bubbles have opposite comparative statics with respect to the interest rate $r$. Let lower case $b$ denote the logarithm of each type of bubble and $b_{T o T, t} \equiv b_{H K, t}+b_{t}$ be the total (log) size of the bubble, then the semi-elasticity of the total bubble to the interest rate is: ${ }^{54}$

\footnotetext{
${ }^{53}$ While it is tempting to associate this bubble with the classic rational bubble in Tirole (1985), the two bubbles have subtly different origins. To highlight these differences, consider that the purely-speculative bubble would persist in this economy even if we removed the OLG structure and considered instead finitelymany infinitely-lived agents as in Harrison and Kreps (1978) and Scheinkman and Xiong (2003). Hence, the OLG structure of Tirole (1985) is not at the core of the purely-speculative bubble discussed in this section; instead, the core of its origin is the "behavioral" assumption that agents agree to disagree. Without this assumption, we would be in the set-up of Tirole (1982), where the "no-trade theorems" rule out this purelyspeculative bubble. Similarly, in Harrison and Kreps (1978) and Scheinkman and Xiong (2003) the purelyspeculative bubble can be sustained even with $r>g$, as assumed in this section, because of the assumption that agents can borrow infinite amounts or, alternatively, have infinite wealth. This leads to the (undesirable) property that the bubble will in expectation grow to eventually account for the entire value of the asset. This can be remedied by introducing deterministic growth in dividends, such that $g>r$, but we maintained the simpler formulation here in the interest of clarity over fuller realism. These subtle differences are not at the core of our tests, but are noted here in the interest of completeness.

${ }^{54}$ In the interest of simplicity, we consider here comparative statics rather than a model with interest rates that change endogenously. We suspect that much of the intuition and the overall result carry over to a more extensive model, but do not formally develop such analysis here. Comparative statics in the presence of multiple equilibria need to be interpreted with care; in particular, the value of $M_{t}$ is a pure sunspot that could, in principle, arbitrarily depend on $r$. In equation 5, we found it most natural to keep $M_{0}$ constant and to consider the evolution of two economies that are identical, even in the realizations of the stochastic process $M_{t}$, other than in the level of the interest rate $r$. We abuse the notation and refer to $b_{T o T, t}$ as the total log-size of the bubble, but we note here that more precisely it is the sum of the log-size of each bubble.
} 


$$
\frac{\partial b_{T o T, t}}{\partial r}=\underbrace{-\frac{1}{r}}_{<0} \underbrace{-\frac{1}{r-\epsilon}}_{<0} \underbrace{+t \frac{1}{1+r}}_{>0}
$$

Each term has an intuitive economic interpretation. The first term, $\left(-\frac{1}{r}<0\right)$, highlights that the fundamental value of the asset falls with the higher interest rate, and since the resale-option bubble is proportional to the fundamental value, the resale-option bubble falls. The second term, $\left(-\frac{1}{r-\epsilon}<0\right)$, highlights the dynamic dimension of the resale-option bubble: its value comes from the fact that today's optimists will be able to sell the asset at a high price to tomorrow's optimists, and so on. A higher interest rate reduces the present value of these future resale cash-flows, and therefore the resale-option bubble coming from the dynamic component. Since both of the terms (the first two in equation 5) associated with the semi-elasticity of resale-option bubbles to interest rates are negative, we conclude that resale-option bubbles decrease in value with increases in interest rates.

On the contrary, the last term, $\left(t \frac{1}{1+r}\right)>0$, shows that the purely-speculative bubble, like the classic rational bubble in Galí (2014), increases with the higher interest rate. This occurs because the bubble, being based on pure speculation, has to grow in expectation at the rate of interest.

To conclude, this section shows that the choice of the class of bubbles considered in theoretical models has important implications for the normative and positive implications of those models. In this light, the fact that our tests rule out the presence of classic rational bubbles in housing markets, in addition to other bubbles that feature failures of the transversality condition, might shift the literature towards focusing on other, more empirically-plausible models of bubbles. The implications of including such possiblyirrational bubbles in macroeconomic models remain an interesting avenue for further research.

\section{Conclusion}

We provide a direct test for bubbles associated with failures of the transversality condition, the most prominent type of which is the classic rational bubble, and find no evidence of such bubbles in housing markets. In our test, we exploit the heterogeneity in ownership contracts for residential real estate in the U.K. and Singapore, which feature both infinitematurity ownership contracts (freeholds) and extremely-long but finite-maturity ownership contracts (leaseholds). If a bubble based on a failure of the transversality condition were present in these housing markets, it would increase the price of freeholds but not that of extremely-long leaseholds. Empirically, we find that after controlling for observable property characteristics, freehold properties trade at the same price as otherwise identical leaseholds with maturities in excess of 700 years. This result holds in every year in our sam- 
ple (1995-2013) and in an extensive set of cross-sections. These findings directly show that bubbles that violate the terminal no-bubble condition were not present in these housing markets, even during periods where the most advanced existing econometric time-series tests detect a classic rational bubble.

Our findings inform the ongoing effort to understand real estate prices and the theoretical effort to distinguish between different models of bubbles. We show that distinguishing across types of bubbles is important, since they have markedly different positive and normative implications. Future research should investigate which conclusions of the theoretical macroeconomics literature, which has mostly relied on classic rational bubbles, are robust to the introduction of (possibly behavioral) bubbles that can occur in finite time. Our work also suggests an interesting line of inquiry for the study of general equilibrium in the presence of borrowing limits. Hellwig and Lorenzoni (2009) show the equivalence between the existence of equilibria with endogenous self-enforcing private debt and the presence of a rational bubble. Relatedly, Scheinkman and Weiss (1986), Kocherlakota (1992), and Santos and Woodford (1997) connect equilibria with exogenous borrowing constraints to rational bubbles. Through the lense of these theoretical equivalence results, our empirical finding that the transversality condition holds casts doubt on the empirical relevance of models of credit constraints that have been shown to rely on the same features of rational bubbles tested in this paper.

\section{References}

Abel, A. B., Mankiw, N. G., Summers, L. H. and Zeckhauser, R. J. (1989), 'Assessing dynamic efficiency: Theory and evidence', Review of Economic Studies 56(1), 1-19.

Abreu, D. and Brunnermeier, M. K. (2003), 'Bubbles and crashes', Econometrica 71(1), 173-204.

Allen, F. and Gale, D. (2004), ' 3 asset price bubbles and monetary policy', Financial Crises and Global Governance p. 19.

Allen, F., Morris, S. and Postlewaite, A. (1993), 'Finite bubbles with short sale constraints and asymmetric information', Journal of Economic Theory 61(2), 206-229.

Arce, Ó. and López-Salido, D. (2011), 'Housing bubbles', American Economic Journal: Macroeconomics 3(1), 212-241.

Badarinza, C. and Ramadorai, T. (2014), 'Home away from home? Safe haven effects and London house prices', Unpublished Manuscript Oxford 2014.

Barberis, N., Greenwood, R., Lawrence, J. and Shleifer, A. (2015), 'Extrapolation and bubbles', Harvard and Yale unpublished manuscript .

Barberis, N. and Shleifer, A. (2003), 'Style investing', Journal of Financial Economics 68(2), 161-199.

Barberis, N., Shleifer, A. and Vishny, R. (1998), 'A model of investor sentiment', Journal of financial economics 49(3), 307-343.

Basco, S. (2014), 'Globalization and financial development: A model of the dot-com and the housing bubbles', Journal of International Economics 92(1), 78-94.

Bernanke, B. S. (2002), 'Asset-price "bubbles" and monetary policy'. Before the New York Chapter of the National Association for Business Economics, New York, New York [Accessed: 201504 10].

Bernanke, B. S. (2010), 'Monetary policy and the housing bubble'. At the Annual Meeting of the American Economic Association, Atlanta, Georgia [Accessed: 201504 10].

Blanchard, O. J. (1979), 'Speculative bubbles, crashes and rational expectations', Economics letters 3(4), 387-389.

Blanchard, O. J. and Watson, M. W. (1982), Bubbles, Rational Expectations and Financial Markets, P. Wachtel. D.C. Heath \& Company. 
Bracke, P., Pinchbeck, T. and Wyatt, J. (2014), The time value of housing: Historical evidence from London residential leases, Technical report, Working Paper.

Brock, W. A. (1982), Asset prices in a production economy, in 'The economics of information and uncertainty', University of Chicago Press, pp. 1-46.

Brunnermeier, M. K. and Oehmke, M. (2013), Bubbles, Financial Crises, and Systemic Risk, Elsevier, Amsterdam.

Burn, E. H., Cartwright, J. and Cheshire, G. C. (2011), Cheshire and Burn's Modern Law of Real Property, Oxford University Press.

Caballero, R. J. and Farhi, E. (2014), The safety trap, Technical report, Working Paper.

Caballero, R. J. and Krishnamurthy, A. (2006), 'Bubbles and capital flow volatility: Causes and risk management', Journal of Monetary Economics 53(1), 35-53.

Capozza, D. R. and Sick, G. A. (1991), 'Valuing long-term leases: The option to redevelop', The Journal of Real Estate Finance and Economics 4(2), 209-223.

Case, K. E. and Shiller, R. J. (2003), 'Is there a bubble in the housing market?', Brookings Papers on Economic Activity 2003(2), 299-362.

Cheshire, P. (2014), Turning houses into gold: the failure of British planning, Technical report, Centre for Economic Performance, LSE.

Cochrane, J. (1992), 'Explaining the variance of price dividend ratios.', Review of Financial Studies $5(2), 243-280$.

Cochrane, J. H. (2011), 'Presidential address: Discount rates', Journal of Finance 66(4), 1047-1108.

Conlon, J. R. (2004), 'Simple finite horizon bubbles robust to higher order knowledge', Econometrica 72(3), 927-936.

DeLong, J. B., Shleifer, A., Summers, L. H. and Waldmann, R. J. (1990a), 'Noise trader risk in financial markets', Journal of political Economy pp. 703-738.

DeLong, J. B., Shleifer, A., Summers, L. H. and Waldmann, R. J. (1990b), 'Positive feedback investment strategies and destabilizing rational speculation', the Journal of Finance 45(2), 379-395.

DeMarzo, P. M., Kaniel, R. and Kremer, I. (2008), 'Relative wealth concerns and financial bubbles', Review of Financial Studies 21(1), 19-50.

Diamond, P. A. (1965), 'National debt in a neoclassical growth model', American Economic Review pp. 1126-1150.

Diba, B. T. and Grossman, H. I. (1987), 'On the inception of rational bubbles', The Quarterly Journal of Economics 102(3), pp. 697-700.

Diba, B. T. and Grossman, H. I. (1988a), 'Explosive rational bubbles in stock prices?', American Economic Review 78(3), 520-530.

Diba, B. T. and Grossman, H. I. (1988b), 'The theory of rational bubbles in stock prices', Economic Journal 98(392), 746-754.

Doblas-Madrid, A. (2012), 'A robust model of bubbles with multidimensional uncertainty', Econometrica 80(5), 1845-1893.

Doblas-Madrid, A. (2014), A finite model of riding bubbles, Technical report, Working Paper.

Engested, T., Hviid, S. and Pedersen, T. (2015), 'Explosive bubbles in house prices? Evidence from the OECD countries', Working Paper.

Evans, G. W. (1991), 'Pitfalls in testing for explosive bubbles in asset prices', American Economic Review 81(4), 922-930.

Fama, E. F. (1970), 'Efficient capital markets: A review of theory and empirical work', Journal of Finance 25(2), 383-417.

Farhi, E. and Tirole, J. (2012), 'Bubbly liquidity', Review of Economic Studies 79(2), 678-706.

Favilukis, J., Ludvigson, S. C. and Nieuwerburgh, S. V. (2010), The macroeconomic effects of housing wealth, housing finance, and limited risk-sharing in general equilibrium, Working Paper 15988, National Bureau of Economic Research.

Flavin, M. and Yamashita, T. (2002), 'Owner-occupied housing and the composition of the household portfolio', American Economic Review 92(1), 345-362.

Flood, R. P. and Garber, P. M. (1980), 'Market fundamentals versus price-level bubbles: the first tests', Journal of Political Economy 88(4), 745-770.

Flood, R. P. and Hodrick, R. J. (1986), 'Asset price volatility, bubbles, and process switching', The Journal of Finance 41(4), 831-842.

Flood, R. P. and Hodrick, R. J. (1990), 'On testing for speculative bubbles', Journal of Economic Perspectives 4(2), 85-101. 
Froot, K. A. and Obstfeld, M. (1991), 'Intrinsic bubbles: The case of stock prices', American Economic Review 81(5), 1189-1214.

Galí, J. (2014), 'Monetary policy and rational asset price bubbles', American Economic Review 104(3), 721-52.

Galí, J. and Gambetti, L. (2014), 'The effects of monetary policy on stock market bubbles: Some evidence', Forthcoming, American Economic Journal: Macroeconomics .

Garino, G. and Sarno, L. (2004), 'Bubbles in U.K. house prices: Some new evidence', Souther Economic Journal 70(4), 777-795.

Garner, S. and Frith, A. (2013), A practical approach to landlord and tenant, Oxford University Press.

Gautier, P. A. and van Vuuren, A. (2014), The estimation of present bias and time preferences using land-lease contracts, Technical report, Working Paper.

Geerolf, F. (2014), Reassessing dynamic efficiency, Technical report, Working Paper.

Genesove, D. and Han, L. (2012), 'Search and matching in the housing market', Journal of Urban Economics 72(1), 31-45.

Giglio, S., Maggiori, M. and Stroebel, J. (2015), 'Very long-run discount rates', The Quarterly Journal of Economics 130(1), 1-53.

Giglio, S. and Severo, T. (2012), 'Intangible capital, relative asset shortages and bubbles', Journal of Monetary Economics 59(3), 303-317.

Glaeser, E. L., Gottlieb, J. and Gyourko, J. (2010), Can cheap credit explain the housing boom?, Technical Report 16230, National Bureau of Economic Research Working Paper.

Glaeser, E. L. and Nathanson, C. G. (2014), Housing bubbles, Technical Report 20426, National Bureau of Economic Research Working Paper.

Glaeser, E. L. and Nathanson, C. G. (2015), 'An extrapolative model of house price dynamics', NBER working paper.

Gordon, M. J. (1982), The Investment, Financing, and Valuation of the Corporation, Greenwood Press.

Harrison, J. M. and Kreps, D. M. (1978), 'Speculative investor behavior in a stock market with heterogeneous expectations', The Quarterly Journal of Economics pp. 323-336.

Hellwig, C. and Lorenzoni, G. (2009), 'Bubbles and self-enforcing debt', Econometrica 77(4), 11371164.

Himmelberg, C., Mayer, C. and Sinai, T. (2005), 'Assessing high house prices: Bubbles, fundamentals, and misperceptions', Journal of Economic Perspectives 19(4), 67-92.

Hong, H., Scheinkman, J. and Xiong, W. (2006), 'Asset float and speculative bubbles', The Journal of Finance 61(3), 1073-1117.

Hong, H., Scheinkman, J. and Xiong, W. (2008), 'Advisors and asset prices: A model of the origins of bubbles', Journal of Financial Economics 89(2), 268-287.

Iwata, S. and Yamaga, H. (2009), 'Land tenure security and home maintenance: Evidence from Japan', Land Economics 85(3), 429-441.

Knight Frank (2013), 'International buyers in London'.

Kocherlakota, N. (2008), 'Injecting rational bubbles', Journal of Economic Theory 142(1), 218-232.

Kocherlakota, N. (2009), 'Bursting bubbles: Consequences and cures', Unpublished manuscript, Federal Reserve Bank of Minneapolis .

Kocherlakota, N. R. (1992), 'Bubbles and constraints on debt accumulation', Journal of Economic Theory 57(1), 245-256.

Mankiw, N. G., Romer, D. and Shapiro, M. D. (1985), 'An unbiased reexamination of stock market volatility', The Journal of Finance 40(3), pp. 677-687.

Martin, A. and Ventura, J. (2012), 'Economic growth with bubbles', American Economic Review 102(6), 3033-3058.

Martin, A. and Ventura, J. (2014), Managing credit bubbles, Technical report, Working Paper.

Mayer, C. (2011), 'Housing bubbles: A survey', Annual Review of Economics 3(1), 559-577.

Merton, R. C. et al. (1985), On the Current State of the Stock Market Rationality Hypothesis, Alfred P. Sloan School of Management, Massachusetts Institute of Technology.

Miao, J. and Wang, P. (2011), Bubbles and credit constraints, Technical report, Working Paper.

Miao, J., Wang, P. and Zhou, J. (2014), Housing bubbles and policy analysis, Technical report, Working Paper.

Milgrom, P. and Stokey, N. (1982), 'Information, trade and common knowledge', Journal of Economic Theory 26(1), 17-27.

Nathanson, C. G. and Zwick, E. (2014), Arrested development: A theory of supply-side speculation 
in the housing market, Technical report, Working Paper.

Novy-Marx, R. (2009), 'Hot and cold markets', Real Estate Economics 37(1), 1-22.

Obstfeld, M. and Rogoff, K. (2009), Global imbalances and the financial crisis: products of common causes, in 'Federal Reserve Bank of San Francisco Global recovery: Asia and the new financial landscape Conference Proceedings'.

O'Connell, S. A. and Zeldes, S. P. (1988), 'Rational ponzi games', International Economic Review pp. 431-450.

Pástor, L. and Veronesi, P. (2003), 'Stock valuation and learning about profitability', Journal of Finance 58(5), 1749-1790.

Pavlidis, E., Yusupova, A., Paya, I., Peel, D., Martinez-Garcia, E., Mack, A. and Grossman, V. (2013), Monitoring housing markets for episodes of exuberance: an application of the Phillips et al. (2012, 2013) GSADF test on the Dallas Fed International House Price Database, Technical Report 165, Federal Reserve Bank of Dallas Globalization and Monetary Policy Institute Working Paper.

Phillips, P. C. B., Shi, S.-P. and Yu, J. (2014), 'Testing for multiple bubbles: Historical episodes of exuberance and collapse in the S\&P 500', Working Paper .

Phillips, P. C. B., Wu, Y. and Yu, J. (2011), 'Explosive behavior in the 1990s Nasdaq: When did exuberance escalate asset values?', International Economic Review 52, 201-226.

Piazzesi, M. and Schneider, M. (2009), 'Momentum traders in the housing market: Survey evidence and a search model', American Economic Review 99(2), 406-411.

Piazzesi, M., Schneider, M. and Stroebel, J. (2013), Segmented housing search, Technical report, Working Paper.

Rosen, S. (1974), 'Hedonic prices and implicit markets: Product differentiation in pure competition', Journal of Political Economy 82(1), 34-55.

Rosenbaum, P. R. and Rubin, D. B. (1983), 'The central role of the propensity score in observational studies for causal effects', Biometrika 70(1), 41-55.

Sá, F. (2014), 'Immigration and house prices in the UK', The Economic Journal .

Samuelson, P. A. (1958), 'An exact consumption-loan model of interest with or without the social contrivance of money', Journal of Political Economy 66(6), 467-482.

Santos, M. S. and Woodford, M. (1997), 'Rational asset pricing bubbles', Econometrica 65(1), 19-57.

Sargent, T. J. and Wallace, N. (1973), 'Rational expectations and the dynamics of hyperinflation', International Economic Review 14(2), pp. 328-350.

Scheinkman, J. A. and Weiss, L. (1986), 'Borrowing constraints and aggregate economic activity', Econometrica 54(1), 23-45.

Scheinkman, J. A. and Xiong, W. (2003), 'Overconfidence and speculative bubbles', Journal of Political Economy 111(6), 1183-1220.

Shiller, R. (1981), 'Do stock prices move too much to be justified by subsequent changes in dividends?', American Economic Review 71(3), 421-436.

Shleifer, A. (2000), Inefficient Markets: An Introduction to Behavioral Finance, Oxford University Press.

Simsek, A. (2010), 'When optimists need credit: asymmetric filtering of optimism and implications for asset prices', MIT Job market paper .

Simsek, A. (2013), 'Belief disagreements and collateral constraints', Econometrica 81(1), 1-53.

Tirole, J. (1982), 'On the possibility of speculation under rational expectations', Econometrica 50(5), 1163-1181.

Tirole, J. (1985), 'Asset bubbles and overlapping generations', Econometrica pp. 1499-1528.

Tyvimaa, T., Gibler, K. M. and Zahirovic-Herbert, V. (2014), 'The effect of ground leases on house prices in Helsinki', Journal of Housing and the Built Environment pp. 1-20.

West, K. D. (1987), 'A specification test for speculative bubbles', Quarterly Journal of Economics 102(3), 553-580.

Wheaton, W. C. and Nechayev, G. (2008), 'The 1998-2005 housing "bubble" and the current "correction": What's different this time?', Journal of Real Estate Research 30(1), 1-26.

Wong, S. K., Chau, K., Yiu, C. and Yu, M. (2008), 'Intergenerational discounting: A case from Hong Kong', Habitat International 32(3), 283-292.

Woodford, M. (1986), 'Stationary sunspot equilibria in a finance constrained economy', Journal of Economic Theory 40(1), 128-137.

Woodford, M. (1990), 'Public debt as private liquidity', American Economic Review 80(2), 382-388.

Xiong, W. and Yu, J. (2011), 'The Chinese warrants bubble', American Economic Review 101(6), 2723 2753. 
Table I: Summary Statistics

Panel A: U.K.

\begin{tabular}{|c|c|c|c|c|c|c|c|c|c|c|}
\hline & \multicolumn{3}{|c|}{ 700+ Leaseholds } & \multicolumn{3}{|c|}{ Freeholds } & \multirow{2}{*}{$\begin{array}{l}\Delta \\
\text { (7) }\end{array}$} & \multirow{2}{*}{$\begin{array}{l}\text { SE } \\
(8)\end{array}$} & \multirow{2}{*}{$\begin{array}{c}\Delta \mathrm{FE} \\
(9)\end{array}$} & \multirow{2}{*}{$\begin{array}{l}\text { SE } \\
\text { (10) }\end{array}$} \\
\hline & $\begin{array}{c}\text { Mean } \\
(1)\end{array}$ & $\begin{array}{c}\text { Median } \\
\text { (2) }\end{array}$ & $\begin{array}{l}\text { Std } \\
(3)\end{array}$ & $\begin{array}{c}\text { Mean } \\
(4)\end{array}$ & $\begin{array}{c}\text { Median } \\
\text { (5) }\end{array}$ & $\begin{array}{l}\text { Std } \\
(6)\end{array}$ & & & & \\
\hline Log Price $(£)$ & 11.26 & 11.29 & 0.71 & 11.70 & 11.74 & 0.73 & -0.44 & 0.03 & -0.01 & 0.01 \\
\hline Bedrooms & 2.74 & 3 & 0.79 & 3.01 & 3 & 0.87 & -0.26 & 0.02 & -0.10 & 0.01 \\
\hline Bathrooms & 1.16 & 1 & 0.44 & 1.30 & 1 & 0.58 & -0.14 & 0.01 & -0.02 & 0.00 \\
\hline Age (years) & 66.6 & 71 & 43.26 & 58.12 & 50 & 48.75 & 8.47 & 1.32 & -2.75 & 0.92 \\
\hline Size $\left(\mathrm{m}^{2}\right)$ & 101.5 & 93 & 55.52 & 112.8 & 100 & 58.17 & -11.26 & 0.77 & -5.04 & 0.51 \\
\hline $\mathrm{N}$ & & 353,309 & & & $7,167,253$ & & & & & \\
\hline
\end{tabular}

Panel B: Singapore

\begin{tabular}{lcccccccccc}
\hline \hline & \multicolumn{3}{c}{$700+$ Leaseholds } & \multicolumn{3}{c}{ Freeholds } & $\Delta$ & SE & $\Delta$ FE & SE \\
& Mean & Median & Std & Mean & Median & Std & & & & \\
& $(1)$ & $(2)$ & $(3)$ & $(4)$ & $(5)$ & $(6)$ & $(7)$ & $(8)$ & $(9)$ & $(10)$ \\
\hline Log Price (SG\$) & 13.97 & 13.89 & 0.53 & 14.02 & 13.92 & 0.63 & -0.05 & 0.04 & 0.02 & 0.07 \\
Age (years) & 4.47 & 0 & 7.41 & 5.20 & 0 & 8.79 & -0.75 & 0.33 & 0.23 & 1.12 \\
Size $\left(\mathrm{m}^{2}\right)$ & 175.5 & 134 & 147.3 & 173.1 & 129.0 & 197.1 & 2.72 & 6.19 & 3.84 & 6.36 \\
\hline $\mathrm{N}$ & \multicolumn{10}{c}{26,197} \\
\hline \hline
\end{tabular}

Note: Table shows summary statistics for the U.K. transaction sample in Panel A, and for the Singapore transaction sample in Panel B. For each of our key hedonic characteristics, we show the mean, median, and standard deviation separately for extremely-long leaseholds and freeholds. We also show the average difference between extremely-long leaseholds and freeholds $(\Delta)$, and the average difference after controlling for the same level of fixed effects as in the hedonic pricing regression $3(\Delta \mathrm{FE})$. For each type of contract, we also report the sample size $(\mathrm{N})$. All standard errors are clustered at the postcode level. 
Table II: Effect of Lease Type on Prices: Aggregate Results

\begin{tabular}{|c|c|c|c|c|c|c|c|c|}
\hline & \multicolumn{4}{|c|}{ ENGLAND \& WALES } & \multicolumn{4}{|c|}{ SINGAPORE } \\
\hline & (1) & $(2)$ & (3) & (4) & (5) & (6) & (7) & (8) \\
\hline 700+ Year Leasehold & $\begin{array}{c}0.001 \\
(0.005)\end{array}$ & $\begin{array}{c}0.001 \\
(0.005)\end{array}$ & $\begin{array}{c}0.001 \\
(0.005)\end{array}$ & $\begin{array}{c}0.000 \\
(0.004)\end{array}$ & $\begin{array}{l}-0.012 \\
(0.035)\end{array}$ & $\begin{array}{l}-0.010 \\
(0.034)\end{array}$ & $\begin{array}{l}-0.007 \\
(0.039)\end{array}$ & $\begin{array}{l}-0.001 \\
(0.038)\end{array}$ \\
\hline Fixed Effects & $\begin{array}{l}\mathrm{PC} \times \mathrm{Y} \\
\times \text { Prop }\end{array}$ & $\begin{array}{c}\mathrm{PC} \times \mathrm{Q} \\
\times \text { Prop }\end{array}$ & $\begin{array}{c}\mathrm{PC} \times \mathrm{M} \\
\times \text { Prop }\end{array}$ & $\begin{array}{l}\mathrm{PC} \times \mathrm{Y} \\
\times \text { Prop }\end{array}$ & $\begin{array}{l}\mathrm{PC} \times \mathrm{Y} \\
\times \text { Prop } \\
\times \text { Title }\end{array}$ & $\begin{array}{c}\mathrm{PC} \times \mathrm{Q} \\
\times \text { Prop } \\
\times \text { Title }\end{array}$ & $\begin{array}{c}\mathrm{PC} \times \mathrm{M} \\
\times \text { Prop } \\
\times \text { Title }\end{array}$ & $\begin{array}{l}\mathrm{PC} \times \mathrm{Y} \\
\times \text { Prop } \\
\times \text { Title }\end{array}$ \\
\hline Controls & $\checkmark$ & $\checkmark$ & $\checkmark$ & $\checkmark$ & $\checkmark$ & $\checkmark$ & $\checkmark$ & $\checkmark$ \\
\hline Restriction & & & & Winsorized & & & & Winsorized \\
\hline R-squared & 0.883 & 0.886 & 0.887 & 0.911 & 0.967 & 0.977 & 0.979 & 0.974 \\
\hline $\mathrm{N}$ & \multicolumn{4}{|c|}{$7,602,276$} & \multicolumn{4}{|c|}{378,768} \\
\hline
\end{tabular}

Note: Table shows results from regression 3. The dependent variable is the log price paid for houses in England and Wales between 1995 and 2013 (columns 1 - 4), and for properties sold in Singapore between 1995 and 2013 (columns 5 - 8). For the U.K. sample, we include fixed effects at the 3-digit postcode by transaction date by property type (detached, semi-detached, terraced) level. In columns 1 and 4 the transaction date is the transaction year; in columns 2 and 3 it is the transaction quarter and month, respectively. We control for property size, the number of bedrooms and bathrooms, property age, property condition, whether there is parking, and the type of heating. Standard errors are clustered at the 3-digit postcode level. For the Singapore sample, we include fixed effects at the 5-digit postcode by transaction date by property type (apartment, condominium, detached house, executive condominium, semi-detached house and terrace house) by title type (strata or land) level. In columns 5 and 8 the transaction date is the transaction year; in columns 6 and 7 it is the transaction quarter and month, respectively. We control for property age, property size and the total number of units in the property. Standard errors are clustered at the 5-digit postcode level. Significance levels: * $(\mathrm{p}<0.10),{ }^{* *}(\mathrm{p}<0.05),{ }^{* * *}(\mathrm{p}<0.01)$. 


\section{Table III: Effect of Lease Type on Prices: Cross-Sectional Results}

\begin{tabular}{lccccccc}
\hline \hline & $(1)$ & $(2)$ & $(3)$ & $(4)$ & $(5)$ & $(6)$ & $(7)$ \\
\hline 700+ Year & $0.012^{*}$ & 0.016 & -0.017 & 0.009 & -0.005 & -0.005 & 0.004 \\
Leasehold & $(0.006)$ & $(0.052)$ & $(0.026)$ & $(0.062)$ & $(0.012)$ & $(0.008)$ & $(0.006)$ \\
Fixed Effects \& & $\checkmark$ & $\checkmark$ & $\checkmark$ & $\checkmark$ & $\checkmark$ & $\checkmark$ & $\checkmark$ \\
Controls & & & & & & \\
Sample & U.K. & Singapore & London & PCL & Top 20\% & Top 20\% & Bottom 20\% \\
& $2002-4$ & 1995,1996, & & & Price/Inc & $\Delta$ Price/Inc & TOM \\
& & 2007 & & & U.K. 2004+ & U.K. 2004-7 & U.K. 2001+ \\
\hline R-squared & 0.828 & 0.969 & 0.892 & 0.871 & 0.833 & 0.884 & 0.875 \\
$\mathrm{~N}$ & $1,106,069$ & 68,415 & 285,281 & 52,336 & 557,368 & 383,115 & 990,513 \\
\hline \hline
\end{tabular}

Note: Table shows results from regression 3. The dependent variable is the log price paid in arms-length housing transactions. In each column, we consider a particular sample where we might have expected the presence of a classic rational bubble. In column 1 we focus on transactions in the U.K. in 2002, 2003, and 2004, and in column 2 on transactions in Singapore in 1995, 1996, and 2007. These are the years in which the time series test of Phillips et al. (2014) suggests the presence of a classic rational bubble in each country (see Section 2.2). In column 3, we focus on transactions in London, and in column 4 on transactions in Prime Central London (Mayfair, Knightsbridge, Belgravia, Chelsea, and Kensington). These are areas with significantly above-average price growth, and which have attracted large inflows of foreign capital. In column 5, we focus on transactions in the U.K. that occurred in areas in the top $20 \%$ of the price-income ratio distribution. The price-income ratio is measured as of 2004, and the regression sample includes all years since that date. We measure the price-income ratio at the Middle Layer Super Output Area (MSOA) level, the most precise level at which average incomes are reported. In column 6, we consider transactions between 2004 and 2007, focusing on the MSOAs with the 20\% largest price-income ratio growth over that period. In column 7 , we focus on those MSOA-years in the bottom $20 \%$ of the time-on-market distribution. The time-on-market information is available since 2001, and we use transactions since that year in our regression. For all U.K. samples, we include fixed effects at the 3-digit postcode by transaction year by property type (detached, semi-detached, terraced) level. We also control for property size, the number of bedrooms and bathrooms, property age, property condition, whether there is parking, and the type of heating. Standard errors are clustered at the 3-digit postcode level. For the Singapore sample, we include fixed effect at the 5 -digit postcode by transaction year by property type (apartment, condominium, detached house, executive condominium, semi-detached house and terrace house) by title type (strata or land) level. We control for property age, property size, and the total number of units in the property. Standard errors are clustered at the 5-digit postcode level. Significance levels: ${ }^{*}(\mathrm{p}<0.10),{ }^{* *}(\mathrm{p}<0.05),{ }^{* * *}(\mathrm{p}<0.01)$. 


\section{Table IV: Effect of Lease Type on Rents and Time-on-Market}

\begin{tabular}{lccccc}
\hline \hline & & LOG(RENT) & \multicolumn{2}{c}{ LOG(TIME-ON-MARKET) } \\
& $(1)$ & $(2)$ & $(3)$ & $(4)$ & $(5)$ \\
\hline 700+ Year Leasehold & -0.008 & -0.006 & 0.002 & $0.016^{* * *}$ & $0.017^{* * *}$ \\
& $(0.035)$ & $(0.034)$ & $(0.032)$ & $(0.003)$ & $(0.004)$ \\
& PC $\times$ Y & PC $\times$ M & PC $\times$ Prop & PC $\times$ Y & PC $\times$ M \\
Fixed Effects & $\times$ Prop & $\times$ Prop & & $\times$ Prop & $\times$ Prop \\
& $\times$ Title & $\times$ Title & & & \\
& $\checkmark$ & $\checkmark$ & $\checkmark$ & $\checkmark$ & $\checkmark$ \\
Controls & & & & U.K. & U.K. \\
Sample & Singapore & Singapore & U.K. & $2001-2013$ & $2001-2013$ \\
\hline R-squared & $2010-2013$ & $2010-2013$ & March 30, 2015 & 20013 \\
N & 0.869 & 0.905 & 0.875 & 0.078 & 0.371 \\
\hline \hline
\end{tabular}

Note: Table shows results from regression 3, with different dependent variables. The dependent variable in columns 1 and 2 is the log rental listing price for all properties listed "for rent" on iProperty.com.sg between 2010 and 2013. We include fixed effects at the 5-digit postcode by transaction date by property type (apartment, condominium, detached house, executive condominium, semi-detached house and terrace house) by title type (strata or land) level. In columns 1 and 2, the transaction date is the transaction year and month, respectively. We also control for property age and property size. Standard errors are clustered at the 5-digit postcode level. The dependent variable in column 3 is the log rental listing price for all houses listed as "for rent" on Rightmove.co.uk and Zoopla.co.uk on March 30, 2015. We include fixed effects at the 3-digit postcode by property type (detached, semi-detached, terraced) level. We also control for the number of bedrooms and bathrooms, and whether the house is furnished. Standard errors are clustered at the 3digit postcode level. In columns 4 and 5, the dependent variable is the log of "time-on-market" between first listing and sale, measured in days, for those houses listed on Rightmove.co.uk between September 2001 and 2013. We include fixed effects at the 3-digit postcode by transaction date by property type (detached, semi-detached, terraced) level. In columns 4 and 5 the transaction date is the transaction year and month, respectively. We also control for property size, the number of bedrooms and bathrooms, property age, property condition, whether there is parking, and the type of heating. Standard errors are clustered at the 3-digit postcode level. Significance levels: ${ }^{*}(\mathrm{p}<0.10),{ }^{* *}(\mathrm{p}<0.05),{ }^{* * *}(\mathrm{p}<0.01)$. 


\section{Table V: Cross-Sectional Analysis by Importance of Maintenance Fees}

\begin{tabular}{|c|c|c|c|c|c|c|}
\hline & (1) & (2) & (3) & (4) & (5) & (6) \\
\hline 700+ Year Leasehold & $\begin{array}{l}-0.005 \\
(0.006)\end{array}$ & $\begin{array}{l}-0.005 \\
(0.006)\end{array}$ & $\begin{array}{l}-0.005 \\
(0.006)\end{array}$ & $\begin{array}{c}0.001 \\
(0.006)\end{array}$ & $\begin{array}{l}-0.007 \\
(0.016)\end{array}$ & $\begin{array}{c}0.001 \\
(0.005)\end{array}$ \\
\hline Fixed Effects & $\mathrm{PC} \times \mathrm{Y}$ & $\mathrm{PC} \times \mathrm{Q}$ & $\mathrm{PC} \times \mathrm{M}$ & $\begin{array}{l}\mathrm{PC} \times \mathrm{Y} \\
\times \text { Prop }\end{array}$ & $\begin{array}{l}\mathrm{PC} \times \mathrm{Y} \\
\times \text { Prop }\end{array}$ & $\begin{array}{l}\mathrm{PC} \times \mathrm{Y} \\
\times \text { Prop }\end{array}$ \\
\hline Controls & $\checkmark$ & $\checkmark$ & $\checkmark$ & $\checkmark$ & $\checkmark$ & $\checkmark$ \\
\hline Sample & $\begin{array}{l}\text { U.K. Flats } \\
2004-2013\end{array}$ & $\begin{array}{l}\text { U.K. Flats } \\
2004-2013\end{array}$ & $\begin{array}{l}\text { U.K. Flats } \\
2004-2013\end{array}$ & $\begin{array}{l}\text { U.K. Houses } \\
2003-2013\end{array}$ & $\begin{array}{c}\text { U.K. Houses } \\
\text { Northern Region } \\
\text { 2011, } 2012\end{array}$ & $\begin{array}{l}\text { U.K. Houses } \\
\text { "Rest of England" } \\
2011,2012\end{array}$ \\
\hline $\begin{array}{l}\text { R-squared } \\
\mathrm{N}\end{array}$ & $\begin{array}{c}0.712 \\
1,344,558\end{array}$ & $\begin{array}{c}0.712 \\
1,344,558\end{array}$ & $\begin{array}{c}0.712 \\
1,344,558\end{array}$ & $\begin{array}{c}0.841 \\
4,367,179\end{array}$ & $\begin{array}{c}0.774 \\
140,102\end{array}$ & $\begin{array}{c}0.817 \\
235,049\end{array}$ \\
\hline
\end{tabular}

Note: Table shows results from regression 3. The dependent variable in columns 1 to 3 is the $\log$ price paid for flats in England and Wales between 2004 and 2013. In columns 4 to 6, it is the log price paid for houses. In column 4, we focus on all transactions since the Commonhold and Leasehold Reform Act 2002. In column 5, we focus on transactions in 2011 and 2012 from the "Northern Region" identified by the English Housing Survey 2011/2012, which includes the NUTS1 regions North West, North East, and Yorkshire and the Humber. In this region, only $2.6 \%$ of owners of leasehold houses reported paying a service charge. In column 6, we focus on transactions in 2011 and 2012 from the "Rest of England" region identified by the English Housing Survey 2011/2012, which includes the NUTS1 regions Eastern, East Midlands, West Midlands and South West. In this region, $30.9 \%$ of owners of leasehold houses reported paying a service charge. In columns 1 to 3, we include fixed effects at the 3-digit postcode by transaction date level (year, quarter, and month, respectively). In columns 4 to 6, we include fixed effects at the 3-digit postcode by transaction year by property type (detached, semi-detached, terraced) level. We control for property size, the number of bedrooms and bathrooms, property age, property condition, whether there is parking, and the type of heating. Standard errors are clustered at the 3-digit postcode level. Significance levels: ${ }^{*}(\mathrm{p}<0.10),{ }^{* *}$ $(\mathrm{p}<0.05),{ }^{* * *}(\mathrm{p}<0.01)$. 


\section{Table VI: Cross-Sectional Analysis by Value of Redevelopment Rights}

\begin{tabular}{|c|c|c|c|c|c|c|}
\hline & (1) & (2) & (3) & (4) & (5) & (6) \\
\hline \multicolumn{7}{|l|}{ 700+ Year Leasehold } \\
\hline Top quintile & $\begin{array}{l}-0.006 \\
(0.009)\end{array}$ & $\begin{array}{l}-0.002 \\
(0.009)\end{array}$ & $\begin{array}{l}0.014^{*} \\
(0.007)\end{array}$ & $\begin{array}{c}0.024^{* * *} \\
(0.007)\end{array}$ & $\begin{array}{c}0.001 \\
(0.008)\end{array}$ & $\begin{array}{l}-0.006 \\
(0.007)\end{array}$ \\
\hline 4th quintile & $\begin{array}{l}-0.011 \\
(0.007)\end{array}$ & $\begin{array}{l}-0.007 \\
(0.007)\end{array}$ & $\begin{array}{l}-0.004 \\
(0.007)\end{array}$ & $\begin{array}{l}0.013^{* *} \\
(0.006)\end{array}$ & $\begin{array}{l}-0.001 \\
(0.007)\end{array}$ & $\begin{array}{c}0.008 \\
(0.007)\end{array}$ \\
\hline 3rd quintile & $\begin{array}{c}0.003 \\
(0.007)\end{array}$ & $\begin{array}{c}0.005 \\
(0.007)\end{array}$ & $\begin{array}{l}-0.001 \\
(0.007)\end{array}$ & $\begin{array}{c}0.008 \\
(0.006)\end{array}$ & $\begin{array}{c}0.009 \\
(0.007)\end{array}$ & $\begin{array}{l}0.015^{* *} \\
(0.006)\end{array}$ \\
\hline 2nd quintile & $\begin{array}{c}0.008 \\
(0.007)\end{array}$ & $\begin{array}{c}0.011 \\
(0.007)\end{array}$ & $\begin{array}{l}-0.001 \\
(0.006)\end{array}$ & $\begin{array}{c}-0.012^{* *} \\
(0.006)\end{array}$ & $\begin{array}{c}0.006 \\
(0.008)\end{array}$ & $\begin{array}{l}-0.002 \\
(0.006)\end{array}$ \\
\hline Bottom quintile & $\begin{array}{c}0.004 \\
(0.011)\end{array}$ & $\begin{array}{c}0.001 \\
(0.013)\end{array}$ & $\begin{array}{l}-0.003 \\
(0.011)\end{array}$ & $\begin{array}{l}-0.004 \\
(0.006)\end{array}$ & $\begin{array}{l}-0.011 \\
(0.011)\end{array}$ & $\begin{array}{l}-0.003 \\
(0.006)\end{array}$ \\
\hline Fixed Effects \& Controls & $\checkmark$ & $\checkmark$ & $\checkmark$ & $\checkmark$ & $\checkmark$ & $\checkmark$ \\
\hline $\begin{array}{l}\text { Dev. Potential } \\
\text { Definition }\end{array}$ & $\begin{array}{c}\Delta \text { Housing } \\
\text { Stock in } \\
\text { LSOA }\end{array}$ & $\begin{array}{c}\Delta \text { Housing } \\
\text { Stock in } \\
\text { LSOA }\end{array}$ & $\begin{array}{c}\text { Share New } \\
\text { in LSOA }\end{array}$ & $\begin{array}{c}\text { Share New } \\
\text { in LSOA } \\
\text { and year }\end{array}$ & $\begin{array}{c}\text { Share Flats } \\
\text { in LSOA }\end{array}$ & $\begin{array}{c}\text { Share Flats } \\
\text { in LSOA } \\
\text { and year }\end{array}$ \\
\hline Sample & Full Sample & 2001-2011 & Full Sample & Full Sample & Full Sample & Full Sample \\
\hline $\mathrm{N}$ & $7,601,627$ & $4,959,583$ & $7,602,276$ & $7,602,276$ & $7,602,276$ & $7,602,276$ \\
\hline
\end{tabular}

Note: Table shows results from regression 3. The dependent variable is the log price paid in arms-length sales of houses in the U.K. between 1995 and 2013. In each column, we report the coefficients on the 700+ leasehold indicator, by quintiles of measured development potential. The different columns correspond to different definitions of redevelopment potential, used to divide the sample into quintiles, and different time periods. The top quintile corresponds to areas with the highest redevelopment potential. In columns 1 and 2, we measure the redevelopment potential by the increase in the housing stock at the LSOA-level between the 2001 and 2011 censuses. Column 1 runs the regression on the full sample, column 2 on the period between the two census observations (2001-2011). In columns 3 and 4, we measure redevelopment potential as the fraction of sales of new properties in each area, while in columns 5 and 6 we measure redevelopment potential as the fraction of sales that are of flats in each area. In columns 3 and 5 we construct the quintiles of redevelopment potential by sorting transactions at the LSOA level; in columns 4 and 6 we instead construct them by sorting at the LSOA $\times$ year level. All specifications include fixed effects at the 3-digit postcode by transaction quarter by property type (detached, semi-detached, terraced) level, as well as controls for property size, the number of bedrooms and bathrooms, property age, property condition, whether there is parking, and the type of heating. Standard errors are clustered at the 3-digit postcode level. Significance levels: ${ }^{*}(\mathrm{p}<0.10),{ }^{* *}(\mathrm{p}<0.05),{ }^{* * *}(\mathrm{p}<0.01)$. 
Figure I: U.K. and Singapore - House Prices and Bubble Index

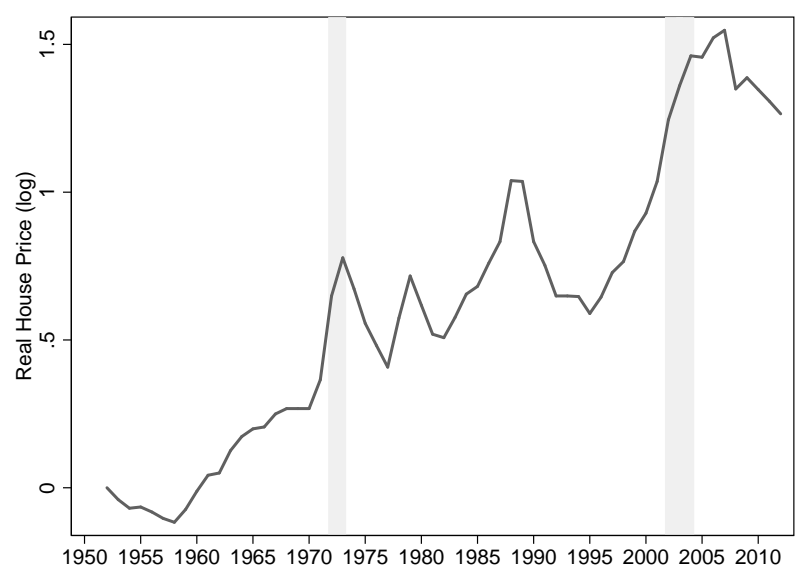

(A) U.K.: Real prices and bubbles

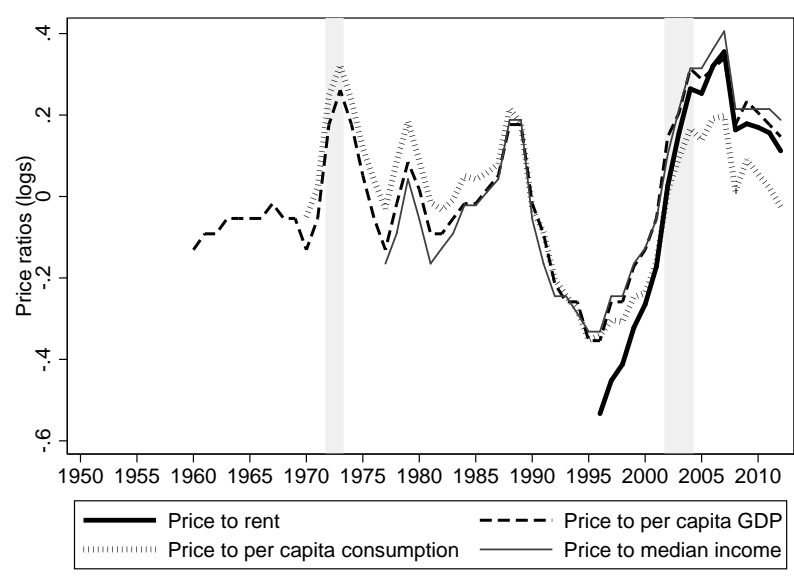

(C) U.K.: Price ratios

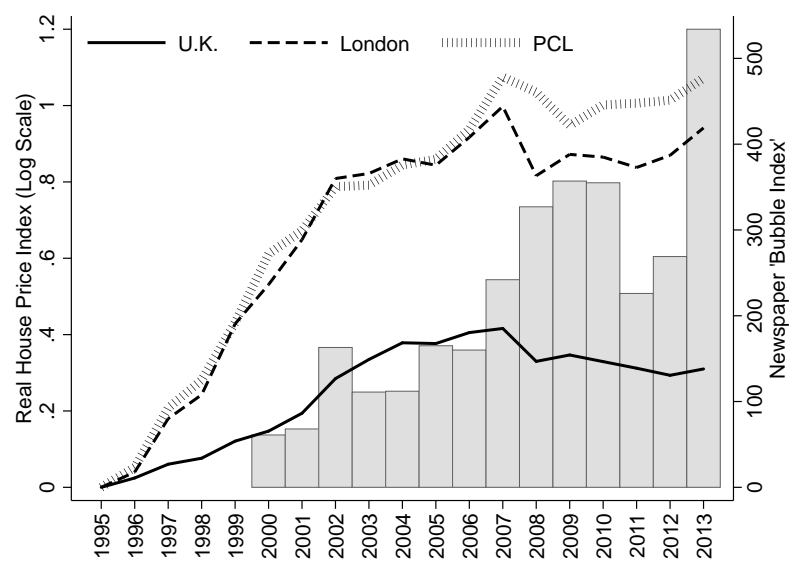

(E) U.K.: Newspaper index

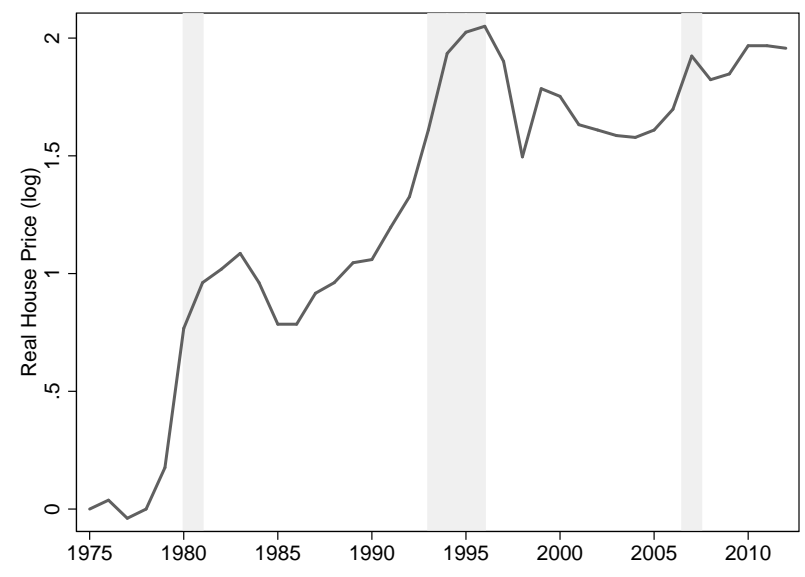

(B) Singapore: Real prices and bubbles

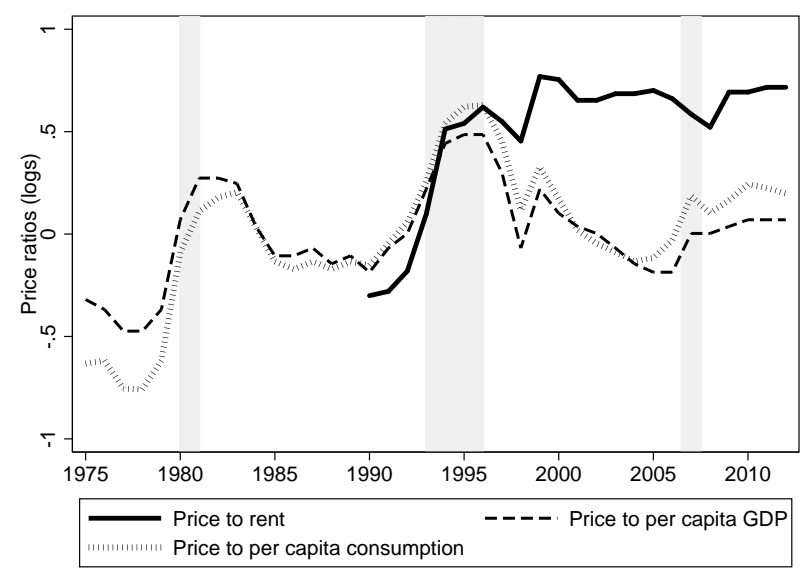

(D) Singapore: Price ratios

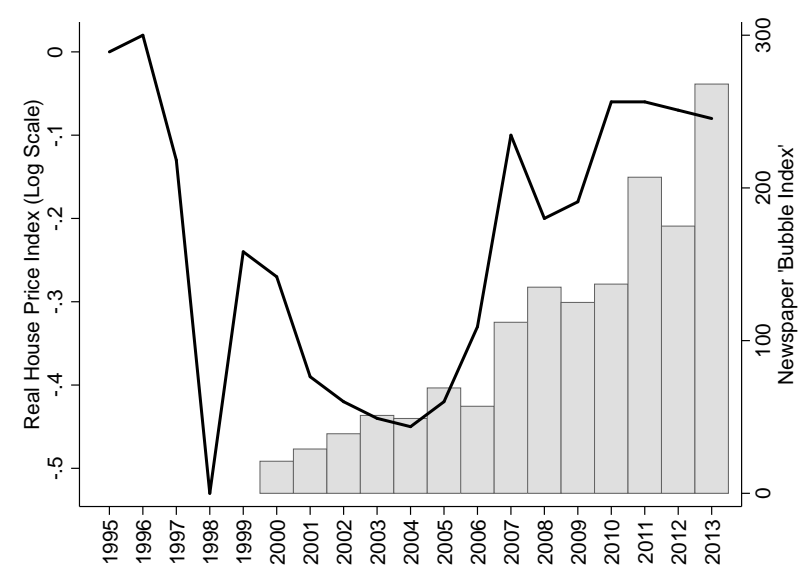

(F) Singapore: Newspaper index

Note: The top row shows the log real house price in the U.K. and Singapore, normalized to 0 at the beginning of the sample. The middle row shows various log scaled price measures in the two countries. Each series is shifted by a constant to improve readability. Shaded areas show the periods in which the Phillips et al. (2014) test detects a classic rational bubble (see Appendix A.2.2.2). The last row reports the real house prices in the U.K., London, Prime Central London (PCL), and Singapore, together with a "bubble index" that counts how often real estate bubbles are mentioned in each country's newspapers. The "bubble index" can only be constructed since 2000. See Appendix A.1.1 for details on the construction of these series. 
Figure II: U.K. - Distribution of Hedonic Characteristics

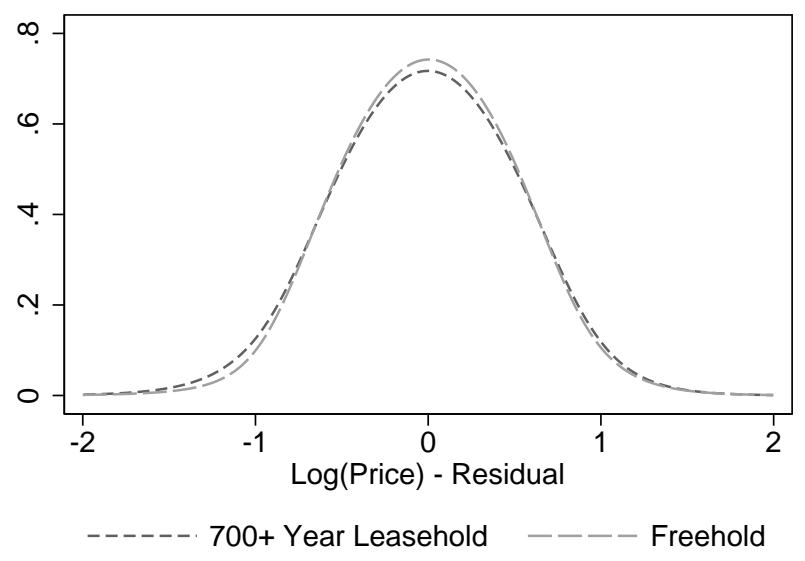

(A) $\log ($ Price)

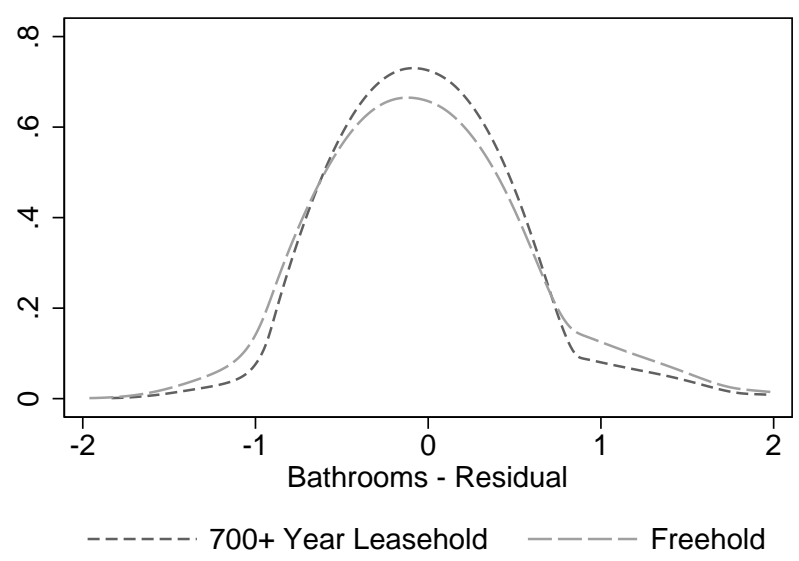

(C) Bathrooms

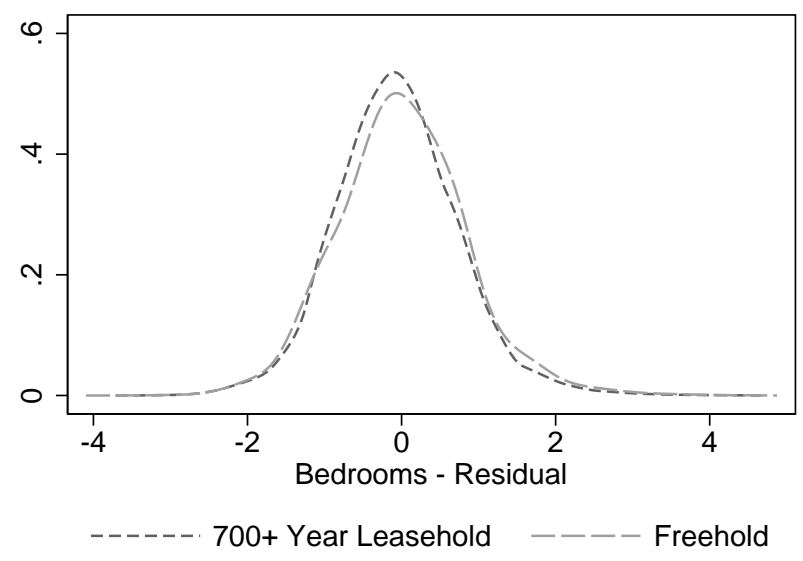

(B) Bedrooms

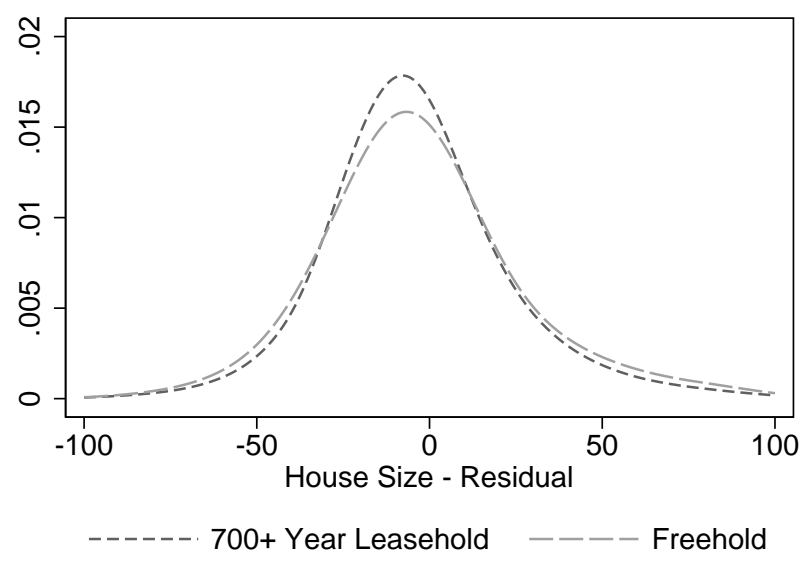

(D) Property Size

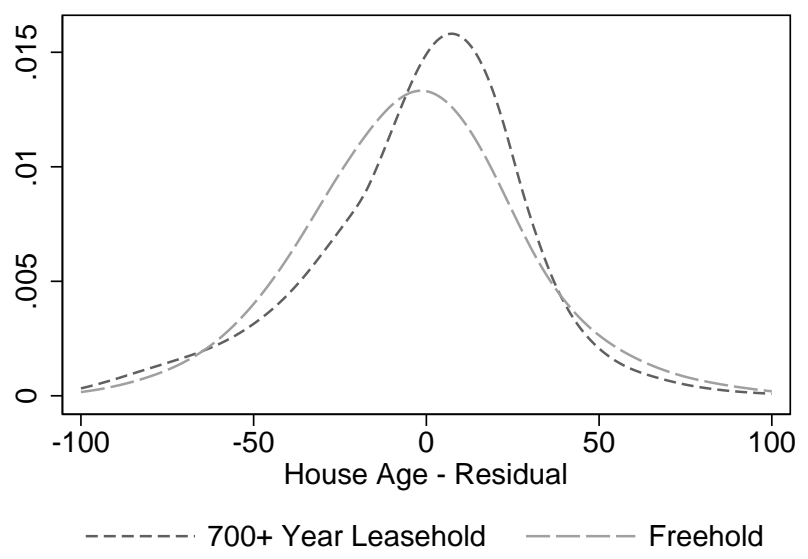

(E) Property Age

Note: Figures show the distribution of the residuals from regressions of property characteristics on 3-digit postcode $\times$ transaction year $\times$ property type fixed effects, separately for freeholds and $700+$ year leaseholds. The sample is houses sold in the U.K. between 1995 and 2013. The characteristics plotted are: the log of the transaction price (Panel A), the number of bedrooms (Panel B), the number of bathrooms (Panel C), property size in square meters (Panel D), and property age in years (Panel E). 


\section{Figure III: Singapore - Distribution of Hedonic Characteristics}

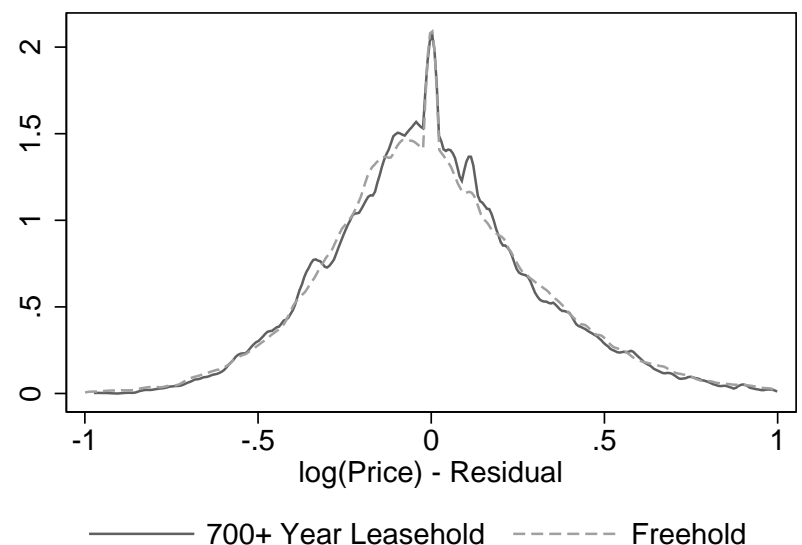

(A) $\log ($ Price)

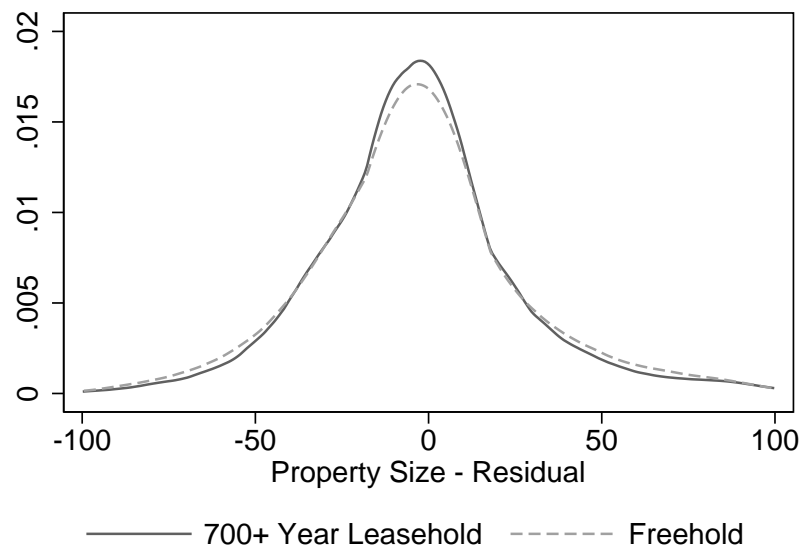

(B) Property Size

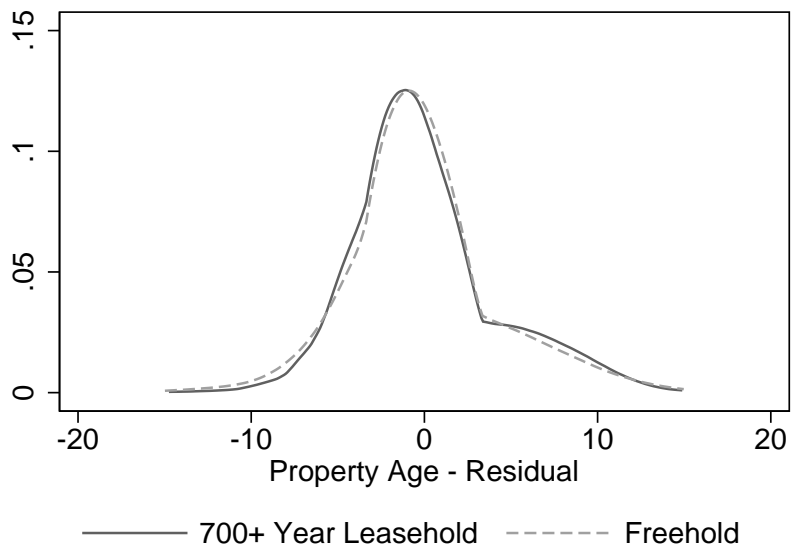

(C) Property Age

Note: Figures show the distribution of the residuals from regressions of property characteristics on property type $\times$ title type (strata or land) $\times$ 5-digit postcode fixed effects, separately for freeholds and 700+ year leaseholds. The sample is properties sold in Singapore between 1995 and 2013. The characteristics plotted are: the log of the transaction price (Panel A), property size in square meters (Panel B), and property age in years (Panel C). 
Figure IV: Time-Series and Cross-Section of Bubble Claim

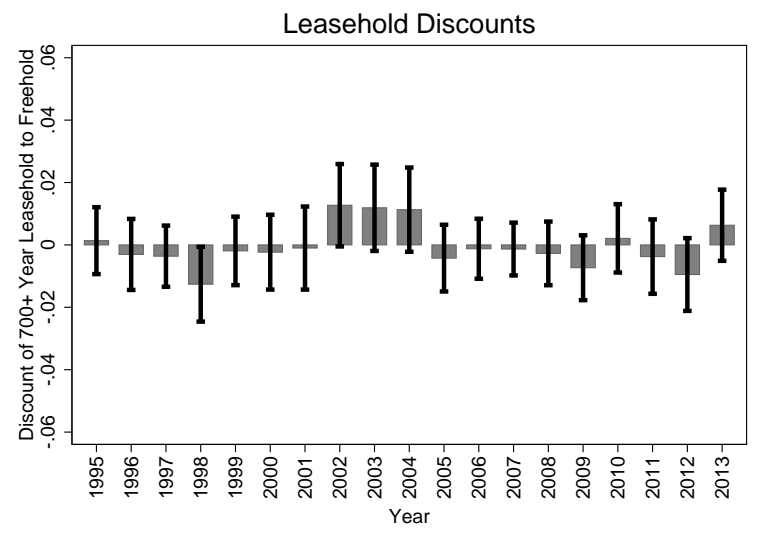

(A) U.K.: By year

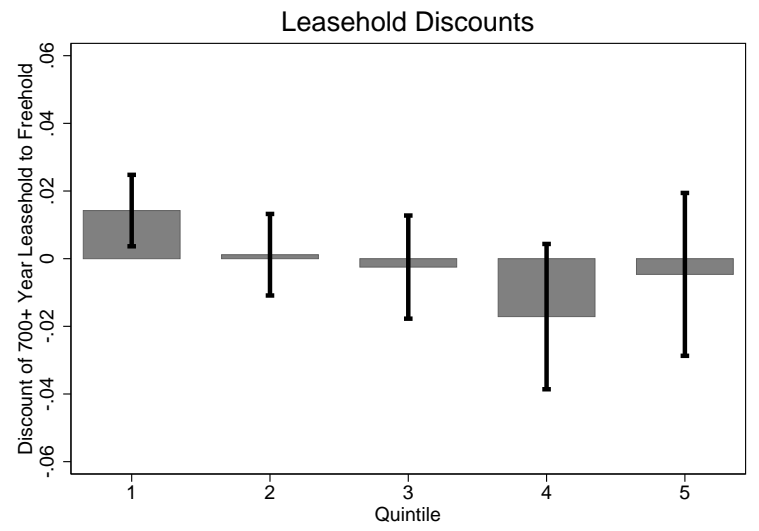

(C) U.K.: By price-income ratio (2004)

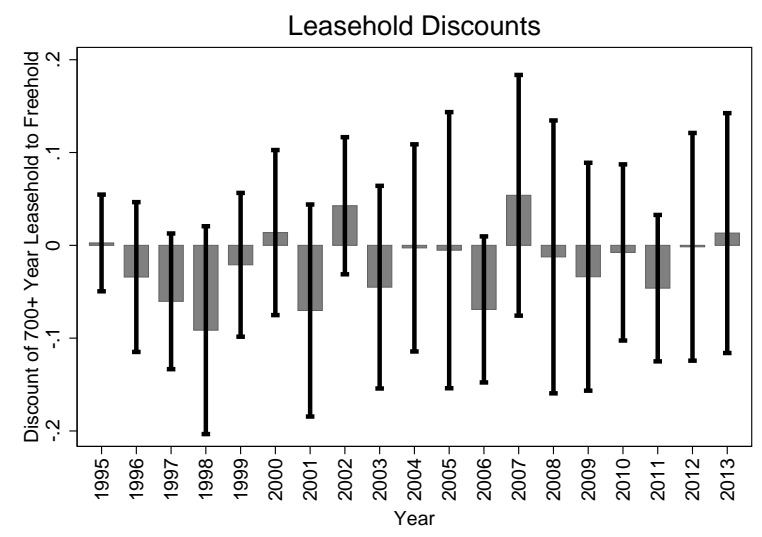

(B) Singapore: By year

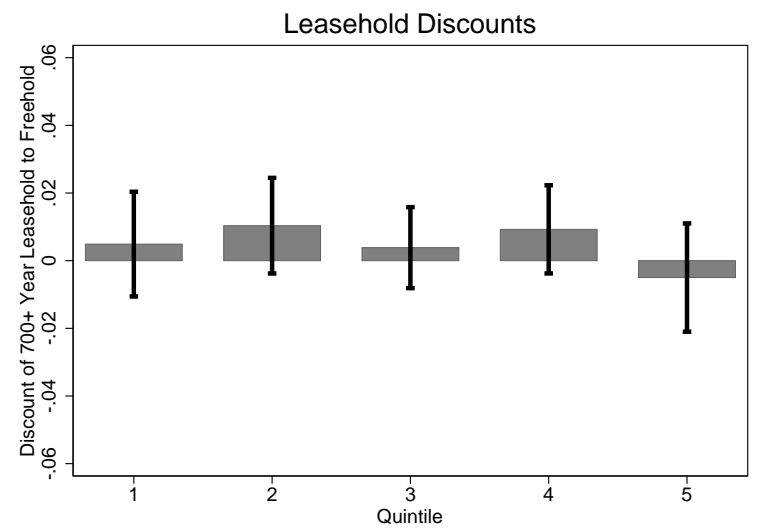

(D) U.K.: By price-income ratio growth (2004-7)

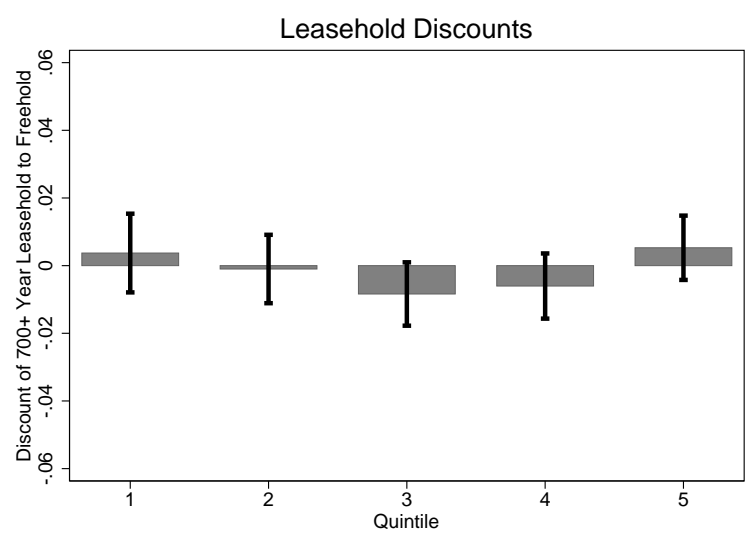

(E) U.K.: By time-on-market

Note: Figure reports estimates of the discount between 700+ year leaseholds and freeholds from regression 3 , dividing the sample along time-series and cross-sectional dimensions. Panel A and B show the coefficients of the 700+ leasehold discount year-by-year for the U.K. and Singapore, respectively. Panels C through E report the coefficients of the 700+ leasehold discount, splitting Middle Layer Super Output Areas by quintiles of measures of the potential for a bubble: the price-income ratio in 2004 (Panel C), the growth of the price-income ratio between 2004 and 2007 (Panel D), and the time-on-market (Panel E). These measures of bubble potential are constructed as in columns 5 - 7 of Table III. The bars indicate the $95 \%$ confidence interval of the estimate using standard errors clustered at the 3-digit postcode level in the U.K., and at the 5-digit postcode level in Singapore. 


\section{Figure V: Cross-Section of Bubble Claim by Redevelopment Potential (U.K.)}

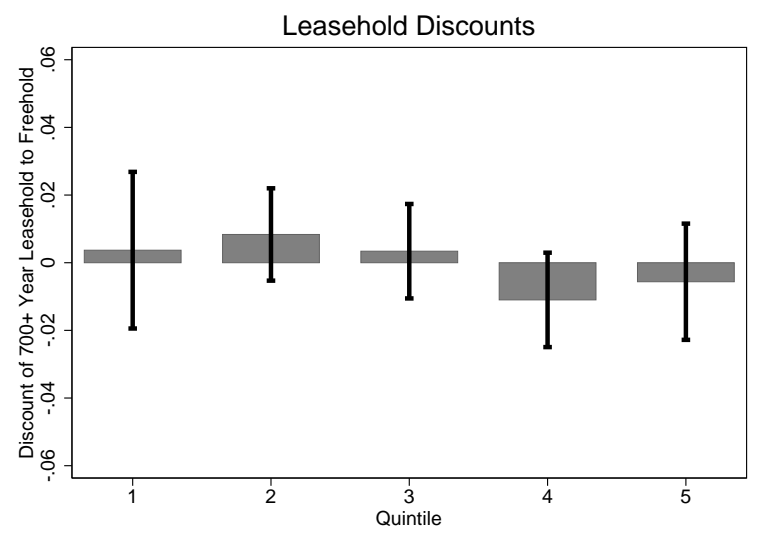

(A) Change in Housing Stock

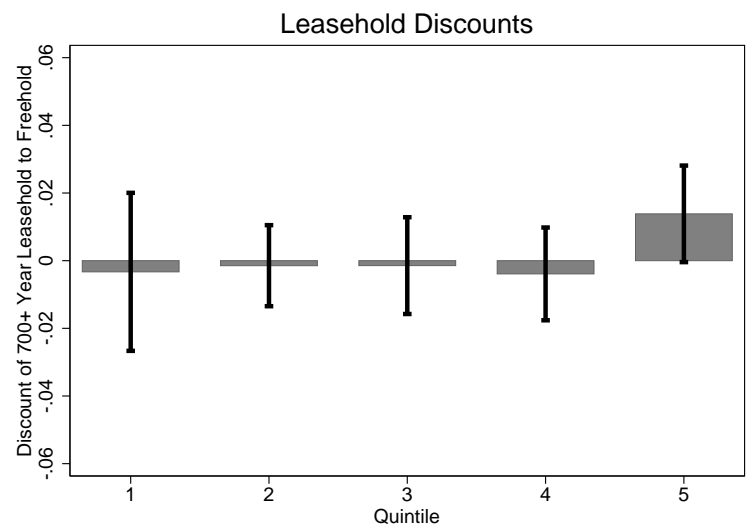

(C) Share of New Properties, by LSOA

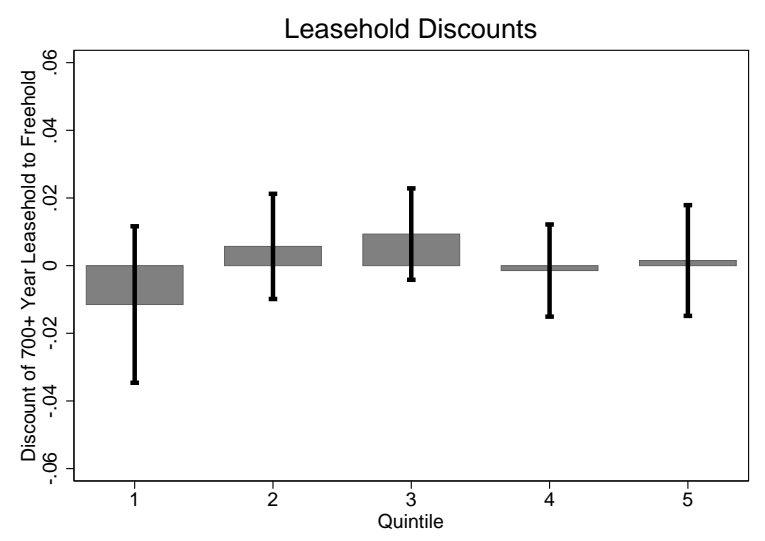

(E) Share of Flats, by LSOA

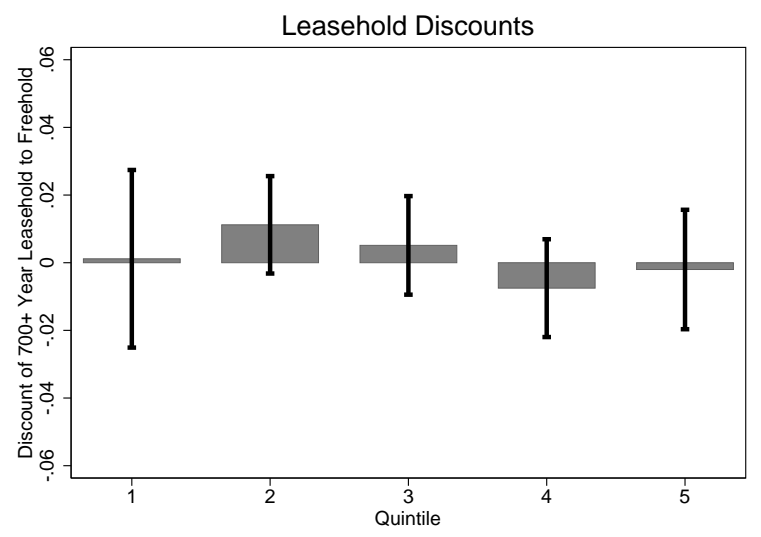

(B) Change in Housing Stock (2001-2011)

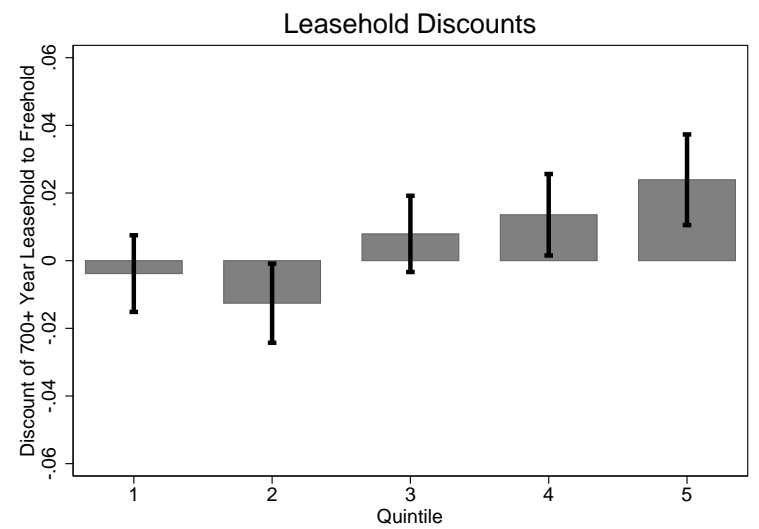

(D) Share of New Properties, by LSOA and year

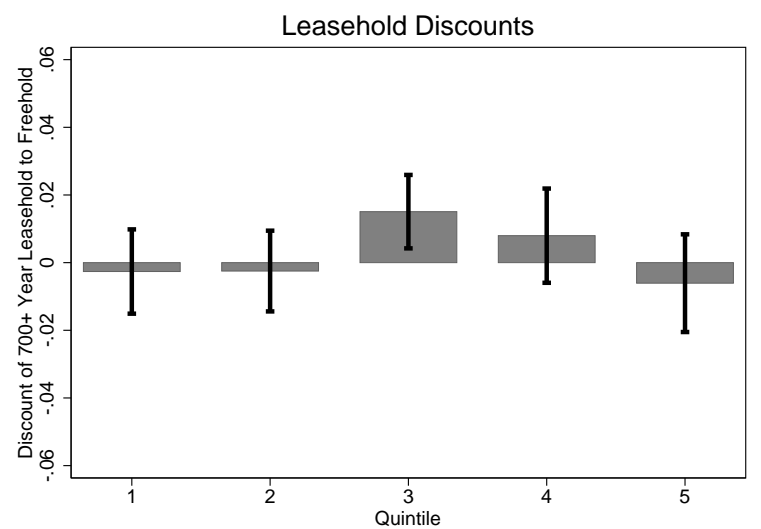

(F) Share of Flats, by LSOA and year

Note: Figures show estimates of the discount between 700+ year leaseholds and freeholds from regression 3 , by quintile of measured redevelopment potential across areas. Higher quintiles indicate higher redevelopment potential. Panel A and B measure redevelopment potential using the growth in the total housing stock between 2001 and 2011. Panel A uses the full sample, while Panel B focuses on transactions in the years 2001-2011. Panels $\mathrm{C}$ and $\mathrm{D}$ measure redevelopment potential by the transaction-share of new properties in each LSOA (Panel C) and each LSOA-year (Panel D). Panels E and F measure redevelopment potential by the transaction-share of flats in each LSOA (Panel E) and each LSOA-year (Panel F). The variables used to measure redevelopment potential - and the quintile subdivision - correspond to the ones described in Table VI. The bars indicate the $95 \%$ confidence interval of the estimate using standard errors clustered at the 3-digit postcode level. 
Figure VI: Time-Series of Freehold Transaction Shares

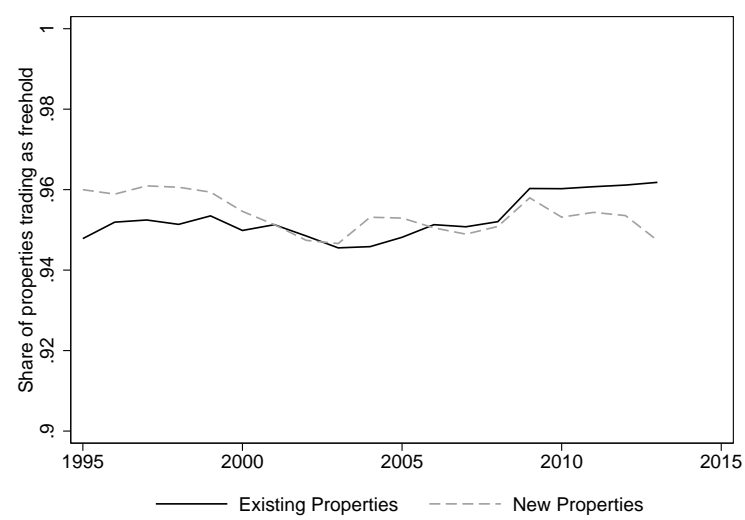

(A) U.K.

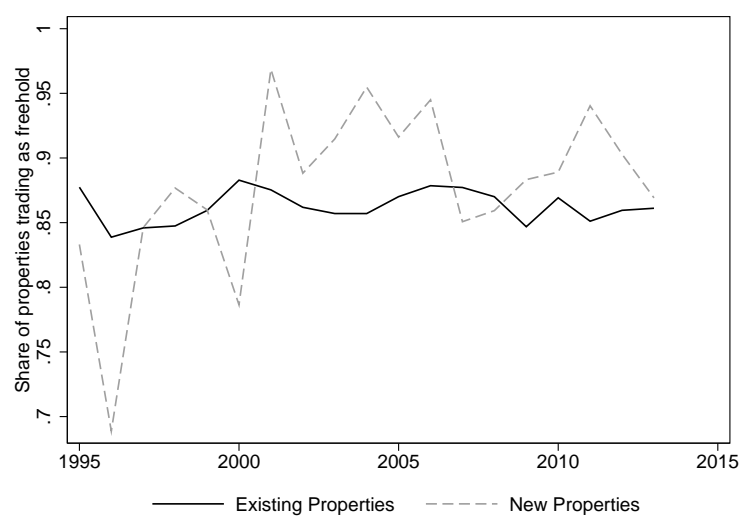

(B) Singapore

Note: Figures show the share of transactions of freeholds in the U.K. (Panel A) and Singapore (Panel B) among the set of transactions of freeholds or leaseholds with more than 700 years remaining. Transaction shares are plotted separately for transactions of new and existing properties. The frequency is annual. 


\title{
No-Bubble Condition: Model-free Tests in Housing Markets
}

\author{
Online Appendix
}

\author{
Stefano Giglio Matteo Maggiori Johannes Stroebel
}

In this online appendix, we provide additional information and results. Appendix A.1 provides more details on the data sources used in this paper. Appendix A.2 reviews and implements existing time-series tests for classic rational bubbles; this evidence shows that the leading existing tests suggest that a classic rational bubble was present in the data during our sample period. Appendix A.3 reviews in much detail the institutional framework that regulates the relationship between leaseholders and freeholders in the U.K., focusing on characteristics that might affect the relative value of extremelylong leaseholds (with maturities of 700 years or more). Finally, Appendix A.4 expands on some of the theoretical propositions in the paper.

\section{A.1 Data Appendix}

This appendix reports details on the sources and construction of data series used throughout the paper. These data are not the main data set of leasehold and freehold transactions and property characteristics, which is described in detail in the main text, but ancillary data such as the series used to build Figure I, or the analysis of foreign inflows of money in the U.K. property market referenced in Section 4.4.

\section{A.1.1 Construction of Figure I}

We first describe the sources and construction of the series plotted in Figure I.

U.K. Real House Price Indices: The real house price index for the U.K. is constructed by combining the Nationwide House Price Index (a nominal series) and the U.K. Office of National Statistics (ONS) "long term indicator of prices of consumer goods and services" (code: CDKO). The CDKO series is the standard measure for historical inflation in the U.K., since the CPI was adopted later than in other countries. The value for the house price index for 2005 was missing in the Nationwide data. We impute it by applying the 2005 growth rate from the Land Registry data for the same year. The price index for London is obtained from the Land Registry. The price index for Prime Central London (PCL) is obtained from the coefficients on the year fixed effects in a hedonic regression with prices as the dependent variable that includes the same controls of our main specification, restricted to PCL only. Both geographically-focused time series are also deflated using the CDKO series.

Singapore Real House Price Index: The nominal annual house price index is from the Urban Redevelopment Authority (series: Price Index, Whole Island. Website: https://spring.ura.gov.sg/lad/ore/ login/index.cfm). The CPI is from Statistics Singapore (series: M211702.1 P219905). We obtain the real house price index by deflating the nominal index by the CPI. 
U.K. Real Rent Index: The real rent index for the U.K. is constructed by dividing the "actual rents for housing" series from the ONS (code: D7CE) by the ONS's "long term indicator of prices of consumer goods and services" (code: CDKO).

Singapore Real Rent Index: The nominal rent index is from the Urban Redevelopment Authority (series: Rent Index, Whole Island. Website: https://spring.ura.gov.sg/lad/ore/login/index.cfm). The CPI is from Statistics Singapore (series: M211702.1 P219905). We obtain the real rent index by deflating the nominal index by the CPI.

U.K. Median Income: The time series for the median income per household, measured in current $£$ per year, is obtained from the ONS publication "The Effects of Taxes and Benefits on Household Income," Table 14: "Average incomes, taxes and benefits by decile groups of ALL households."

GDP per capita (U.K. and Singapore): The time series of GDP per capita are obtained from the World Bank Open Dataset, using the Stata software wbopendata. We use the code NY.GDP.PCAP.CN, for the country codes GBR (for the U.K.) and SGP (for Singapore). The series are in current values of the local currency.

Private final consumption expenditures per capita (U.K. and Singapore): The time series of private final consumption expenditures per capita are obtained from the World Bank Open Dataset, using the Stata software wbopendata. We use the code NE.CON.PRVT.PC.KD, for the country codes GBR (for the U.K.) and SGP (for Singapore). The series are in 2005 US\$.

Bubble Index: For the U.K., the "bubble index" counts the number of times the phrases "real estate bubble" or "housing bubble" and one of "U.K.," "UK", "United Kingdom," or "England" jointly appear in one of the following newspapers: The Sun, The Daily Mail, The Daily Telegraph, The Times, The Sunday Times, The Guardian, The Financial Times, The Independent, The Observer, The Daily Mirror, and The Sunday Mirror, as reported by ProQuest. For Singapore, the "bubble index" counts the number of times the phrases "real estate bubble" or "housing bubble" and "Singapore" jointly appear in all Englishlanguage newspapers and periodicals reported by ProQuest. In both countries, the "bubble index" can only be constructed from the year 2000 onwards.

\section{A.1.2 Data Sources for Cross-Sectional Analysis}

In Sections 4 and 5, we test for cross-sectional heterogeneity in the price difference between extremelylong leaseholds and freeholds along a number of key dimensions; such analysis helped us, for example, to confirm that there was no classic rational bubble across areas with differential redevelopment potential. In this appendix, we describe the data sources for constructing our measures of cross-sectional heterogeneity. 
Price-Income Ratio: In order to construct the price-income ratio, we require information on disaggregated measures of income. In particular, we use the series "Income: Model-Based Estimates at MSOA level" produced by the Regional and Neighborhood Outputs and Analysis Division (RNOAD) of the Office of National Statistics (ONS). This data series is available at the Middle Layer Super Output Areas (MSOA) level. The minimum population in an MSOA is 5,000, and the mean is 7,200. These income estimates are available for the years 2004 and 2007.

We combine these data on average incomes with information on the median transaction price at the MSOA-level, a data series produced by the Public Policy Division of the ONS by analyzing raw transaction data from the Land Registry. All data are obtained through the Neighborhood Statistics portal of the ONS. All data series are accessible at: https://neighbourhood.statistics.gov.uk/dissemination/.

Housing Stock Growth: To construct the growth of the housing stock we use data from the 2001 and 2011 U.K. censuses. The data series for the number of dwellings is UV55 in the 2001 census, and QS418EW in the 2011 census. The housing stock is computed at the Lower Layer Super Output Area (LSOA) level. There are 34,378 unique LSOAs, with between 400 and 1,200 households.

Other Cross-sectional Variation: We also consider cross-sectional variation in the relative pricing of leaseholds and freeholds along a number of other dimensions, including the average time on market, the share of transactions that are of flats, and the share of transactions that are for new properties. These measures of market activity are constructed within the transaction data set described in the main text.

\section{A.1.3 U.K. Rent Data}

Rental listing data for the U.K. were obtained by systematically downloading all rental listings that were live on March 30, 2015, on the two online listing portals rightmove.co.uk and zoopla.co.uk. ${ }^{1}$ From these rental listings, we extract information on the number of bedrooms, the number of bathrooms, and whether the property is furnished or unfurnished. These are used as controls in our hedonic regression analysis. Since rental listings do not contain information on the precise location of the property, we had to extract property location by reverse-geocoding the location of a marker placed by the portals on Google Maps. This marker is placed at the center of the property's complete postcode. While this does not reveal the precise location of the property, U.K. postcodes are extremely small geographic areas: the median (mean) postcode has 14 (18) households. This means that the overwhelming majority of postcodes only contains properties that are trading on the same contract structure (i.e., freehold or extremely-long leasehold). For all postcodes for which we can verify from the Land Registry data that they only contain properties of one contract type, we assign that contract type to all rental listings located in that postcode.

Since we cannot precisely match each rental listing to the property information in our baseline data, we do not control for hedonic characteristics beyond those contained in the rental listing. However, all

\footnotetext{
${ }^{1}$ As described in the paper, the rental data for Singapore were generously provided by iProperty.
} 
of our findings are confirmed if we assign each property the average characteristics of properties in that postcode (as discussed above, there are only a few relatively homogeneous properties in each postcode).

\section{A.1.4 Foreign Buyers}

In Section 4.4, we perform our test for classic rational bubbles on two subsamples of the data: London and Prime Central London (PCL). As highlighted in the main text, PCL is an area of particular interest for our tests since it exhibits many features that are commonly associated with housing bubbles. In this section, we provide details on one of these dimensions: the share of homes purchased by foreign buyers.

London is a socially and ethnically diverse city. Savills (2012) reports that 35\% of the residents of Greater London were born outside the U.K., and that a large number of properties each year are bought by foreign nationals that are U.K. residents. A more striking pattern, however, is the strong increase in purchases of London properties by foreign nationals who are not U.K. residents. This pattern, which is highly concentrated in the high-end market of PCL, has lead to a number of complaints that it induces abnormal house price growth in these areas, that it reduces housing affordability for current residents, and that it creates house price bubbles and financial instability. These complaints are exemplified by the newspaper articles or think-tank reports below:

- The Guardian, June 20, 2013, (accessed on April 19, 2015): "Prime central London property prices inflate bubble fears:"

Land Registry figures show the most expensive areas of the country - and those that have seen some of the biggest increases in prices - are the neighbourhoods that estate agents like to call "prime central London".[...] It may seem that the only way is up, but politicians, retailers and even estate agents are warning that expensive homes are creating soaring rents, an exodus of small shops and a ghost town atmosphere, and that the market could turn out to be a bubble. [...] One big concern about the PCL boom is that it is leading to streets where nobody actually lives. "More and more stats and anecdotes indicate that 'Fortress Central London' is emptying of residents," says Ed Mead of Douglas \& Gordon, an estate agency with 11 branches across the capital. He says many overseas buyers own multiple homes around the world and rarely spend time in any one, however much it cost. As a result, parts of PCL fail the neighbourhood test of having milk and newspapers on sale within a short walk of where people live. "Why should owners care? They're never here to need them," Mead says.

- The Daily Mail, August 8, 2013, (accessed on April 19, 2015): "Wealthy foreign buyers boost London property bubble which 'could burst' (and one in 10 mortgages are now buy-to-let):"

Demand from wealthy overseas buyers for multi-million pound London homes is fuelling a property bubble in the capital, experts say. [...] 'That just cannot carry on,' 
buying agent Henry Pryor told the Guardian, adding that the capital was 'in a bubble'. [...] Meanwhile the number of properties in London's most desirable postcodes being snapped up by foreign buyers has sparked fears UK buyers are being priced out of the market.

- The Civitas think-tank report by David and Bentley (2014):

Estimates vary, but billions of pounds of overseas money are pouring into the London residential property market every year. The totals have been rising in recent years, most notably at the top end of the market. When it comes to prime central London property, Savills says $£ 7$ billion of international money was spent on high-end London homes last year, with only $20 \%$ of prime property purchases being from the UK. Most importantly, two-thirds were investors rather than owner-occupiers. London Property Partners found up to $85 \%$ of prime London property purchases in 2012 were made with overseas money. Just $15 \%$ were by UK buyers. [...] The UK property market is being used as an investment vehicle by the global super-rich and increasingly the simply well-to-do. The inflationary impact of this extra cash is good news for property owners (until they want to trade up the housing ladder). It is good news for estate agents on commission, who report with glee every pulse and surge in the market. But it is not good for those already being priced out at the bottom.

Allegedly, foreign residents are buying these properties as trophies (e.g., they tend not to rent them out), to evade their home country capital controls/taxes, and as a store of value. Asset markets that attract significant capital flows from investors looking for a store of value are more likely to exhibit features of a bubble. For example, bubbles in Farhi and Tirole (2012) arise because of a shortage of assets that can act as a store of value (i.e., safe assets and assets with high pledgeability). Of course, at the same time, there are fundamental reasons for the strong house price growth in these areas, such as a shortage in land that can be developed for housing, and restrictions on redevelopment of PCL historic listed buildings.

Many estate agents report the share of their sales that have a foreign buyer. For example, Savills (2012) reports that foreign buyers accounted for 59\% of all PCL sales in 2011-12, up from 46\% in $2007 .^{2}$ They note, however, that an estimated $66 \%$ of these foreign nationals are U.K. residents. Strutt \& Parker's (2012) provide similar numbers, reporting that in the six months up to January $2012,60 \%$ of all their sales in PCL featured a foreign buyer.

In Section 4.4 we identified two areas of particular interest for our test, London and PCL, not only based on the broader picture of the market provided above, but (mostly) based on the quantitative analysis in Knight Frank (2013). Knight Frank scanned 3,500 Land Registry titles for newlybuilt properties in the boroughs of London, including the PCL boroughs, with sales prices ranging from $£ 200,000$ to $£ 5,000,000$. The study analyzes the number of foreign-resident buyers, based on the address of the buyer reported on the Land Registry title. Many properties, particularly in the high-end

\footnotetext{
${ }^{2}$ For London as a whole, they reported 34\% of foreign buyers in 2011-12 and 24\% in 2011.
} 
market, are bought via holding companies or trusts rather than by individuals. In this case the sales were classified as international, with the exception of registered social landlords, or other obviously U.K.-based entities. While this assumption might lead to overestimating the share of foreign buyers, since some U.K. residents might also set up foreign holding companies for their property transactions, it is supported by a number of publications confirming that such non-standard ownership structures are predominantly used by foreigners. ${ }^{3}$ In the two years ending June 2013, 69\% of newly-built PCL properties were bought by foreign nationals, while $49 \%$ of the sales involved foreign residents. The share of buyers who are foreign residents falls from the $49 \%$ of PCL to $20 \%$ when looking at all London boroughs. ${ }^{4}$ This markedly different market share of foreigners was (part of) the motivation for showing our results separately for London and PCL, to verify the absence of a classic rational bubble even in those markets that attracted large-scale inflows of foreign capital.

\section{A.2 Existing Time-Series Tests of Rational Bubbles}

In this appendix, we review the most commonly used existing time-series tests of rational bubbles, and apply these tests to the housing markets in the U.K. and Singapore. ${ }^{5}$ Much of the literature on testing rational bubbles builds on the test of Diba and Grossman (1988a), which is based on an analysis of integration and cointegration of the time-series of dividends and prices. This class of tests relies on the insight that a rational bubble introduces an explosive component in the asset price but not in the dividends, and specifically tests for this component.

This section proceeds as follows: first, we review the theory of the integration and cointegration tests, covering the original tests of Diba and Grossman (1988a) as well as the subsequent literature that extended those tests to overcome some of the shortcomings of the original approach; we then apply these tests to our data on the U.K. and Singapore housing markets; finally, we show that our results are consistent with the existing literature that has applied similar time-series tests.

\section{A.2.1 Integration and Cointegration Tests for Rational Bubbles}

Under the assumption of constant discount rates, the price of an asset is given by: ${ }^{6}$

$$
P_{t}=\sum_{j=1}^{\infty} \frac{1}{(1+r)^{j}} E_{t} D_{t+j}+B_{t},
$$

\footnotetext{
${ }^{3}$ See, for example, the report by ICIJ and the Guardian on BVI-based purchases of U.K. property available at: http://www.icij.org/offshore/secret-london-real-estate-speculators (accessed April 19, 2015).

${ }^{4}$ The definition of London used in our paper, for example in Table III, corresponds to the boroughs included in Inner London by Knight Frank (2013).

${ }^{5}$ For a review of this literature, also see Gurkaynak (2008).

${ }^{6}$ It is typical in this literature to assume constant discount rates for mathematical convenience. As long as discount rates are stationary, the cointegration properties of prices are minimally affected by the presence of the additional transitory component induced by time-variation in discount rates. This transitory component becomes more important for the tests if the discount rates are extremely persistent. For more details see Craine (1993), Timmermann (1995), and Phillips and Yu (2011).
} 
where the bubble component $B_{t}$ satisfies the difference equation:

$$
E_{t} B_{t+1}=(1+r) B_{t}, \quad \text { with } \quad B_{0}>0 .
$$

The bubble grows on average at rate $r>0$, and, as noted in Diba and Grossman (1988b), has to be strictly positive at all times. Diba and Grossman (1988a) study how these features of the bubble affect the stationarity of the price process, $P_{t}$. In particular, they observe that under the null hypothesis of no bubble, the degree of integration of $P_{t}$ is the same as that of $D_{t}$. For example, if dividends are stationary, prices are also stationary; if dividends have a unit root, prices will inherit that unit root. On the contrary, the presence of a bubble introduces an explosive component in prices that is not present in dividends. This implication of a rational bubble yields two empirical tests that we review below.

\section{A.2.1.1 The Right-Tailed ADF Test}

Diba and Grossman (1988a) propose a test whereby a bubble is detected in the data if prices are integrated of higher order than dividends. For example, a bubble is detected if first differences in prices are integrated of at least order 1, while dividends in levels are stationary or have a unit root. Tests for explosive patterns in prices can be performed using right-tailed Augmented Dickey-Fuller (ADF) tests. ADF tests can be used to test for a unit root in the variable of interest $\left(P_{t}\right.$ or $\left.D_{t}\right)$ against the stationary alternative (left-tailed test), or against the explosive alternative (right-tailed test). Since the limiting distribution for the test statistic is nonstandard, critical values for the test are obtained via Monte Carlo simulations. Phillips et al. (2014a) emphasize that the choice of the regression specification employed to perform the ADF test is important, because the regression needs to nest plausible specifications either under the null or under the preferred alternative model. To test for stationarity against a unit root (for example, to test the stationarity of the price-rent ratio), we use the standard general specification of the ADF test:

$$
x_{t}=a+b t+\delta x_{t-1}+\sum_{j=1}^{k} \phi_{j} \Delta x_{t-j}+e_{t} .
$$

The null hypothesis in the ADF test is that $\delta=1$, and the alternative hypothesis is that $\delta<1 .^{7}$ We allow for the linear trend term, $b t$, while specifying that under the null model $b=0$, to capture the possibility that under the alternative model $x_{t}$ might be stationary around a trend.

Phillips et al. (2014a) argue that when testing for the presence of an explosive root as an alternative hypothesis (right-tailed test), rather than a unit root, the specification A.2, as used in Diba and Grossman (1988a), is not appropriate, because in this case both the null and the alternative models feature $b=0$. They suggest that for right-tailed tests a better specification imposes $b=0$, and specifies:

$$
x_{t}=\alpha+\delta x_{t-1}+\sum_{j=1}^{k} \phi_{j} \Delta x_{t-j}+e_{t} .
$$

\footnotetext{
${ }^{7}$ An $F$-test for the joint hypothesis that $\delta=1$ and $b=0$ has also been proposed. However, this test is not one-sided, and in the bubbles test we want to keep separate the deviation from the null towards stationarity and the presence of explosive roots, so we will confine ourselves to one-sided tests.
} 
The null hypothesis is still $\delta=1$, but the alternative hypothesis is now $\delta>1$. We follow this suggested specification in our implementation of the right-sided test.

\section{A.2.1.2 Cointegration Tests}

Diba and Grossman (1988a) propose a second test which directly exploits the restriction that, under the null hypothesis of no rational bubble, not only should prices and dividends have the same degree of integration, but they should also be cointegrated. A rational bubble breaks the cointegration by inducing a more explosive pattern in prices than in dividends. The intuition behind this argument can be understood, for example, by using the Campbell and Shiller (1987) log-linearization of Equation A.1 under $B_{t}=0, \forall t$, which yields:

$$
\begin{aligned}
p_{t}-d_{t} & =h+\sum_{j=0}^{\infty} \rho^{j} E_{t} \Delta d_{t+1+j} \\
\rho & =\frac{1}{1+\exp (\overline{d-p})} \\
h & =\frac{-\log (\rho)+(1-\rho) \log \left(\frac{1}{\rho}-1\right)-r}{1-\rho}
\end{aligned}
$$

where lower case variables denote logarithms, so that, for example, $p_{t}=\log \left(P_{t}\right) . r$ is the (constant) expected return on the asset, and $\overline{d-p}$ is the average log dividend-price ratio. Campbell and Shiller (1987) point out that in the absence of a rational bubble, the log price-dividend ratio is stationary as long as dividend growth is stationary. Diba and Grossman (1988a) test this restriction with a cointegration test for log-prices and log-dividends.

\section{A.2.1.3 The SADF Test}

While theoretically appealing, the original tests by Diba and Grossman (1988a) described above have important drawbacks. Evans (1991) points out that, in finite samples, these tests have low power to detect the presence of rational bubbles that periodically collapse. Intuitively, a price series with a collapsing bubble may look stationary if the sample is short enough, since the price would appear to revert to the mean when the bubble collapses. This observation has limited the applicability of the original tests, and has prompted the subsequent literature to develop more sophisticated econometric tests aimed at overcoming this limitation.

Among this new class of tests, an important extension of the right-tailed ADF test that explicitly allows for periodically collapsing rational bubbles was developed by Phillips et al. (2011). This test exploits the idea that if a rational bubble is present in sample, but might collapse at some point, prices may not display explosive behavior when the full sample is considered, but should behave in an explosive way up to the collapse of the bubble. The procedure looks for such periods by testing for explosive behavior in all subsamples from time $t_{1}$ (the initial period of the sample, kept fixed) up to all possible end dates of the bubble $t_{2}$. This test is denoted sup-ADF (SADF), because it is constructed by taking the 
sup across the ADF statistic in all the subsamples.

In particular, denote by $A D F_{\epsilon}$ the ADF statistic obtained using data from time 0 up to time $[\epsilon T]$, where $\epsilon \in(0,1), T$ is the total sample size, and the operator [.] returns the integer part of its argument. The test statistic tends in distribution to:

$$
A D F_{\epsilon} \rightarrow \frac{\int_{0}^{\epsilon} \tilde{W} d W}{\left(\int_{0}^{\epsilon} \tilde{W}^{2}\right)^{1 / 2}}
$$

where $W$ is a standard Brownian motion and $\tilde{W}(r)=W(r)-\int_{0}^{1} d W$. The sup-ADF test has the limiting distribution:

$$
S A D F=\sup _{\epsilon \in\left[\epsilon_{0}, 1\right]} A D F_{\epsilon} \rightarrow \sup _{\epsilon \in\left[\epsilon_{0}, 1\right]} \frac{\int_{0}^{\epsilon} \tilde{W} d W}{\left(\int_{0}^{\epsilon} \tilde{W}^{2}\right)^{1 / 2}}
$$

where $\epsilon_{0}$ is the minimum window size considered for the bubble test. Optimal choice methods for $\epsilon_{0}$ are discussed in Phillips et al. (2011), and the critical values for the test are obtained by Monte Carlo simulation. In addition, the procedure allows to estimate the origination date $\epsilon_{e}$ and the collapse date $\epsilon_{f}$ of the bubble, as described in Phillips et al. (2011), by choosing the earliest and latest date in which the $A D F_{\epsilon}$ statistic is above its corresponding critical value.

Note that both the ADF and the SADF tests for explosive patterns are right-tailed tests, in which the null hypothesis is that prices are unit root, and the alternative hypothesis is that rational bubbles are present in the sample. Rejecting the null (when the test statistic is larger than the critical values) indicates the presence of a (potentially periodically collapsing) rational bubble in the data.

\section{A.2.1.4 The GSADF Test}

Phillips et al. (2014) note that the methodology developed in Phillips et al. (2011) may still fail to detect bubbles if more than one bubble is present in the sample. To address this, Phillips et al. (2014) develop a further extension of the SADF test that tests for bubbles in every subperiod $t_{1}$ to $t_{2}$ in the data (in this case $t_{1}$ is not kept fixed to be the initial date of the sample). This test is denoted as the generalized-sup-ADF (GSADF) test.

The intuition behind this procedure is to test for the presence of a collapsing bubble using the SADF test in every subsample of the data: while the SADF test can detect one bubble in the sample it analyzes, different SADF tests conducted over different windows are able to detect many separate bubbles. The GSADF test is given by:

$$
G S A D F=\sup _{\epsilon_{2} \in\left[\epsilon_{0}, 1\right], \epsilon_{1} \in\left[0, \epsilon_{2}-\epsilon_{0}\right]} A D F_{\epsilon_{1}}^{\epsilon_{2}}
$$

where $A D F_{\epsilon_{1}}^{\epsilon_{2}}$ is the standard ADF test constructed using the sample from $\left[\epsilon_{1} T\right]$ to $\left[\epsilon_{2} T\right]$. Phillips et al. (2014) also show how to provide estimates of the start and end dates of the bubbles by looking at the $S A D F$ test across subperiods. In what follows, we apply the ADF, SADF and GSADF tests to the U.K. and Singapore housing markets. 


\section{A.2.2 Data and empirical tests}

We implement the above tests for classic rational bubbles on house price and rent series for the U.K. and Singapore. For the U.K., our real house price series covers the period 1952-2013, and our real rent series covers the period 1996-2013. ${ }^{8}$ For Singapore, our real house price series covers the period 1975-2012, and our real rent series covers the period 1990-2013. ${ }^{9}$ The short samples for rent series limit the implementability of integration tests for rents and cointegration tests for rents and house prices. Of course, this limitation does not apply to tests that only require house price data.

We implement the tests using the log, rather than the level, of prices and rents because a linear trend in the alternative model of a number of the tests is more plausible when considering log prices and dividends rather than levels. The (unreported) results are very similar when using levels.

\section{A.2.2.1 Cointegration Tests}

Following Diba and Grossman (1988a), we look at the cointegration between log prices and log rents. In particular, Campbell and Shiller (1987) note that economic theory constrains the cointegrating vector between prices and rents to be $[1,-1]$, i.e., the difference $p_{t}-d_{t}$ should be stationary in the absence of a rational bubble. We can test this restriction by performing a left-tailed ADF test on the time series $p_{t}-d_{t}$. The null hypothesis is that there is a unit root in the series, while the alternative hypothesis derived from economic theory - is that the series is stationary (without deterministic trends). We cannot reject the null of a unit root in the price-rent ratio for either country (ADF statistics are -1.91 in the U.K. and -2.37 in Singapore, with 10\% left-sided finite-sample critical values of -2.68 and -2.58 , respectively). These tests, therefore, are a first indication that a rational bubble might be present in these markets.

\section{A.2.2.2 Tests for Explosive Patterns in Prices}

We also implement the tests in Phillips et al. (2011) and Phillips et al. (2014) that extend the original tests in Diba and Grossman (1988a). Table A.1 reports tests for rational bubbles using the ADF test, the sup-ADF (SADF) test, and the generalized sup-ADF (GSADF) test to check for explosive patterns in house price series. Note that the procedures by Phillips et al. (2011) and Phillips et al. (2014) can be used to detect explosive patterns either in the price series $p_{t}$ or in the price-rent ratio $p_{t}-d_{t} .{ }^{10}$ Here we focus on the real price series, given the short sample of rents available. The test is a right-tailed test of a unit root against the alternative of an explosive process. ${ }^{11}$

The results of the right-tailed tests are striking: while the full-sample ADF test fails to find explosive patterns, both the sup-ADF and the generalized sup-ADF tests find statistically significant evidence in

\footnotetext{
${ }^{8}$ Both series are at the annual frequency. Nominal house prices are from Nationwide. Rents are obtained from the Office of National Statistics, code D7CE (actual rents for housing). Inflation is obtained from the Office of National Statistics, code CDKO.

${ }^{9}$ Both series are at the quarterly frequency. Nominal house prices and rents are from the Urban Redevelopment Authority. Inflation is obtained from the national accounts (http://www.singstat.gov.sg/statistics/browse_by_ theme/prices.html).

${ }^{10}$ Phillips et al. (2011) focus on the price series, while Phillips et al. (2014) focus on the price-rent ratio. Pavlidis et al. (2013) perform their analysis on both.

${ }^{11}$ Note that the alternative model does not allow for a time trend, for the reasons discussed above and in Phillips et al. (2014a).
} 
favor of rational bubbles both in the U.K. and in Singapore. Overall, the time-series evidence (both using cointegration restrictions and ADF tests) strongly supports the presence of a classic rational bubble in these markets. These time-series tests can also be used to identify the beginning and end dates of the bubbles they detect. Figure I plots the time series of real house prices for the U.K. and Singapore, and shades periods in which a bubble was detected at the $10 \%$ level (using the rolling SADF test as described in Phillips et al. (2014)). The bubble-dating procedure clearly identifies strong run-ups in prices as bubbles. In particular, for the U.K. it identifies two bubbly episodes: 1972-1973 and 2002-2004. ${ }^{12}$ For Singapore, it identifies three bubbly subperiods: 1980-1981, 1993-1996, and 2007.

\section{A.3 Leaseholds and Freeholds: Institutional Details}

In this section, we discuss the legal environment regulating the relationship between landlords (freeholders) and tenants (leaseholders) in England and Wales. In this discussion, we draw heavily on the textbook treatments of these issues in Garner and Frith (2013), Burn et al. (2011), and Abbey and Richards (2013).

In most cases, the rights and obligations of a landlord and a leaseholder are fixed by express covenants that are incorporated in the lease. In addition, there are covenants which, although not directly addressed in the leasehold, are part of the contractual agreement by English common law. These are intended to provide a minimum level of protection for both parties. We first focus on the content of these implied obligations, before discussing the express obligations commonly included in leasehold contracts.

\section{A.3.1 Implied Obligations}

Covenants implied by common law are intended to provide a minimum level of protection for freeholders (landlords) and leaseholders (tenants), even in the absence of an express agreement in the lease. For the freeholder, implied covenants include the following:

1. Quiet enjoyment - This obligation prohibits the landlord, or any party acting for the landlord, to substantially disturb the enjoyment of the property by the leaseholder for the duration of the lease. In other words, the tenant has the full benefit of the rights of possession for the duration of the lease.

2. Non-derogation from grant - The essence of this obligation, which is closely related to the obligation guaranteeing quiet enjoyment, is the principle that "a grantor, having given a thing with one hand is not to take away the means of enjoying it with the other" (Birmingham, Dudley and District Banking Co. $v$ Ross (1888) 38 C D at 313). This prevents the landlord, for example, from erecting a fence that would prevent the tenant from entering the property under contract.

3. Fitness of Habitation - In general, there is no requirement for the landlord to ensure that the premises are, or will be, fit for habitation, and no covenant is implied that would require him to

\footnotetext{
${ }^{12}$ Note that the bubble does not appear statistically significant in 2003, but is significant in both 2002 and 2004.
} 
carry out repairs. This is based on the principle of caveat lessee or "lessee beware," taken to imply that in the absence of any agreement between the parties, neither side generally is responsible for repairs. We deal with express agreements on repairs below. Some exceptions to this general rule, however, apply to "houses let on low rent." Section 8(1) of the Landlord and Tenant Act 1985 provides that for houses let at low rent (i.e., below $£ 56$ outside London, and below $£ 80$ in London), the landlord is required to:

- Ensure that the house is of a condition fit for human habitation at the commencement of the tenancy;

- Ensure that during the course of the tenancy the house will be kept reasonably fit for human habitation.

These minimal requirements hold only for qualifying properties and, even then, only if the lease does not stipulate that it is upon the tenant to put the house in a condition reasonably fit for human habitation. As we discuss below, most leaseholds address the assignment for maintenance responsibilities explicitly.

For a leaseholder, the following covenants are implied by Common Law:

1. To Pay (Ground) Rent - In practice, the ground rent is always an explicit part of the contract. We described in Section 5.3.3 that the so-called "ground rents" for houses on extremely-long leaseholds are very small to negligible in magnitude (of the order of $£ 20$ per year).

2. To Pay Taxes - The leaseholder is required to pay all taxes such as council taxes.

3. To Allow the Landlord Entry for Required Repairs - In general, leasehold contracts grant the leaseholder the exclusive possession of the property, including the right to exclude the freeholder. If the freeholder enters without permission, she is trespassing. However, if the landlord is required by the lease to carry out repairs, she is thereby granted the right to enter to carry out such repairs. The landlord is not entitled to carry out improvements or alterations, only repairs.

4. Not to Deny Landlord's Title - The tenant is prevented from denying that the landlord has an interest in the land, for example by suggesting that the land is vested in a third party other than the landlord, as this would be paramount to denying the tenancy altogether; in that case, the landlord is entitled to repossess the property.

5. To Use the Property in a "Tenant-Like Manner" - This covenant is not too precisely defined, but is taken to mean that a leaseholder must perform everyday tasks around the house. Denning LJ provided some guidance on this in Warren $v$ Keen [1954] 1 QB 15 at 20.

"The tenant must take proper care of the place. He must, if he is going away for the winter, turn off the water and empty the boiler. He must clean the chimneys, where necessary, and also the windows. He must mend the electric light when it fuses. He 
must unstop the sink when it is blocked by his waste. In short, he must do the little jobs about the place which a reasonable tenant would do. In addition, he must, of course, not damage the house, willfully or negligently; and he must see his family and guests do not damage it: and if they do, he must repair it."

However, as described above, unless otherwise specified in a covenant,

"[i]f the house falls into disrepair through fair wear and tear or lapse of time, or for any reason not caused by him, the tenant is not liable to repair it."

As we discuss below, while implied covenants generally do not govern the responsibility for maintenance, it almost always is specified in express covenants of extremely-long leaseholds that it is the responsibility of the lessee to maintain a property.

None of the restrictions implied by Common Law are likely to significantly restrict the valuation of a leasehold property. The law also regulates the process of reversion of the property and land at leasehold expiry to the freeholder. The general principle is that the lease, much like a tenancy, has finite maturity and that at expiry the full enjoyment of the property and land returns to the freeholder. This covers the vast majority of cases; in a minority of cases, the leaseholder is afforded extra protection. The Local Government and Housing Act 1989 provides "security of tenure" to qualifying leaseholders who might otherwise be too adversely affected by the leasehold expiry. The security of tenure provision stipulates that for qualified leaseholders, and in the absence of a court-approved claim for possession by the freeholder, an assured periodic tenancy commences after lease expiration. This tenancy removes all property rights connected to the leasehold, and obliges the former leaseholder to pay market rent on the property to the landlord going forward. ${ }^{13}$

To qualify for this protection, the leasehold must be on the lessee's primary residence, and the lease must have been originally granted for more than 21 years and at low ground rent. ${ }^{14}$ In addition, certain properties are excluded from this protection: (i) if the landlord is the Crown, a local authority, a housing association, or charitable housing trust; (ii) if a statutory lease extension (for flats) has been obtained and the extended lease is expiring; (iii) if the property is of high value, as defined in the Act. A landlord seeking to take possession of the property at the end of the lease needs to serve a notice (generally between 6 and 12 months before the lease expiration date) and, even in the case of tenants who are afforded the special protection described above, has several grounds to obtain possession by court order. The most common grounds for possession are that: (i) the landlord wishes to carry out works that cannot be performed with a tenant in place, (ii) equivalent alternative accommodation is available for the tenant to rent at market value in the private property market, (iii) the tenant has not respected some parts of the lease agreement (like paying ground rent and service charges, tenant-induced negligent damage of

\footnotetext{
${ }^{13}$ Where an agreement between freeholder and tenant cannot be reached on the appropriate market-level rent, the parties can resort to the Rent Assessment Committee to set the rent.

${ }^{14}$ Low rent is taken to be "no ground rent payable" or specific low amounts of ground rent payable depending on the start date of the leasehold. See the original Act for more details.
} 
the property, disturbance of other occupants of the property), or (iv) the landlord wishes to occupy the premises herself or for the use of her immediate family.

\section{A.3.2 Express Obligations}

While the covenants implied by Common Law provide a basic minimum standard of protection in case the involved parties fail to specify responsibilities in their contract, most leasehold contracts contain express agreements that regulate the obligations and rights of freeholder and leaseholder in greater detail. In the following, we discuss covenants on the tenant that might affect the value of extremelylong leaseholds relative to freeholds. We argue that none of these requirements have a significant effect on the value of extremely-long leaseholds.

1. Use of Property - The general Common Law rule is that, unless otherwise specified, the tenant might use the property for any lawful purpose; some leasehold contracts therefore stipulate certain prohibitions against changing the use of a particular property. They may, for example, prohibit commercial use, use as a religious meeting house, or use as a brothel. Very often, these covenants pass onto the leaseholder a set of local zoning regulations that also apply to the owners of the freehold. In the following, we provide a number of examples of such covenants that we found in actual leases we inspected manually:

[Example 1] The land tinted pink on the filed plan is subject to the following stipulations contained in a Deed dated 10 August 1923 made between (1) [Person A], (2) [Person B] (3) [Person C].

(a) No church chapel synagogue or other place of public worship or instruction manufacturing premises institution nursing home lunatic asylum sanatorium creche school public motor garage licensed premises theatre cinematograph theatre or other place of amusement shop or business premises shall be erected on the premises and no buildings now or at any time to be erected thereon shall at any time be used except as private dwellinghouses only but no objection shall be made to user of the premises at present erected on the land as a private residential hotel.

(b) Any dwellinghouse when erected on the said premises shall be of the value of $£ 900$ at least in prime cost of materials and labour exclusive of any outbuildings stabling or motor garage.

(c) The front wall of any dwellinghouses to be erected on the premises shall range and be set back from Poynders Road within the boundary line to be fixed by the London County Council and in accordance with the provisions of the Housing and Town Planning Scheme of the District.

[Example 2] No manufacture trade business or operations of a noisome dangerous or noisy kind shall be carried on in or upon the land or any building thereon and no 
building thereon shall be used as a hotel, public house, or tavern or for the sale of beer wines and spirits.

[Example 3] Not within 25 years of the date hereof to construct on and/or use the Property for any single purpose-built exhibition space in excess of 2000 square meters in area.

[Example 4] Not to use the parking spaces on the Property save for the purpose of parking one private motor vehicle in each space.

[Example 5] Not to fell, lop, or top any tree situated within the Property without the prior written consent of the Local Planning Authority, nor to remove or destroy any tree or shrub planted on the Property as part of any landscaping scheme and to replace any such tree or shrub which may fail or die.

2. Alterations and Improvements - Leasehold contracts might stipulate that leaseholders have to seek the consent of freeholders before engaging in any substantial changes to the property. ${ }^{15}$ These restrictions are often in place for a limited period of time only. For example, the following covenant is an alteration restriction from an actual leasehold contract we examined:

Not for a period of two years from the date hereof, without the prior written consent of the transferor, which shall not be unreasonably withheld or delayed: (i) to construct or allow to be constructed any additional building structure or extension or lay any sewers or drains on any part of the Property; (ii) to make any alterations to any Buildings or the external appearance of any part of the Property.

Notice that the covenant stipulates that consent to any redevelopment shall not be unreasonably withheld. More generally, Section 19(2) of the Landlord and Tenant Act 1927 maintains that no freeholders are allowed to "unreasonably withhold consent" to any redevelopment proposal:

In all leases whether made before or after the commencement of this Act containing a covenant condition or agreement against the making of improvements without a licence or consent, such covenant condition or agreement shall be deemed, notwithstanding any express provision to the contrary, to be subject to a proviso that such licence or consent is not to be unreasonably withheld; but this proviso does not preclude the right to require as a condition of such licence or consent the payment of a reasonable sum in respect of any damage to or diminution in the value of the premises or any neighbouring premises belonging to the landlord, and of any legal or other expenses properly incurred in connection with such licence or consent nor, in the case of an

\footnotetext{
${ }^{15}$ An absolute ban of alterations or additions is uncommon, as highlighted by Burn et al. (2011), and considered unacceptable in long leases, as described in Abbey and Richards (2013).
} 
improvement which does not add to the letting value of the holding, does it preclude the right to require as a condition of such licence or consent, where such a requirement would be reasonable, an undertaking on the part of the tenant to reinstate the premises in the condition in which they were before the improvement was executed.

Whether a particular alteration is an improvement is generally determined on a case-by-case basis, but is to be considered from the perspective of the tenant. If, for example, a tenant rents two adjacent shops and wishes to remove a dividing wall to create a larger shop, this would be considered an improvement, even if the letting value from the landlord's point of view would be larger with two separate shops (see Woolworth \& Co v Lambert [1937] Ch 37).

While the statute does not stop the freeholder from seeking a reasonable sum should the proposed changes diminish the value of the premises, or any adjacent premises of the freeholder, the requirements do not present major obstacles to value-enhancing redevelopment of properties.

In order to reasonably withhold consent, or to receive reimbursement, the freeholder has to show that her claim loses in value as a result of the redevelopment. While this might be relevant in the case of relatively short leases with 10-15 years of remaining maturity, for leaseholds with hundreds of years of remaining maturity the present value of any future loss in value of a freeholder's claim is small to non-existent. This makes withholding consent on improvements in extremely-long leases very hard for freeholders. In addition, if the only loss to the freeholder is pecuniary, she cannot withhold consent reasonably, but is required to grant consent in exchange for reasonable compensation by the leaseholder, based on any demonstrated damage to the value of the premise.

When a leaseholder believes that a freeholder has unreasonably withheld consent to an alteration or improvement, Section 53(1)(b) of the Landlord and Tenant Act 1954 regulates that the tenant can obtain a declaration from a county court to allow her to carry out the redevelopment in spite of the absence of consent.

On balance, therefore, there are a number of significant protections for leaseholders against being prevented from conducting alterations and improvements to the property. However, whether those are sufficiently powerful to ensure that there are no price discounts for leasehold properties relative to freehold properties is an empirical question. To address that question, in Section 5.3.2 of the paper we exploit cross-sectional differences in the value of redevelopment options, and find the relative pricing of extremely-long leaseholds and freeholds to be identical, even in areas with very high redevelopment potential. This confirms the very small quantitative effect that any restrictions on redevelopment have on the value of extremely-long leaseholds.

3. Sublet of Property - The basic implied principle is that, unless there is specific agreement to the contrary, a tenant is free to grant his interest to a third party, either by assignment or by underlease. Therefore, some leases explicitly formalize the scope of the leaseholder's right to sublet the property, i.e., to rent it out to somebody else. For example, covenants could be inserted requiring leaseholders to obtain the freeholder's permission to sublet the property. As for many 
other covenants, any requirements imposed on the leaseholder are severely limited by the general principle that the freeholder cannot "unreasonably withhold" consent to a sublet. Section 19(1) of the Landlord and Tenant Act 1927 stipulates as follows:

In all leases whether made before or after the commencement of this Act containing a covenant condition or agreement against assigning, under-letting, charging or parting with possession of demised premises or any part thereof without licence or consent, such covenant condition or agreement shall, notwithstanding any express provision to the contrary, be deemed to be subject

(a) to a proviso to the effect that such licence or consent is not to be unreasonably withheld, but this proviso does not preclude the right of the landlord to require payment of a reasonable sum in respect of any legal or other expenses incurred in connection with such licence or consent; and

(b) (if the lease is for more than forty years, and is made in consideration wholly or partially of the erection, or the substantial improvement, addition or alteration of buildings, and the lessor is not a Government department or local or public authority, or a statutory or public utility company) to a proviso to the effect that in the case of any assignment, under-letting, charging or parting with the possession (whether by the holders of the lease or any under-tenant whether immediate or not) effected more than seven years before the end of the term no consent or licence shall be required, if notice in writing of the transaction is given to the lessor within six months after the transaction is effected.

In addition, the Landlord and Tenant Act 1988 places the burden of showing that any refusal or the imposition of any conditions was reasonable on the landlord. The law explicitly prohibits to refuse to allow permission for subletting the property on grounds of a person's sex, race, religion, sexual orientation, or disability. The Act also gives tenants the right to sue for damages suffered as a result of a landlord's unreasonable refusal.

Sometimes covenants are inserted that allow the freeholder to charge a nominal fee for registering a sublet in order to recover any administrative costs. A number of judicial cases have regulated the maximum fee that freeholders can charge for the granting of approval for a sublet. In Holding and Management (Solitaire) Limited vs. Cherry Lilian Norton (LRX/33/2011), the court decided that a fee in excess of $£ 40+$ VAT was not merited.

Again, as with the restrictions on redevelopment, the requirement to not unreasonably withhold consent to the sublet provides significant protections to the leaseholder's ability to rent out the property. Indeed, if this were not the case, we would expect significant price differences between extremely-long leaseholds and freeholds particularly for flats, which have a much more active rental market than houses. In Section 5.3.2 we show that there is no price difference between 
extremely-long leaseholds and freeholds for flats, suggesting that restrictions on subletting do not have a significant effect on the valuation of extremely-long leaseholds.

4. Property Maintenance \& Service Charges - As described in the main body of the paper, there are two common structures for assigning maintenance responsibilities in long-term leases. The simplest one assigns both the responsibility and the financial burden of maintaining the property to the leaseholder. This structure is more common for standalone houses, where there are few common areas to be maintained, and the leaseholder is generally in charge of all aspects of property maintenance. The second structure assigns the responsibility for some activities, such as carrying out repair work, to the freeholder, but then allows the freeholder to recoup the costs from the leaseholder via a service charge. Service charges are payments by the leaseholder for services provided by the landlord. In addition to the cost of maintenance and repairs, these can include charges for the insurance of the building and, in some cases, provision of central heating, lifts, porterage, estate staff, lighting, and the cleaning of common areas. This arrangement is more common in flats or multiple housing units, since the presence of common areas and shared exteriors of the building naturally give rise to the need of centralized management.

The Landlord and Tenant Act 1985, s18-30, regulates many of the aspects related to service charges; we provide a brief summary only. Service charges can either be collected as costs arise, or, more commonly, are collected through periodic payments. Any accumulated funds paid by leaseholders are held in a "sinking fund." There is an obligation on the side of the landlord (Landlord and Tenant Act 1987, s42) to keep the funds in trust, and the contributions of the tenants are treated as shares of both the costs of any services, and proportional claims to any unspent funds. Since the sinking funds can at times contain substantial sums (for example, just before the beginning of major works), the Landlord and Tenant Act 1987, s42, places strict burdens on the landlord, who has to communicate to tenants a designated bank account at a qualifying financial institution and present timely balances and expense reports. The landlord is criminally liable for failing to comply with these duties.

More generally, the Landlord and Tenant Act 1985 places several restrictions on the freeholder to prevent abuse of the leaseholder:

- Relevant Costs: The Act provides a definition of which costs sustained by the landlord can be recovered via the service charge. The general principle is that if the lease does not expressly oblige or allow the landlord to undertake an activity, then its cost cannot be included in the service charge.

- Reasonable Costs: The Act stipulates that costs can be charged only "to the extent that they are reasonably incurred and only if the services or works provided are of reasonable standard." This protects the tenant against landlords that increase costs, through negligence or intent, by overcharging or performing works at a level considered unreasonable (more on this below). 
- Timely Disclosure: The Act requires the timely disclosure by the landlord of expenses payable under the service charge:

If any of the relevant costs taken into account in determining the amount of any service charge were incurred more than 18 months before a demand for payment of the service charge is served on the tenant, then (subject to subsection (2)), the tenant shall not be liable to pay so much of the service charge as reflects the costs so incurred.

- Consultation: When the landlord is proposing expensive works or entering in a long-term agreement with third parties about maintenance of the property, she is required to consult with the tenants. The landlord is required to send an initial notice to each tenant highlighting the planned works and the reasons why the works are necessary, and inviting each tenant to respond to the notice within 30 days. After 30 days the landlord has to obtain professional estimates (at least one of which has to be from a party unconnected to the landlord) of the costs of the works, and supplies the estimates to the tenants. After a further 30 days, and having considered any tenant responses, the landlord can enter into an agreement to perform the works. If consultation and information requirements are not respected, a tenant may lawfully withhold a service charge payment.

In the event of a dispute between landlord and tenant, the Commonhold and Leasehold Reform Act 2002 stipulates that an application may be made to a Leasehold Valuation Tribunal (now the First-tier Tribunal, Property Chamber) to challenge the reasonableness of a service charge. The Act also provides a right for leaseholders of flats to force the transfer of the landlord's management functions to a special company set up by them - a "right to manage" (RTM) company. This does not require the landlord's consent and the leaseholders do not have to show that the current management is at fault, which they would have to do if they recurred to the tribunal to contest an unreasonable service charge. Having obtained the right to manage the building, the leaseholders are responsible for all functions previously assigned to the freeholder under the lease; they can of course delegate such functions to a managing company of their choosing.

5. Covenants to Insure - Similar to maintenance works, in some cases the lease requires that the leaseholder insures the property, usually a house, through an insurer nominated or approved by the landlord. For flats, it is more common for the freeholder to arrange the building insurance and then recover the cost via the service charge. The tenant may consider that she can get cheaper insurance from different companies and may be concerned as to the cover provided. The provisions of the Commonhold and Leasehold Reform Act 2002, in addition to determining a disclosure, information, and reasonableness requirement for landlord-provided or designated insurance, also provide in Section 164 the right for the leaseholder to arrange her own insurance, provided she notifies the landlord. 


\section{A.3.3 Lease Term and "No Uncertain Term" Doctrine}

Both in the U.K. and in Singapore, leaseholds are finite maturity contracts; at the expiration of the lease, the land and structure revert to the underlying freeholder. This finite maturity is the essence of the contract, and the reason different contracts exist in the first place. The law is strict and explicit in stipulating that the term, as in the finite maturity of the lease, must be both explicit and certain. This was highlighted by Lord Templeman in the U.K. House of Lords decision on Prudential Assurance Co Ltd v London Residuary Body [1991] UKHL 10:

"My Lords, I consider that the principle in Lace v Chantler [1944] K.B. 368, reaffirming 500 years of judicial acceptance of the requirement that a term must be certain, applies to all leases and tenancy agreements."

The law prohibits uncertain lease terms such as "until such event occurs," or the possibility of openended leases where no specific maturity date is set. This principle invalidates, for example, some leases written during World War II that specified duration as "for the duration of the War." Such terms were deemed uncertain and, therefore, the leases were declared invalid. Leases that stipulate the maximum duration of the lease to be "for T's life" or "until T marries," would be similarly invalid, as these terms are uncertain. More leniency is afforded to setting the start date of a lease, since a lease where a specific start date is not set is assumed to have started immediately. Along these lines, Blackstone, in his Commentaries, 1st ed. (1766), Book II, remarks that:

"Every estate which must expire at a period certain and prefixed, by whatever words created, is an estate for years. And therefore this estate is frequently called a term, 'terminus', because its duration or continuance is bounded, limited and determined: for every such estate must have a certain beginning, and certain end."

This principle is reaffirmed again in The Law of Property Act 1925, which states that:

"The only estates in land which are capable of subsisting or of being conveyed or created at law are - An estate in fee simple absolute in possession; A term of years absolute."

Here the phrase "an estate in fee simple absolute in possession" is what we refer to as a freehold and the phrase "a term of years absolute" is what we call a leasehold of finite maturity.

Say $v$ Smith (1530) 1 Plowden 269 establishes the principle that if a "lease for a certain term purported to add a term which was uncertain; the lease was held valid only as to the certain term." This rules out that a lease contract may give rise to any right of uncertain, including infinite, maturity; those rights of infinite maturity would be considered invalid, and the overall lease only valid in as long as it grants other rights with clear finite maturity. In this landmark decision, Judge Anthony Brown J. remarks:

"Every contract sufficient to make a lease for years ought to have certainty in three limitations, viz. in the commencement of the term, in the continuance of it, and in the end of it; 
so that all these ought to be known at the commencement of the lease, and words in a lease, which don't make this appear, are but babble. And these three are in effect but one matter, showing the certainty of the time for which the lessee shall have the land, and if any of these fail, it is not a good lease, for then there wants certainty.[...] Every lease for years ought to have a term certain and or determination."

We conclude this section by reiterating that the law very explicitly makes leases finite maturity contracts on penalty of being invalid, and that any addendum to a lease that purports to grant potentially infinite maturity is considered invalid. On the contrary, freeholds are infinite maturity contracts. ${ }^{16}$

\section{A.4 Further Theoretical Details}

We next provide further details on the results of Section 3.2.

Discounts in a Modern Asset Pricing Model. In the set-up of Section 1, recall that:

$$
P_{t}=\sum_{s=1}^{\infty} E_{t}\left[\xi_{t, t+s} D_{t+s}\right]+B_{t}, \quad B_{t} \equiv \lim _{T \rightarrow \infty} E_{t}\left[\xi_{t, t+T} P_{t+T}\right]
$$

where $\xi_{t, t+s} \equiv \prod_{j=0}^{s-1} \xi_{t+j, t+j+1}$ and $B_{t}=E_{t}\left[\xi_{t, t+1} B_{t+1}\right]$. Also recall that for a finite maturity asset, like the T-maturity leasehold we have:

$$
P_{t}^{T}=\sum_{s=1}^{T} E_{t}\left[\xi_{t, t+s} D_{t+s}\right]
$$

Subtracting A.5 from A.4 we obtain:

$$
\begin{aligned}
P_{t}-P_{t}^{T} & =\sum_{s=1}^{\infty} E_{t}\left[\xi_{t, t+T+s} D_{t+T+s}\right]+B_{t} \\
& =\sum_{s=1}^{\infty} E_{t}\left[\xi_{t, t+T+s} D_{t+T+s}\right]+E_{t}\left[\xi_{t, t+T} B_{t+T}\right] \\
& =E_{t}\left[\xi_{t, t+T}\left[\sum_{s=1}^{\infty} \xi_{t+T, t+T+s} D_{t+T+s}+B_{t+T}\right]\right] \\
& =E_{t}\left[\xi_{t, t+T} E_{t+T}\left[\sum_{s=1}^{\infty} \xi_{t+T, t+T+s} D_{t+T+s}+B_{t+T}\right]\right] \\
& =E_{t}\left[\xi_{t, t+T} P_{t+T}\right]
\end{aligned}
$$

Equality (A.7) makes use of the recursive nature of the bubble: $B_{t}=E_{t}\left[\xi_{t, t+1} B_{t+1}\right]$. Equality (A.8) makes use of the recursive definition of the SDF: $\xi_{t, t+s} \equiv \prod_{j=0}^{s-1} \xi_{t+j, t+j+1}$. Equality (A.9) makes use of the law of iterated expectations. Equality (A.10) makes use of the price of the freehold as in Equation (A.4) moved

\footnotetext{
${ }^{16}$ This does not mean that there are no one-off trades of expired leaseholds as rare collectible items, but such a market is, if existent at all, extremely small, and does not fulfill the common beliefs requirement in Tirole (1985).
} 
forward $T$ periods. Then by using Equation (A.10), we have:

$$
\lim _{T \rightarrow \infty}\left(P_{t}-P_{t}^{T}\right)=\lim _{T \rightarrow \infty} E_{t}\left[\xi_{t, t+T} P_{t+T}\right]=B_{t}
$$

where the last equality follows from the definition of the bubble in Equation (A.4). Equation (A.11) is the basis of the empirical test strategy described in Section 3.2.

Discounts in a Gordon Growth Model Following the classic valuation model of Gordon (1982), we assume that cash flows arising in each future period are discounted at a constant rate $r$, so that the $T$-period discount factor is $e^{r T}$. Rents grow at a constant rate $g$, so that they evolve according to $D_{t+s}=D_{t} e^{g s}$. We consider a deterministic environment only in the interest of simplicity. The price of the $T$-maturity leasehold, a claim to the rents for $T$ periods, is:

$$
P_{t}^{T}=\int_{t}^{t+T} e^{-r(s-t)} D_{t} e^{g(s-t)} d s=\frac{D_{t}}{r-g}\left(1-e^{-(r-g) T}\right) .
$$

The price of the freehold, the infinite maturity claim, is: $P_{t}=\lim _{T \rightarrow \infty} P_{t}^{T}=\frac{D_{t}}{r-g}$, with $r>g$. Notice that we are deriving the fundamental value and hence imposed the no-bubble transversality condition $\left(B_{t}=0\right)$ in taking the limit. The price discount for a $T$-maturity leasehold with respect to the freehold is:

$$
\operatorname{Disc}_{t}^{T} \equiv \frac{P_{t}^{T}}{P_{t}}-1=-e^{-(r-g) T}
$$

Section 3.2 uses Equation (A.12) above to verify that, under the assumption of no bubbles, maturities $(T)$ in excess of 700 years approximate the infinite limit of the theory well for conventional, and even conservative, choices of net discount rates $(r-g)$.

\section{Appendix References}

Abbey, R. and Richards, M. (2013), Property Law Handbook 2013-2014, Oxford University Press.

Burn, E. H., Cartwright, J. and Cheshire, G. C. (2011), Cheshire and Burn's Modern Law of Real Property, Oxford University Press.

Campbell, J. Y. and Shiller, R. (1987), 'Cointegration and tests of present value models.', Journal of Political Economy 95, 1062-1088.

Craine, R. (1993), 'Rational bubbles: A test.', Journal of Economic Dynamics and Control 17, 829-846.

David, G. G. and Bentley, D. (2014), 'Finding shelter: Overseas investment in the UK housing market', Civitas: Institute for the Study of Civil Society .

Diba, B. T. and Grossman, H. I. (1988a), 'Explosive rational bubbles in stock prices?', American Economic Review 78(3), 520-530.

Diba, B. T. and Grossman, H. I. (1988b), 'The theory of rational bubbles in stock prices', Economic Journal 98(392), 746-754. 
Evans, G. W. (1991), 'Pitfalls in testing for explosive bubbles in asset prices', American Economic Review 81(4), 922-930.

Farhi, E. and Tirole, J. (2012), 'Bubbly liquidity', Review of Economic Studies 79(2), 678-706.

Garner, S. and Frith, A. (2013), A practical approach to landlord and tenant, Oxford University Press.

Gordon, M. J. (1982), The Investment, Financing, and Valuation of the Corporation, Greenwood Press.

Gurkaynak, R. (2008), 'Econometric tests of asset price bubbles: taking stock', Journal of Economic Survey 22(1), 166-176.

Knight Frank (2013), 'International buyers in London'.

Pavlidis, E., Yusupova, A., Paya, I., Peel, D., Martinez-Garcia, E., Mack, A. and Grossman, V. (2013), Monitoring housing markets for episodes of exuberance: an application of the Phillips et al. (2012, 2013) GSADF test on the Dallas Fed International House Price Database, Technical Report 165, Federal Reserve Bank of Dallas Globalization and Monetary Policy Institute Working Paper.

Phillips, P. C. B., Shi, S.-P. and Yu, J. (2014a), 'Specification sensitivity in right-tailed unit root testing for explosive behaviour', Oxford Bulletin of Economic and Statistics 76(3), 315-333.

Phillips, P. C. B., Shi, S.-P. and Yu, J. (2014b), 'Testing for multiple bubbles: Historical episodes of exuberance and collapse in the S\&P 500', Working Paper.

Phillips, P. C. B., Wu, Y. and Yu, J. (2011), 'Explosive behavior in the 1990s Nasdaq: When did exuberance escalate asset values?', International Economic Review 52, 201-226.

Phillips, P. C. B. and Yu, J. (2011), 'Dating the timeline of financial bubbles during the subprime crisis', Quantitative Economics 2, 455-491.

Savills (2012), 'The world in London'.

Strutt \& Parker's (2012), 'London buyer profile: Nationality'.

Timmermann, A. (1995), 'Cointegration tests of present value models with a time-varying discount factor.', Journal of Applied Econometrics 10, 17-31.

Tirole, J. (1985), 'Asset bubbles and overlapping generations', Econometrica pp. 1499-1528. 


\section{Table A.1: Time-Series Tests of Rational Bubbles}

\begin{tabular}{lcc}
\hline \hline Series & U.K. (prices) & SG (prices) \\
\hline ADF stat & -1.19 & -1.80 \\
$10 \%$ CV & -0.49 & -0.42 \\
$5 \%$ CV & -0.08 & -0.04 \\
$1 \%$ CV & 0.72 & 0.69 \\
SADF stat & $1.11^{*}$ & $2.32^{* * *}$ \\
$10 \%$ CV & 0.92 & 1.00 \\
$5 \%$ CV & 1.21 & 1.29 \\
$1 \%$ CV & 1.85 & 1.89 \\
GSADF stat & $1.67^{*}$ & $3.49^{* * *}$ \\
$10 \%$ CV & 1.59 & 1.77 \\
$5 \%$ CV & 1.92 & 2.06 \\
$1 \%$ CV & 2.62 & 2.62 \\
\hline \hline
\end{tabular}

Note: Table shows results of the right-tailed ADF, SADF and GSADF tests for unit roots against the alternative hypothesis that the series is explosive. The first row of each set reports the statistic, and the remaining rows report the small-sample critical values obtained from simulations. Each column performs the test on a different time series: yearly real log house prices for the U.K. (from Nationwide) and quarterly real log house prices for Singapore (from URA). The sample for the U.K. is 1952-2013; the sample for Singapore is 1975-2013. Significance levels for the test: ${ }^{*}(\mathrm{p}<0.10),{ }^{* *}(\mathrm{p}<0.05),{ }^{* * *}(\mathrm{p}<0.01)$. 
Table A.2: Characteristics of Buyers of Leaseholds and Freeholds: U.K. Houses

\begin{tabular}{|c|c|c|c|c|c|}
\hline & \multicolumn{2}{|c|}{ Sample } & \multicolumn{3}{|c|}{ Leasehold $\Delta$} \\
\hline & $\begin{array}{l}\text { Mean } \\
(1)\end{array}$ & $\begin{array}{l}\text { St. Dev. } \\
\text { (2) }\end{array}$ & $\begin{array}{c}\text { Unconditional } \\
\text { (3) }\end{array}$ & $\begin{array}{c}\text { Conditional I } \\
\text { (4) }\end{array}$ & $\begin{array}{c}\text { Conditional II } \\
\text { (5) }\end{array}$ \\
\hline Age Head of Household (years) & 52.35 & 15.59 & -1.79 & $\begin{array}{l}-0.75 \\
(0.21)\end{array}$ & $\begin{array}{l}-0.51 \\
(0.21)\end{array}$ \\
\hline Weekly Income $(£)$ & 351.2 & 451.3 & -66.22 & $\begin{array}{l}-4.03 \\
(4.31)\end{array}$ & $\begin{array}{c}4.44 \\
(4.13)\end{array}$ \\
\hline Number of People in Household & 2.59 & 1.27 & -0.03 & $\begin{array}{c}-0.04 \\
(0.02)\end{array}$ & $\begin{array}{c}0.01 \\
(0.02)\end{array}$ \\
\hline Number of Dependent Children & 0.58 & 0.96 & -0.01 & $\begin{array}{c}-0.01 \\
(0.01)\end{array}$ & $\begin{array}{c}0.02 \\
(0.01)\end{array}$ \\
\hline Head of Household Married & 0.66 & 0.47 & -0.03 & $\begin{array}{c}-0.01 \\
(0.01)\end{array}$ & $\begin{array}{c}0.01 \\
(0.01)\end{array}$ \\
\hline First Time Buyer & 0.38 & 0.49 & 0.06 & $\begin{array}{l}-0.02 \\
(0.01)\end{array}$ & $\begin{array}{l}-0.02 \\
(0.01)\end{array}$ \\
\hline Currently Has Mortgage & 0.59 & 0.49 & 0.02 & $\begin{array}{c}0.00 \\
(0.01)\end{array}$ & $\begin{array}{c}-0.01 \\
(0.01)\end{array}$ \\
\hline Very Satisfied with Neighborhood & 0.48 & 0.50 & -0.06 & $\begin{array}{c}0.01 \\
(0.01)\end{array}$ & $\begin{array}{l}0.01 \\
0.01\end{array}$ \\
\hline
\end{tabular}

Note: Table shows summary statistics on characteristics of owners of freehold houses and leasehold houses in the Survey of English Housing. The data contain information on 187,335 households in England surveyed between 1993 and 2007. The first two columns provide the sample means and standard deviations of the outcome variables. Column 3 shows the unconditional average difference between leasehold owners and freehold owners (e.g., on average, heads of households owning leasehold properties are 1.8 years younger than heads of households owning freehold properties). Columns 4 and 5 show the $\beta$ coefficient of the following regression: Outcome $_{i}=\alpha+\beta$ Leasehold $_{i}+\xi X_{i}+\phi_{\text {PropertyType } \times \text { Region } \times \text { Year }}+\varepsilon_{i}$. Column 4 does not include any additional controls in $X_{i}$, column 5 includes dummy variables for property age and the number of rooms. Standard errors are clustered at the level of the fixed effects. 


\section{Figure A.1: U.K. Sample - Distribution of 700+ Year Leaseholds}

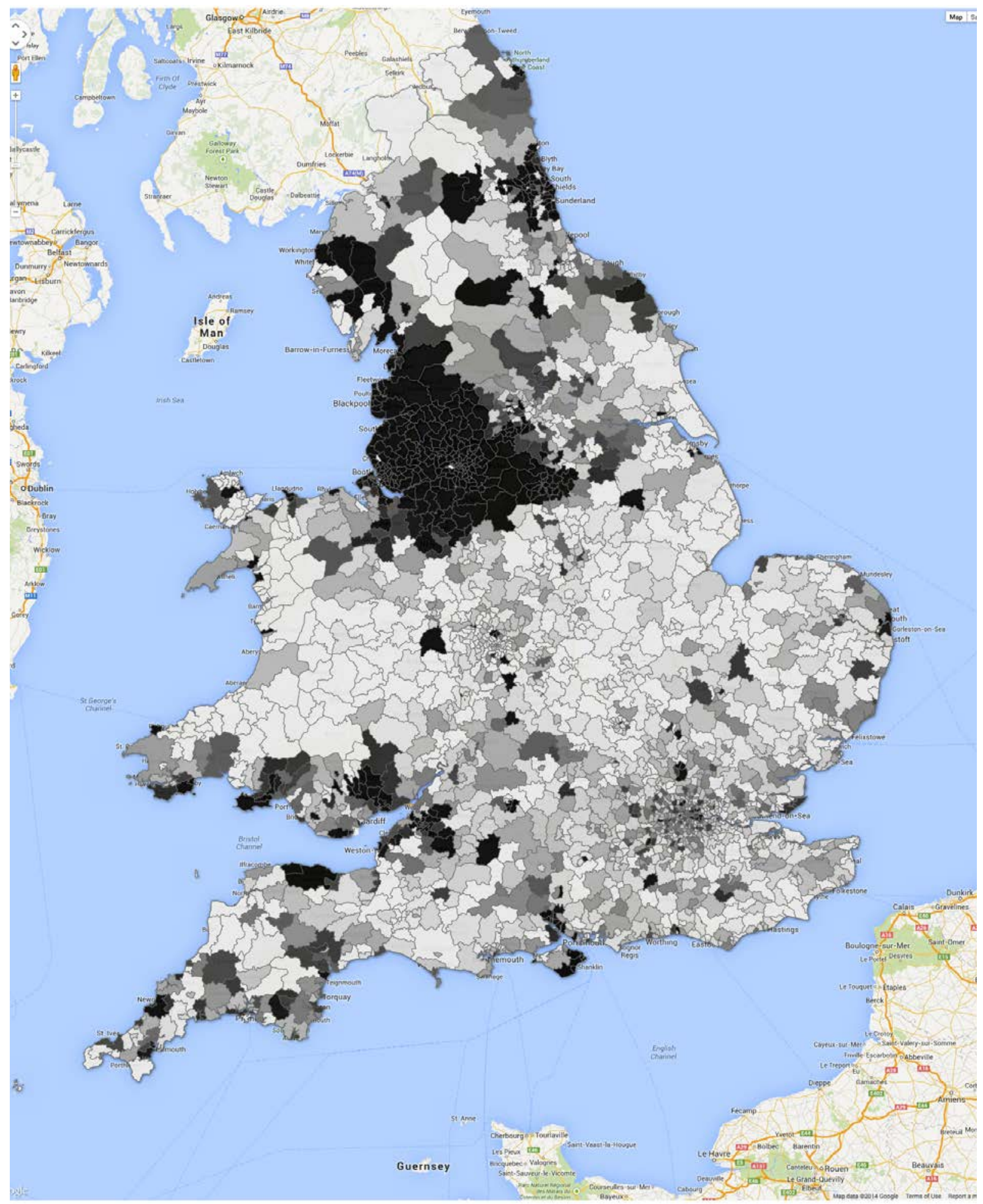

Note: The map shows the fraction of transactions of leaseholds with more than 700 years remaining for each 3-digit U.K. postcode. White indicates that the fraction was $0 \%$. Black indicates that $2 \%$ or more of the transactions were of extremely-long leaseholds, with scales of gray indicating intermediate percentages. 
Figure A.2: U.K. Sample - Distribution of 700+ Year Leaseholds - London

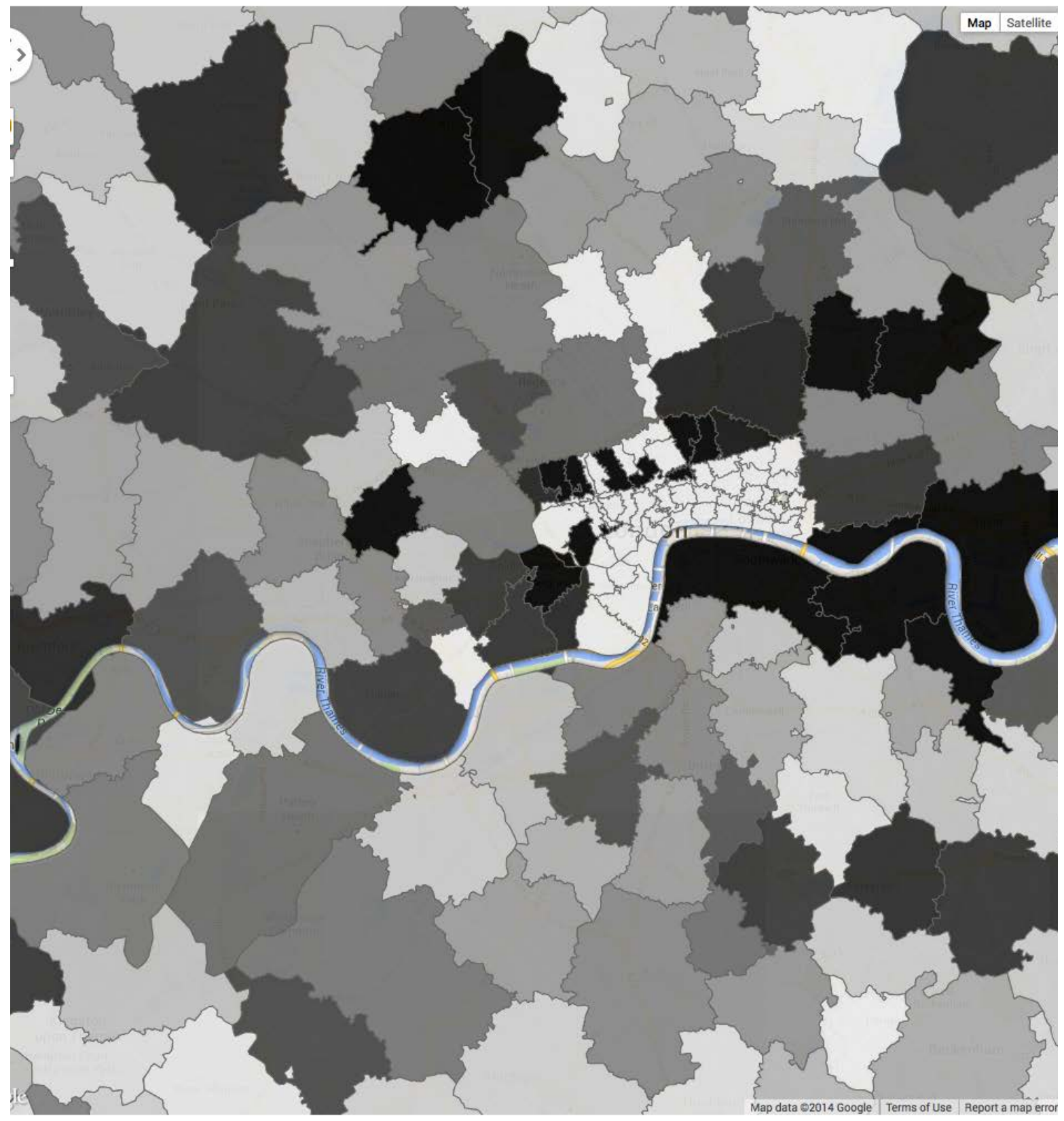

Note: The map shows the fraction of transactions of leaseholds with more than 700 years remaining for each 3-digit U.K. postcode. White indicates that the fraction was $0 \%$. Black indicates that $2 \%$ or more of the transactions were of extremely-long leaseholds, with scales of gray indicating intermediate percentages. The figure zooms in on London. 


\section{Figure A.3: Price Effect of Hedonic Characteristics - U.K.}

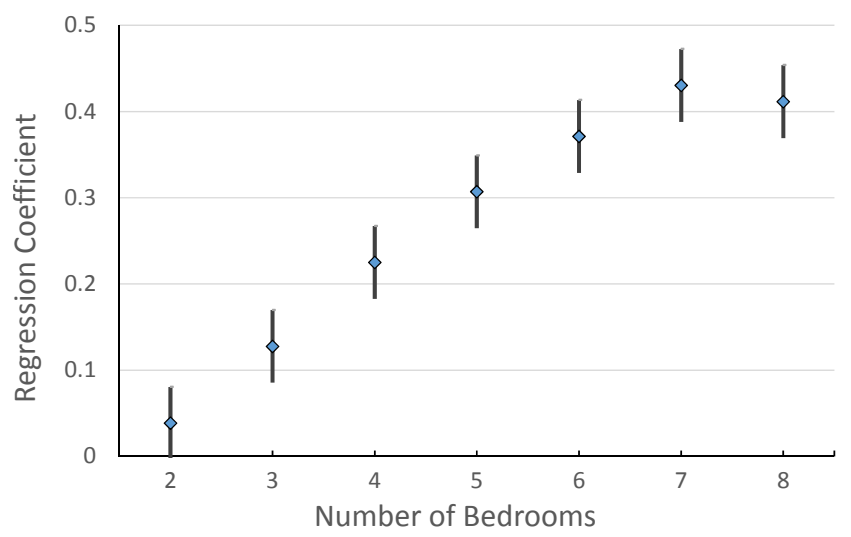

(A) For Sale: Effect of Bedrooms

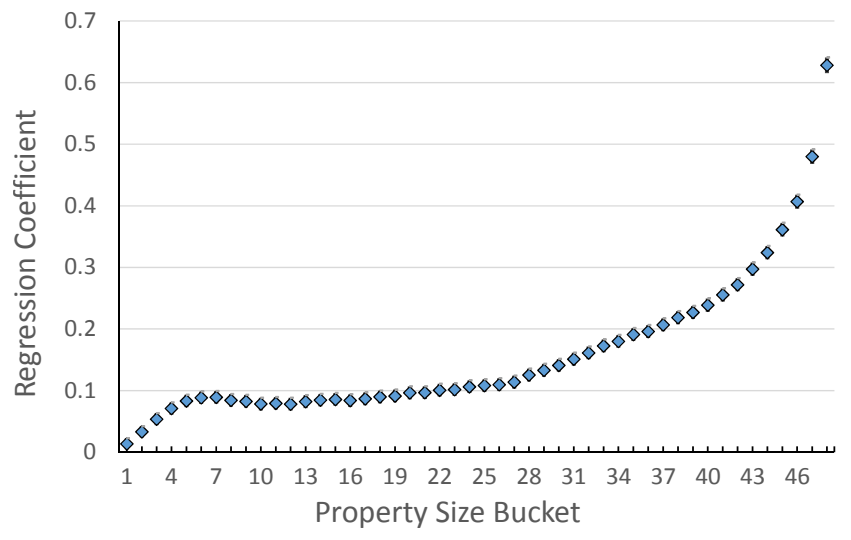

(C) For Sale: Effect of Property Size

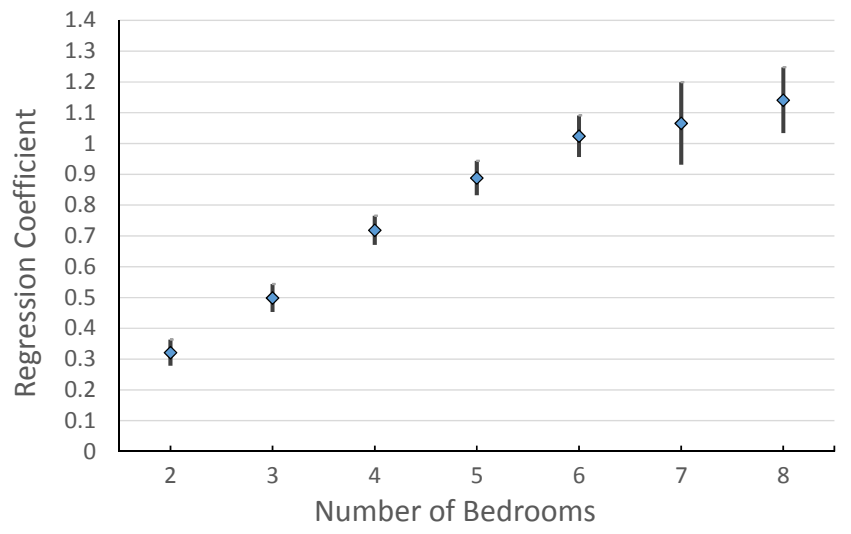

(E) For Rent: Effect of Bedrooms

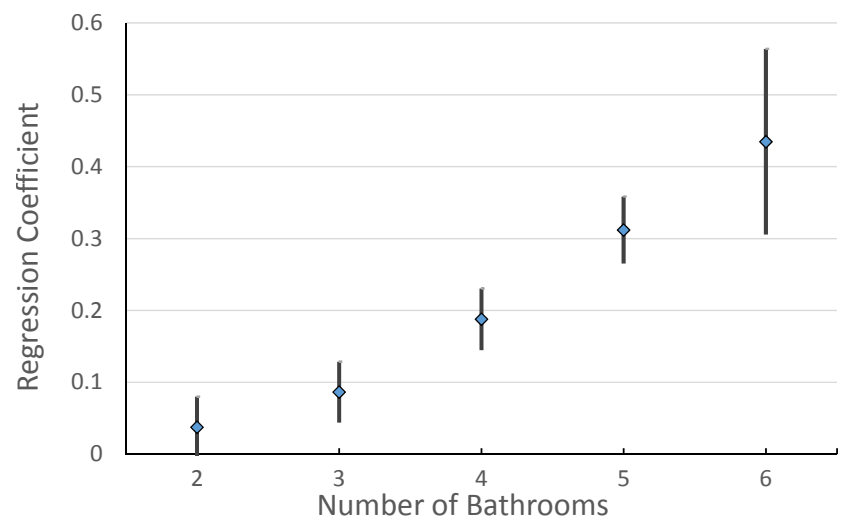

(B) For Sale: Effect of Bathrooms

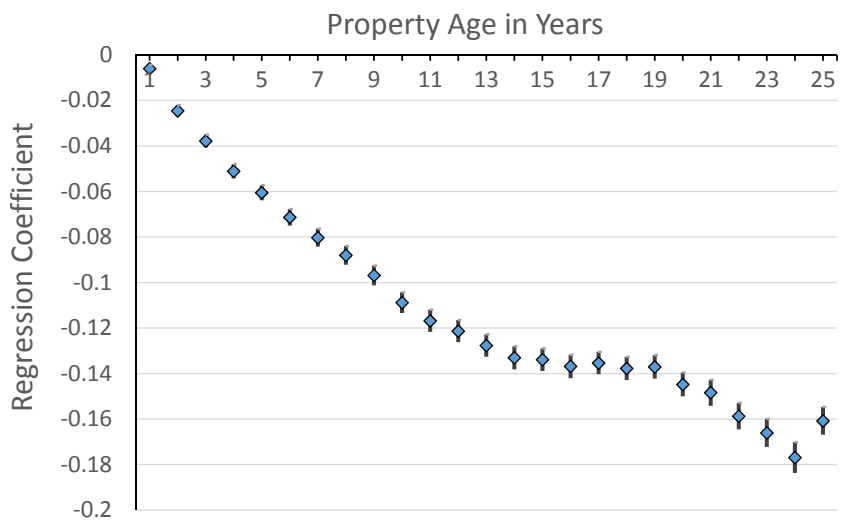

(D) For Sale: Effect of Property Age

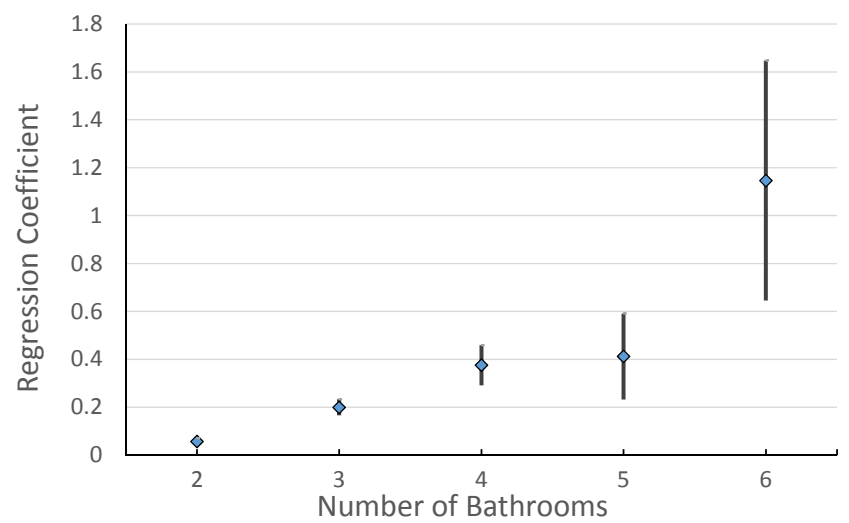

(F) For Rent: Effect of Bathrooms

Note: Figures show coefficients on hedonic controls from regression 3. In Panels A - D, the dependent variable is the log price paid for houses in England and Wales between 1995 and 2013. Panel A shows coefficients on indicators for the number of bedrooms, Panel B on indicators for the number of bathrooms, Panel C on 50 equally-sized property size bucket indicators, and Panel D on indicators for property age. The regression includes other control variables and fixed effects as in column 1 of Table II. In Panels E and F, the dependent variable is the log rental listing price for all houses listed as "for rent" on Rightmove.co.uk and Zoopla.co.uk on March 30, 2015. Panel E shows coefficients on the number of bedrooms, Panel F on the number of bathrooms. We also include other controls variables and fixed effects as in column 3 of Table IV. For every characteristic, the first bucket is omitted from the regression to avoid collinearity. The bars show $95 \%$ confidence intervals for standard errors clustered at the 3-digit postcode level. 


\section{Figure A.4: Singapore - Price Effect of Hedonic Characteristics}

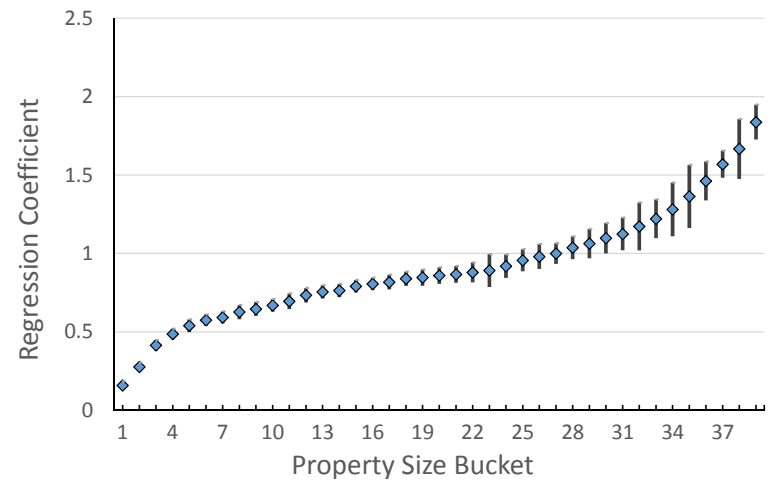

(A) For Sale: Effect of Property Size

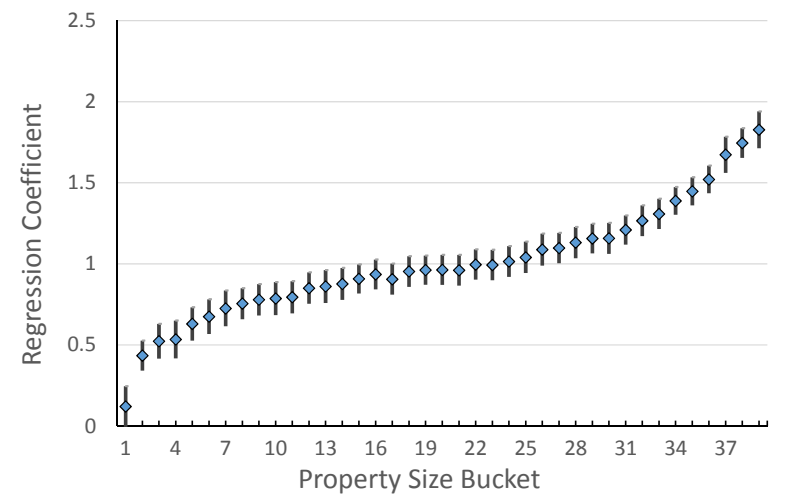

(C) For Rent: Effect of Property Size

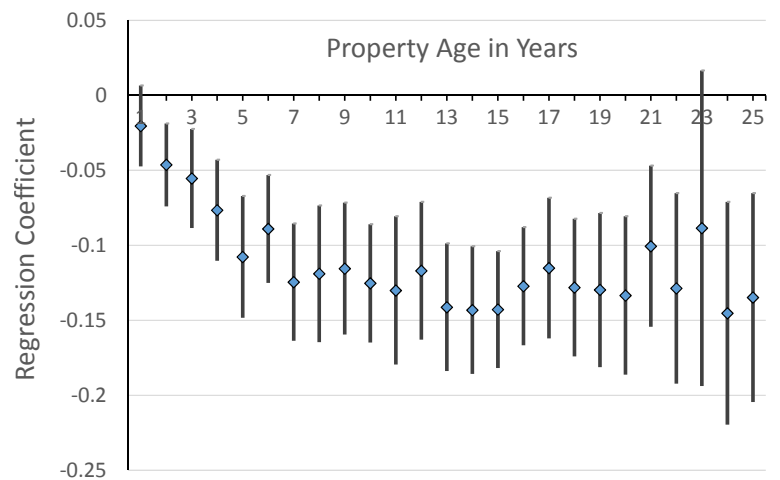

(B) For Sale: Effect of Property Age

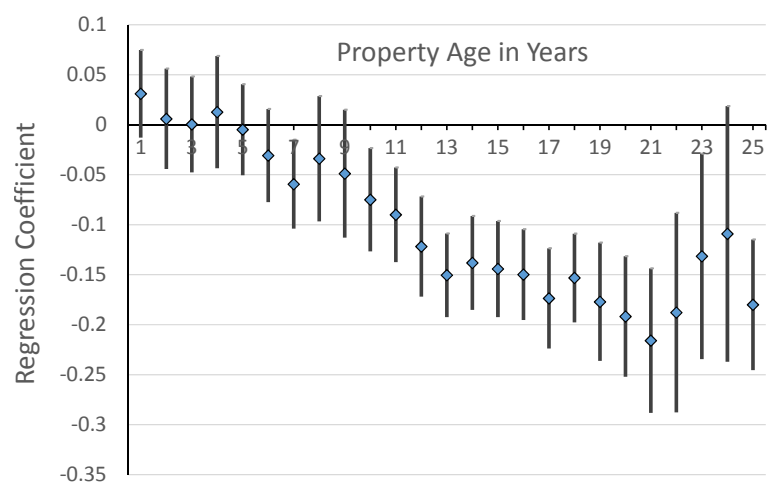

(D) For Rent: Effect of Property Age

Note: Figures show coefficients on hedonic controls from regression 3. In Panels A and B, the dependent variable is the log price paid for properties sold in Singapore between 1995 and 2013. Panel A shows the coefficients on 40 equally-sized property size bucket indicators, Panel B on indicator variables for property age. The regression includes other control variables and fixed effects as in column 5 of Table II. In Panels C and D, the dependent variable is the log rental listing price for all properties listed "for rent" on iProperty.com.sg between 2010 and 2013. Panel C shows the coefficients on 40 equally-sized property size bucket indicators, Panel D on indicator variables for property age. The regression includes other control variables and fixed effects as in column 1 of Table IV. For every characteristic, the first bucket is omitted from the regression to avoid collinearity. The bars show 95\% confidence intervals for standard errors that are clustered at the 5-digit postcode level. 
Figure A.5: Sample Property Listing in the U.K.

\section{3 bedroom apartment for sale}

Crown Lane Gardens, London, SW16

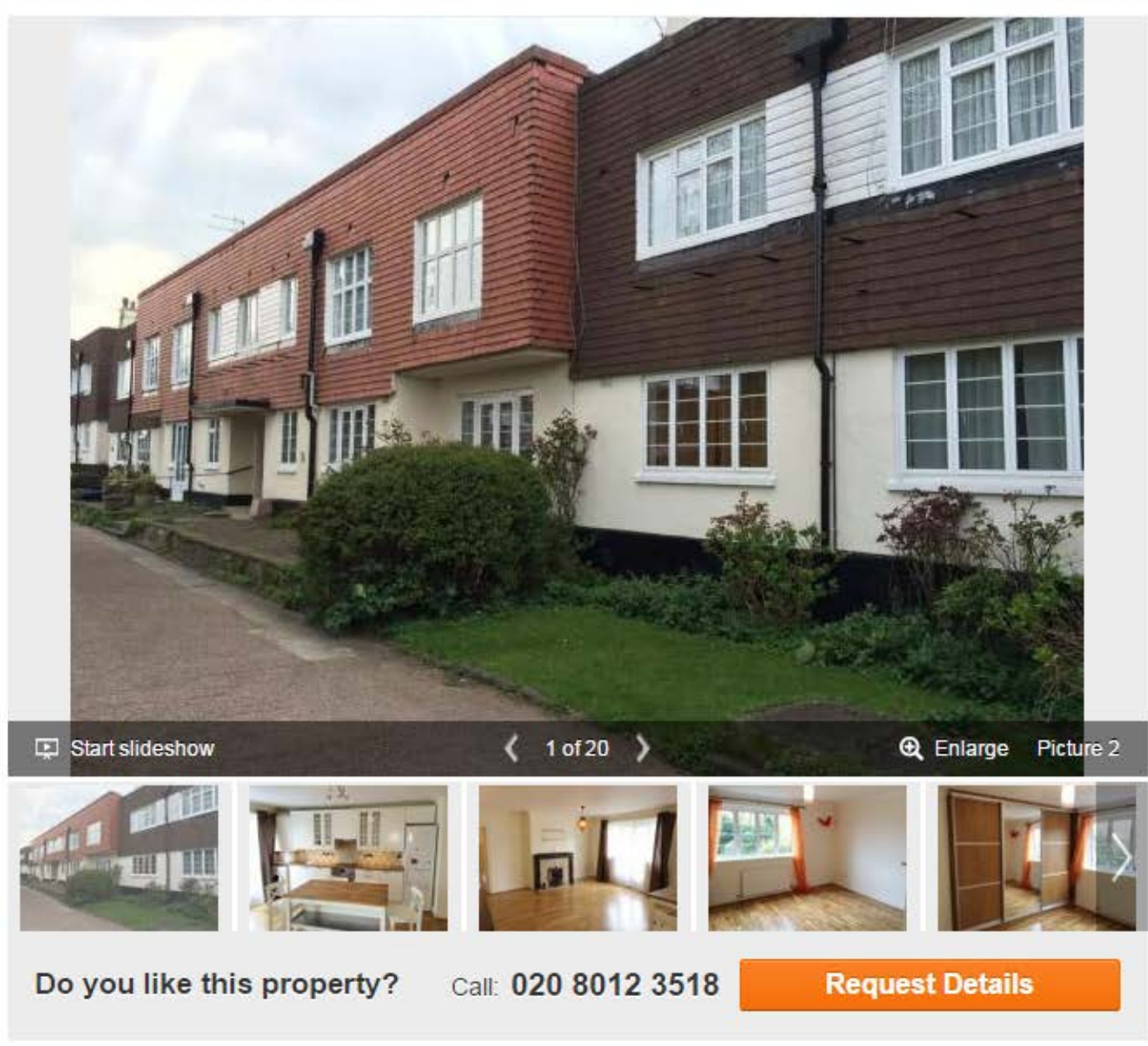

Offers in Excess of

$£ 400,000$

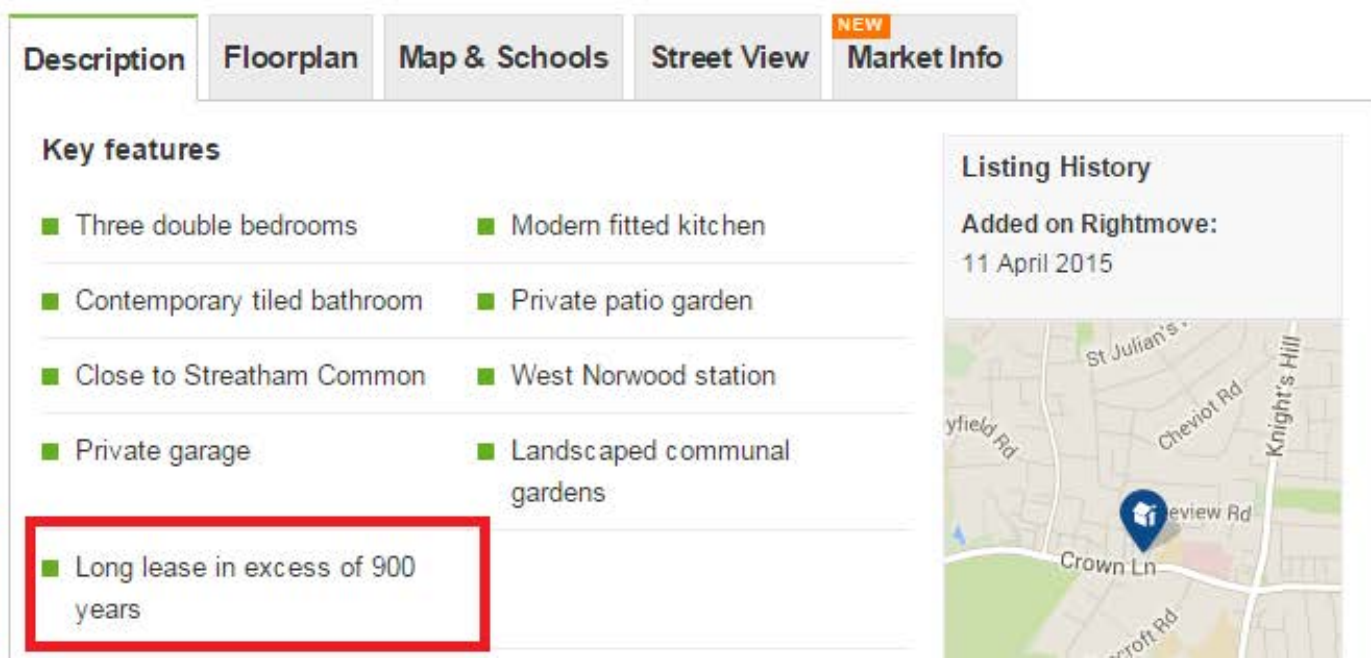

Note: Figure shows an example of a property listing on rightmove.co.uk. 
Figure A.6: Sample Property Listing in the U.K.

\section{1 bedroom apartment for sale}

Langford Court, Abbey Road, St John's Wood, NW8
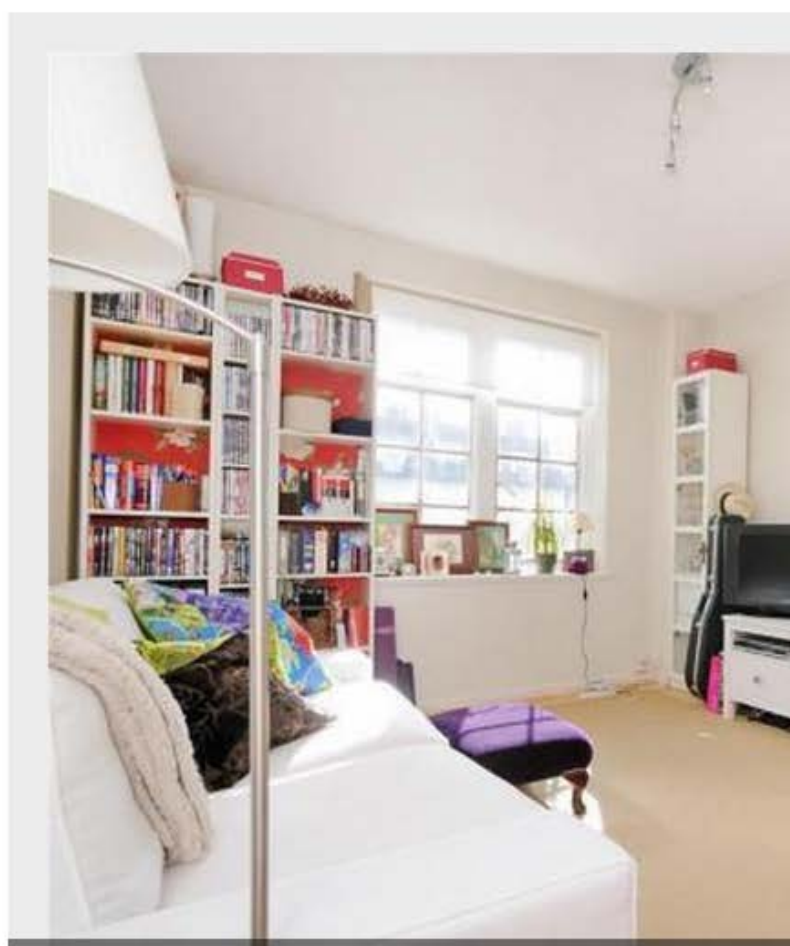

$\square$ Start slideshow

\section{$\langle 1$ of 8$\rangle$}

Photo 1
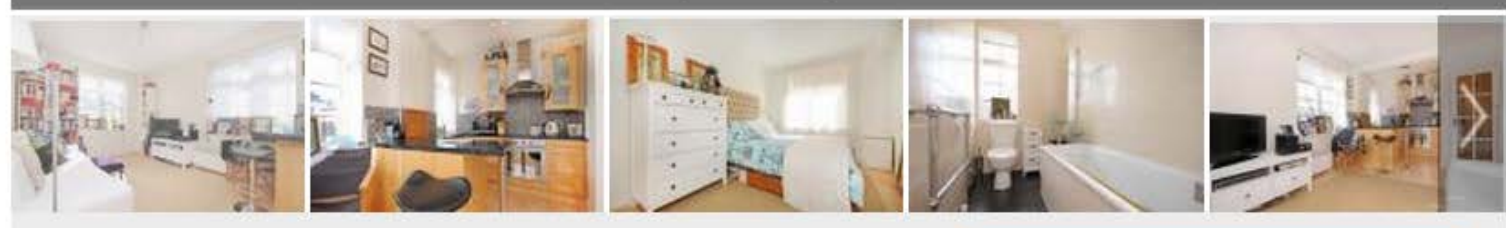

Do you like this property?

Call: 02080125460

Request Details

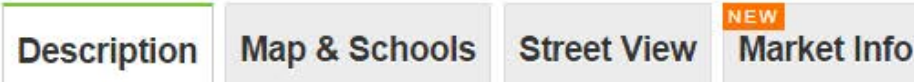

Key features

- Tenure: Leasehold 166 Years

- Heating \& Hot Water being Porter

included in the service charge
Listing History

Added on Rightmove:

21 April 2015 annum approx.(T.B.C)

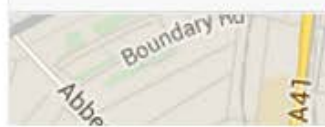

Note: Figure shows an example of a property listing on rightmove.co.uk. 
Figure A.7: Sample Property Listing in Singapore

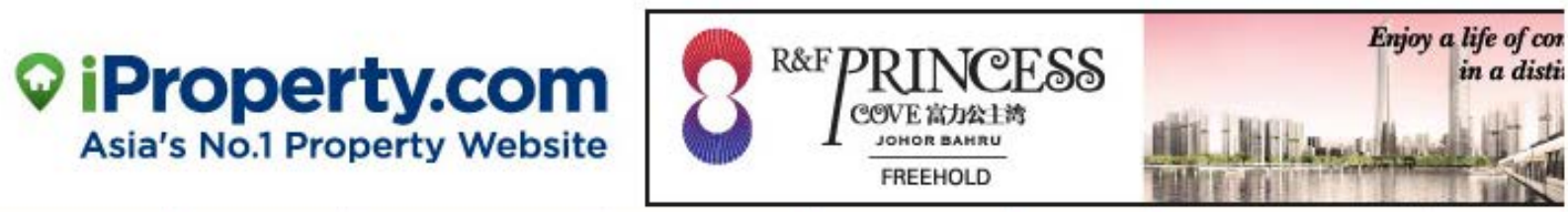

\begin{tabular}{|c|c|c|c|c|c|c|}
\hline For Sale & For Rent & New Launches & Commercial & Overseas & Loans & Home \& Lifestyle \\
\hline
\end{tabular}

Home $*$ Search Result

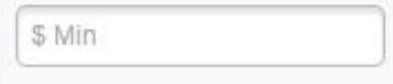

$\$$ Max

:E LIST $\triangle$ PHOTO

Landed Propertles for Sale (3201 Result(s))

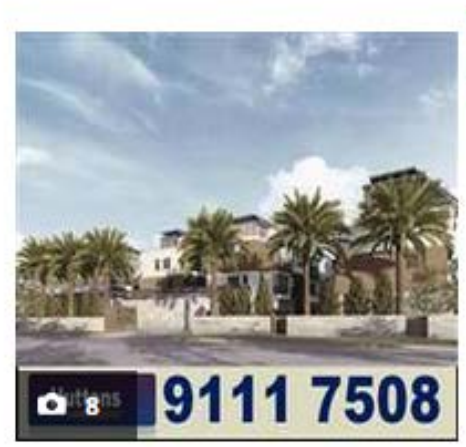

\section{PALMS Sixth Avenue - Freehold}

Sixth Avenue, $\$ \$$ Price BEFORE Rebate! Enquiry Wel...

Semi Detached

Built-up: 4,596 sq. ft.

Price PSF: SGD 1,186.51

Posted On: 21/04/2015

는 4
SGD $5,453,200$

Ivy Yap

HUTTONS ASIA PTE LTD

C $+659111 \ldots$

FEATURED

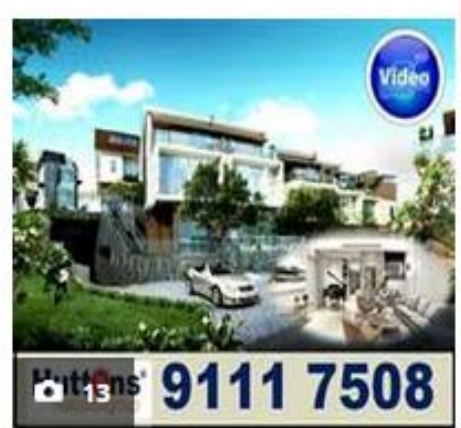

\section{The Whitley Residences- Freehold}

SGD 5,100,000

Whitley Road, Corner Unit, 5 Ensuite Bedroom + Ho...

Ivy Yap

Semi Detached

Built-up: 5,543 sq. $\mathrm{ft}$.

Price PSF: SGD 920.08

Posted On: 21/04/2015

56

Note: Figure shows an example of a property listing on www.iproperty.com.sg. 
Figure A.8: Sample Property Listing in Singapore

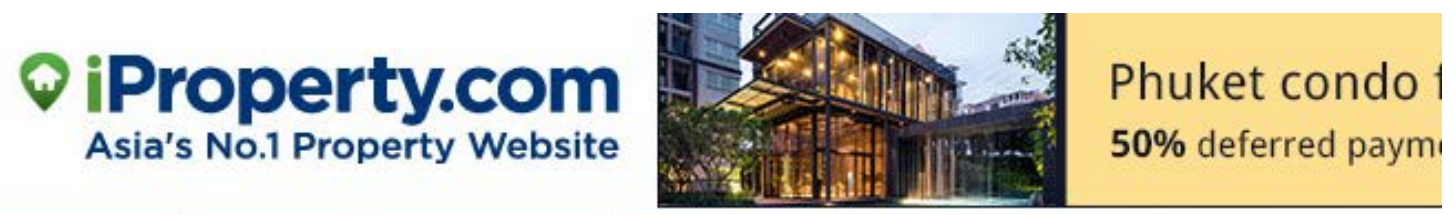

\begin{tabular}{|l|l|l|l|l|l|l|l|l|l} 
For Sale & For Rent & New Launches & Commercial & Overseas Lons & Home Lifestyle
\end{tabular}

웁 Home > Private Apartments for Sale > District $10>$ Dukes Residences
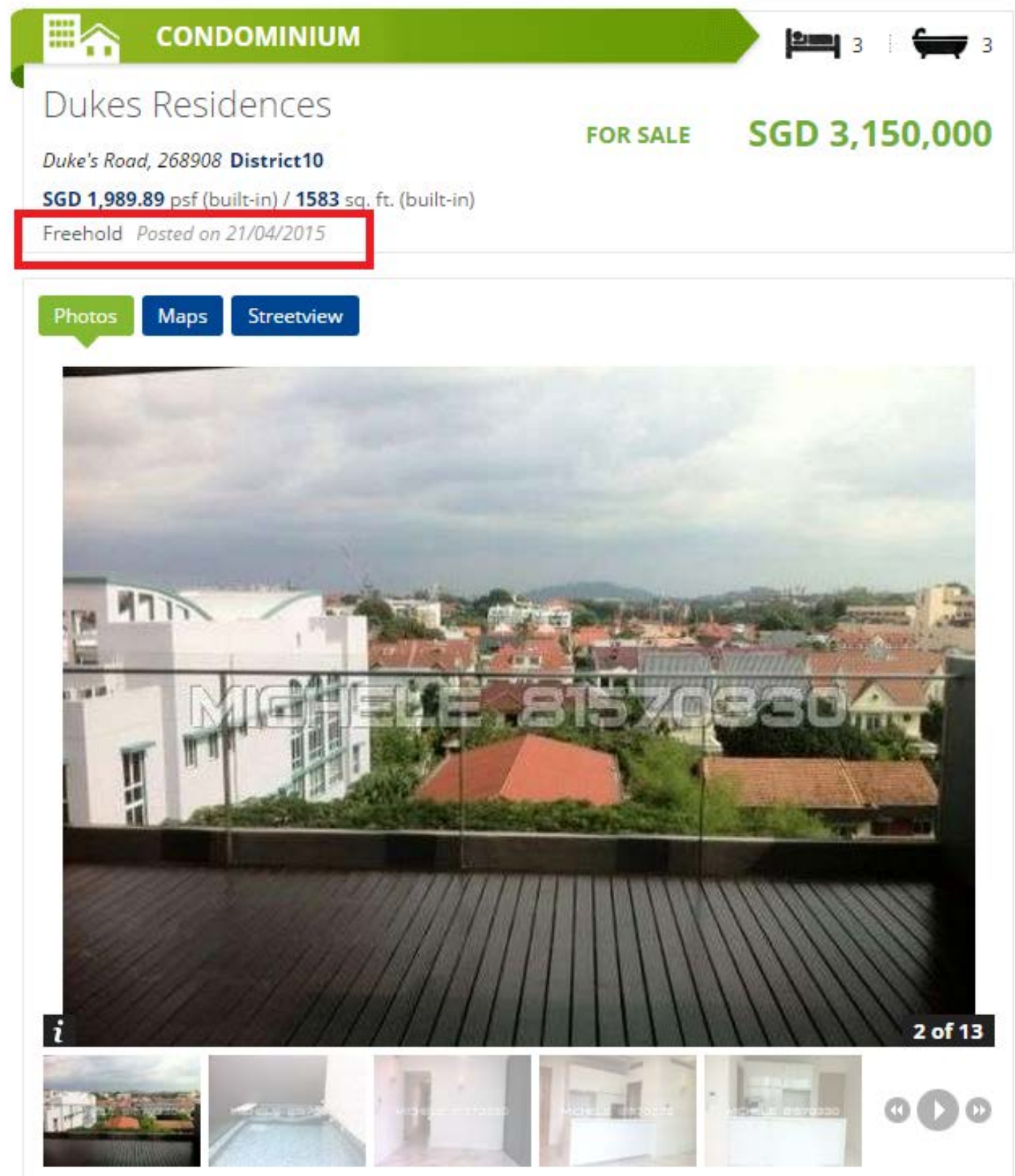

Note: Figure shows an example of a property listing on www.iproperty.com.sg. 
Figure A.9: Sample Property Listing in Singapore

\section{iProperty.com VIEW INTERNATIONAL PROPE Asia's No.1 Property Website \\ PRE-REGISTERAT}

\begin{tabular}{|l|l|l|l|l|l|l} 
For Sale & For Rent & New Launches & Commercial & Overseas & Loans & Home \& Lifest
\end{tabular}

C Home > Private Apartments for Sale > District $14>$ Sims Urban Oasis

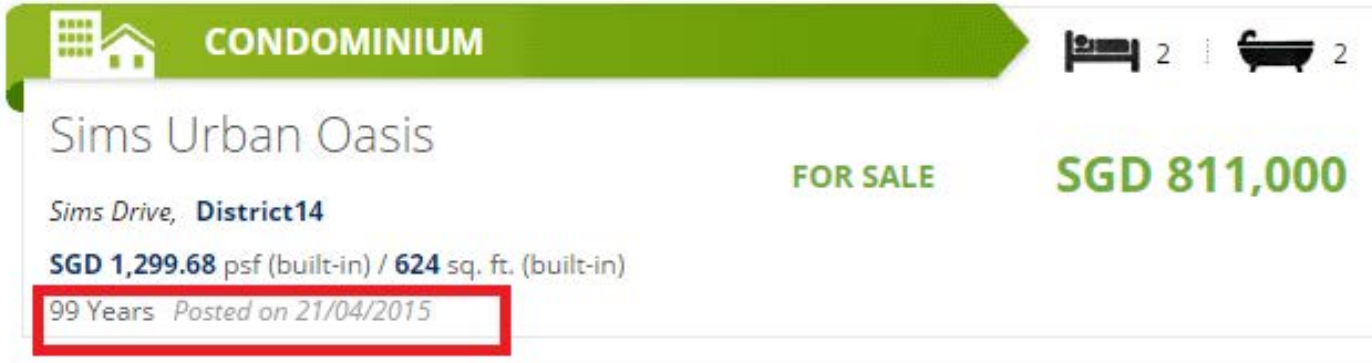

\section{Photos}

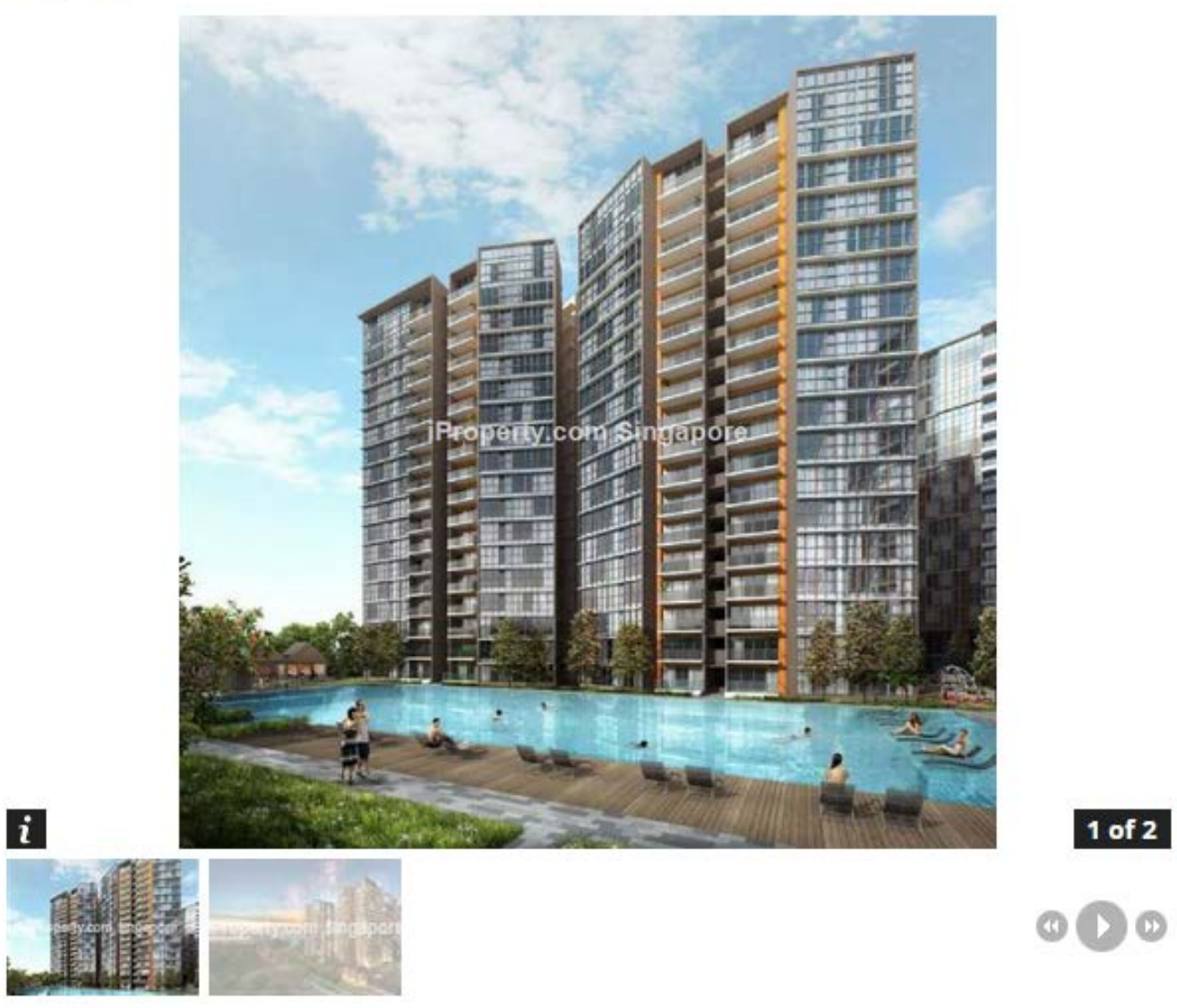

Note: Figure shows an example of a property listing on www.iproperty.com.sg. 